Report No. BMI-1489 (Rev.)

UC-25 Metals, Ceramics and Materials

(TID-4500, 16th Ed.)

Contract No. W-7405-eng-92

\title{
PROGRESS RELATING TO CIVILIAN \\ APPLICATIONS DURING \\ DECEMBER, 1960
}

by

Russell W. Dayton

Clyde R. Tipton, Jr.

January 1, 1961

\section{BATTELLE MEMORIAL INSTITUTE 505 King Avenue \\ Columbus 1 , Ohio}




\section{DISCLAIMER}

This report was prepared as an account of work sponsored by an agency of the United States Government. Neither the United States Government nor any agency Thereof, nor any of their employees, makes any warranty, express or implied, or assumes any legal liability or responsibility for the accuracy, completeness, or usefulness of any information, apparatus, product, or process disclosed, or represents that its use would not infringe privately owned rights. Reference herein to any specific commercial product, process, or service by trade name, trademark, manufacturer, or otherwise does not necessarily constitute or imply its endorsement, recommendation, or favoring by the United States Government or any agency thereof. The views and opinions of authors expressed herein do not necessarily state or reflect those of the United States Government or any agency thereof. 


\section{DISCLAIMER}

Portions of this document may be illegible in electronic image products. Images are produced from the best available original document. 
$\equiv$

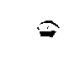

$=$

$=$

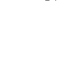

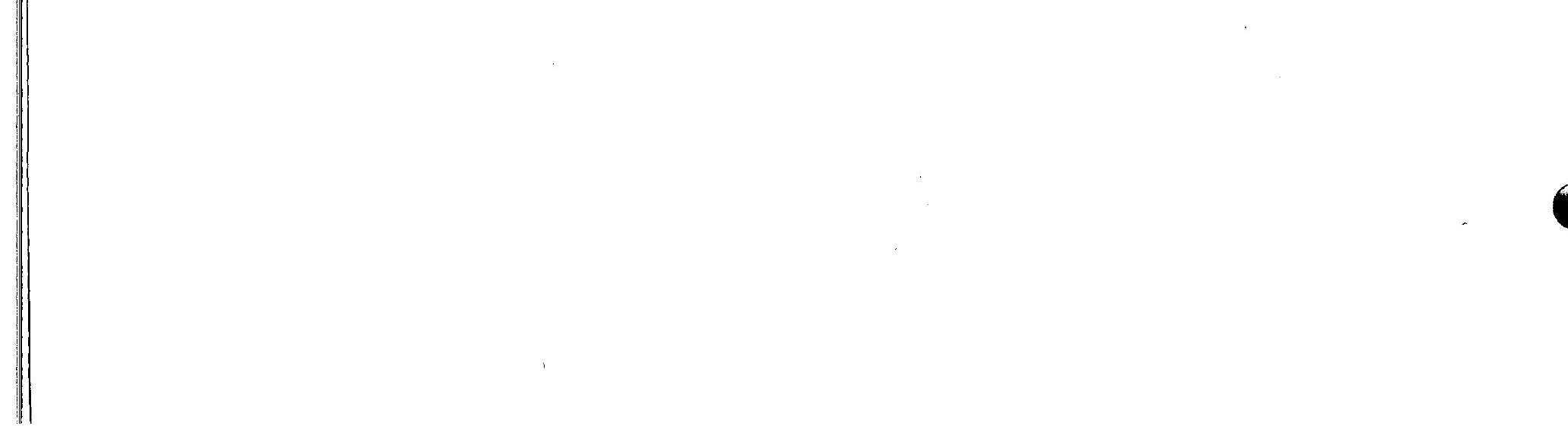


High-Pressure High-Temperature Solid-State Studies . . . . . . . . . . . . . . . $_{\text {. }}$ A-2 Irradiation-Surveillance Program on Type 347 Stainless Steel . . . . . . . . . . . . . . . . A-3 Development of High-Strength Niobium-Base Alloys . . . . . . . . . . . . . . . . . . . . A-4 Investigation of the Creep Properties of Zircaloy-2 During Irradiation at Elevated Temperatures . A-4 Radiation Stability and Boron-Containing Powders. . . . . . . . . . . . . . . . . A-6 Friction and Wear of Sliding Surfaces in Sodium Environments . . . . . . . . . . . . A-7 Determination of Oxygen in Sodium at Concentrations Below 10 PPM . . . . . . . . . . . . . . . . A-7 Development of Miniature Heating Elements for a Power-Balancing-Type

Thermal-Neutron Flux Sensor . . . . . . . . . . . . . . . . . . . . . . . A-9

B. STUDIES OF ALLOY FUELS (AEC-DRD) . . . . . . . . . . . . . . . . . . . . . . . . . . . B-1

Development of Niobium-Uranium Alloys . . . . . . . . . . . . . . . . . . . B-1

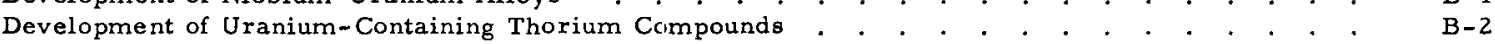

A Study of Plutonium-Containing Fuel Alloys . . . . . . . . . . . . . . . . . . . . . . $\quad$. B-3

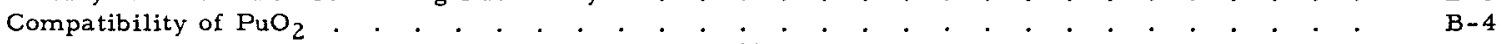

Irradiation Study of Metastable Beta-Phase Urarium Alloys . . . . . . . . . . . . . B-5

C. FISSION-GAS RELEASE FROM REFRACTORY FUELS (AEC-DRD) . . . . . . . . . . . . . . C- 1

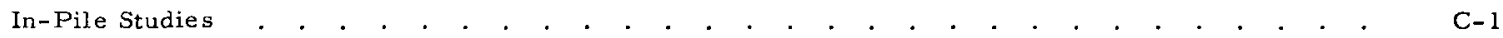

D. JENERAL FUEL-ELEMENT DEVELOPMENT (AEC-DRD) . . . . . . . . . . . . . . . . . . . D-1

Fabrication of Cermet Fuel Elements . . . . . . . . . . . . . . . . . . . . . D-1

Irradiation of Cermet Fuels . . . . . . . . . . . . . . . . . . . . . . . . . . . . . . . . . .

Development of Low-Cost Tubular Fuel Elements . . . . . . . . . . . . . . . . . D-4

Factors Affecting Pressure Bonding . . . . . . . . . . . . . . . . . . . . . . . . . . . . . . . .

E. GAS-PRESSURE BONDING OF CERAMIC, CERMET, AND DISPERSION FUEL ELEMENTS

(AEC-FUEL CYCLE) . . . . . . . . . . . . . . . . . . . . . . . . . . . . . E-1

Uranium Dioxide Compaction Studies . . . . . . . . . . . . . . . . . . . . . . E-1

Gas-Pressure-Bonding Studies . . . . . . . . . . . . . . . . . . . . . . . . . . . . $\quad$ E-2

F. DEVELOPMENT OF URANIUM CARBIDE (A EC-FUEL CYCLE) . . . . . . . . . . . . . . . . . . F- I

Alternate Fabrication Methods for UC . . . . . . . . . . . . . . . . . . . . . F-2

Melting and Casting Techniques for Uranium-Ca:bon Alloys . . . . . . . . . . . . . . F-3

Mechanical and Physical Properties of Uranium Monocarbide . . . . . . . . . . . . . . . . . . . . . . . F-4

Uranium Monocarbide Diffusion Studies . . . . . . . . . . . . . . . . . . . . F-

Effects of Radiation on UC. . . . . . . . . . . . . . . . . . . . . . . . . . . . . . F-5

G. PHYSICAL RESEARCH (AEC-DR) . . . . . . . . . . . . . . . . . . . . . . . . . . . . . G- 1

Growth of $\mathrm{UO}_{2}$ Single Crystals . . . . . . . . . . . . . . . . . . . . . . . . . . . G-1

H. RADIOISOTOPE AND RADLATION APPLICATIONS (AEC-.OID) . . . . . . . . . . . . . . . H-1

Use of Intrinsic Radioactive Tracers for Process Control . . . . . . . . . . . . . . H-

Graft-Polymerization Studies

I. ASSISTANCE TO AEC-EURATOM PROGRAM . . . . . . . . . . . . . . . . . . . . . . . . . . . . . I-1

VOID-DISTRIBUTION AND HEAT-TRANSFER STUDIE: . . . . . . . . . . . . . . . . . . . . I-

DEVELOPMENT OF URANIUM MONONITRIDE. . . . . . . . . . . . . . . . . . . . . . . . . I-2

Powder-Metallurgy Studies . . . . . . . . . . . . . . . . . . . . . . . . I-2

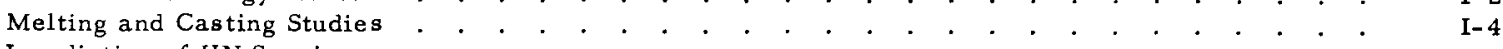

Irradiation of UN Specimens 
TABLE OE CONTENTS

(Continued)

J. MATERLALS DEVELOPMENT AND EVALUATION (HAPO)

Thermal Conductivity and Electrical Conductivity of $\mathrm{UO}_{2}$. . . . . . . . . . . . . . . J J-1

Mechanical Properties of Zirconium Alloys . . . . . . . . . . . . . . . . . . . . . . . . J-2

Materials of Construction for the Fused Chloride-Electrolytic UO $\mathrm{O}_{2}$ Process . . . . . . . . . . J-3

L. COATED-PARTICLE FUEL MATERLALS (AEC-DRD)

L- 1

Evaluation of Commercial Products . . . . . . . . . . . . . . . . . . . . . . L-

Particle-Coating Studies . . . . . . . . . . . . . . . . . . . . . . . . . . . . .

Ceramic-Matrix Studies . . . . . . . . . . . . . . . . . . . . . . . . . . . . . .

Fuel-Irradiation Studies

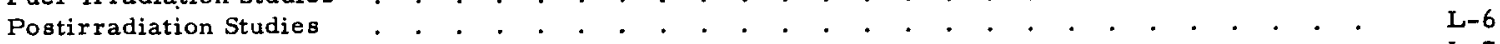

Physics and Engineering Guidance . . . . . . . . . . . . . . . . . . . . . $\quad$ L-7

Fission-Gas-Release Studies. . . . . . . . . . . . . . . . . . . . . . . . . L-8

Fuel-Compatibility Studies . . . . . . . . . . . . . . . . . . . . . . . . L-10

Coolant-Compatibility Studies . . . . . . . . . . . . . . . . . . . . . . . L L-11

Radiation-Damage Studies . . . . . . . . . . . . . . . . . . . . . . . . L-11

Thermal-Conductivity Studies . . . . . . . . . . . . . . . . . . . . . . . L-11

M. PROBLEMS ASSOCIATED WITH THE RECOVERY OF SPENT REACTOR FUEL ELEMENTS (ORNL) • • M- 1

Corrosion Studies of the Fluoride-Volatility Process . . . . . . . . . . . . . . . . M-1

Study of the Effects of Irradiation on Cladding- and Core-Dissolution Processes . . . . . . . . M-1

P. PEBble-BED REACTOR MATERLALS (S\& P) . . . . . . . . . . . . . . . . . . . . . . . . P-1

Laboratory Evaluation of Fueled-Graphite Spheres . . . . . . . . . . . . . . . . P-1

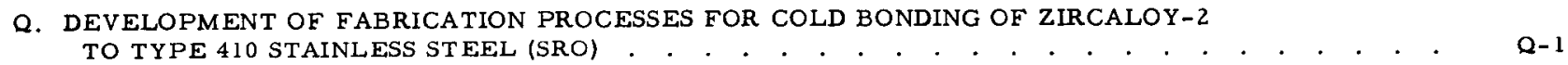

Friction Bonding . . . . . . . . . . . . . . . . . . . . . . . . . . . . . . . $\quad$.

Effects of Surface Preparation in Roll Forming . . . . . . . . . . . . . . . . . . . . . Q

Explosive Joining. . . . . . . . . . . . . . . . . . . . . . . . . . . . $\quad$ Q-2

S. DEVELOPMENT OF MATERIALS FOR THE MGCR AND HTGR (GA) . . . . . . . . . . . . . . S- 1

DEVELOPMENT AND EVALUATION OF FUEL ELEMENTS FOR THE MGCR . . . . . . . . . . S-1

Radiation-Effects Study of Potential Fuels . . . . . . . . . . . . . . . . . . . S-1

Experimental Capsule Studies . . . . . . . . . . . . . . . . . . . . . . . . . . . S-1

T- DEVELOPMENTAL STUDIES FOR THE SM-2 (ALCO) . . . . . . . . . . . . . . . . . . . . . . . T- 1

Radiation-Stability Studies of Reference and Alternate SM-2 Fuels . . . . . . . . . . . T-1

U. GAS-COOLED REACTOR PROGRAM (AGN) . . . . . . . . . . . . . . . . . . . . . . . . . . U-

Advanced ML-1 Fuel Pellets. . . . . . . . . . . . . . . . . . . . . . . . . . . . . U-1

An Alternate Method of Fabricating Advanced ML-1 Fuels . . . . . . . . . . . . . . . . . . . . U-2

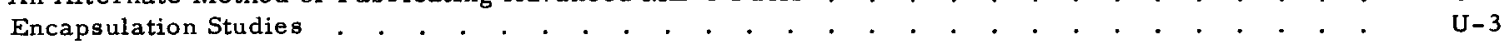

High-Temperature Fatigue Evaluation of Hastelloy X Tubing . . . . . . . . . . . . . U U

ML-1 Critical-Assembly Experiments . . . . . . . . . . . . . . . . . . . . . . . . . . . . $\quad$ U-4

V. CORROSION OF THORIUM AND URANIUM UNDER STORAGE CONDITIONS (LIVERMORE) . . . . . . . V-1

Electrodeposited Coatings for Thorium (SC) . . . . . . . . . . . . . . . . . . . . . . . . . . . . V-1

Corrosion Evaluation (UCRL). . . . . . . . . . . . . . . . . . . . . . . . . . . . . . . . .

X. GAS-PRESSURE BONDING OF BERYLLIUM-CLAD ELEMENTS (ORNL) . . . . . . . . . . . . . . . X-1 
REPORTS RELATING TO CIVILIAN APPLICATIONS ISSUED DURING IJECEMBER, 1960

BMI-1476 "Effects of Irradiation on the Mechanical Properties of Tantalum", by Charles K. Franklin, David Stahl, Frederic R. Shober, and Ronald F. Dickerson.

BMI-1479 "High-Temperature Compatibility of $\mathrm{Al}_{2} \mathrm{O}_{3-}, \mathrm{BeO}-$, and Metal-Coated $\mathrm{UO}_{2}$ Particles With Graphite and Coke", by Arnold F. Gerds and Allison K. Smalley.

BMI-1480 "Progress Relating to Civilian Applications During November, 1960", by Russell W. Dayton and Clycle R. Tipton, Jr.

BMI-1482 "VMR Critical-Assembly Studies", by Richard A. Egen, Lee H. Bettenhausen, William S. Hogan, David A. Dingee, and Joel W. Chastain.

BMI-1483 "The Effect of Radiation on Selected Properties of Spherical Graphite Fuel Elements", by Allison K. Smalley, Richard J. Burian, Arnold F. Gerds, Gilbert E. Raines, and Ward S. Diethorn. 


\title{
REACTOR MATERIALS AND COMPONENTS (AEC-DRD)
}

\author{
R. F. Dickerson
}

Reactions between $\mathrm{UO}_{2} .67$ and $\mathrm{Al}_{2} \mathrm{O}_{3}$ at pressures of 60,000 atm are being studied in some detail. At temperatures up to $1000 \mathrm{C}$ the gamma high-pressure modification of $\mathrm{UO}_{2} .67$ was formed. At $1200 \mathrm{C}$ the conversion of gamma $\mathrm{Al}_{2} \mathrm{O}_{3}$ to alpha $\mathrm{Al}_{2} \mathrm{O}_{3}$ occurred, and at $1300 \mathrm{C}$ a reaction compound was formed which is not produced at normal pressure. Preliminary studies indicate that the composition of the compound is near $\mathrm{UAlO}_{4}$ but this will be verified by further work. A study of the $\mathrm{U}_{3} \mathrm{O}_{8}-$ $\mathrm{CrO}_{3}$ system is also in progress, and initial results indicate that a high-pressure reaction does occur.

Irradiation of ten capsules containing Type 347 stainless steel specimens is continuing in the ETR; however, two capsules designed for irradiation at temperatures caused by gamma heating have been removed from the WTR. Loss of thermocouples made it impossible to know irradiation temperatures, and, consequently, the value of the tests was greatly reduced. The ETR capsules have accumulated fast-neutron exposures as high as about $8.43 \times 10^{21}$ nvt.

The study of niobium-base alloys as potential cladding for the EBR is continuing with a recrystallization study of the binary alloys containing $2.37 \mathrm{w} / 0$ chromium, 3.34 $\mathrm{w} / \mathrm{o}$ zirconium, and $5.21 \mathrm{w} / \mathrm{o}$ vanadium and a ternary alloy containing $1.56 \mathrm{w} / \mathrm{o}$ zirconium and $1.09 \mathrm{w} / 0$ chromium. Room-temperature hardness measurements indicate stress relief at about $1038 \mathrm{C}$. Metallographic studies are in progress.

Final thermal mock-up tests were cornpleted on the in-pile capsule to be used for the in-pile creep tests on Zircaloy-2. The results of these tests indicate that suitable heat transfer can be obtained so that a test temperature of $650 \mathrm{~F}$ can be maintained in the test reactor. This capsule is now tentatively scheduled for insertion in the WTR on February 23, 1961. Thin sections of specimens deformed at room temperature and $650 \mathrm{~F}$ have been examined by electron microscopy. The material deformed at room temperature showed a striation apparently related to slip systems, whereas the Zircaloy2 deformed at $650 \mathrm{~F}$ did not show these striations. At this point it does not seem likely that structural differences noted are relatec to the yield point previously observed in short-time tensile tests at this temperature.

Experimental work on the program concerned with the suitability of hafnium diborides as an alternate control material or burnable poison has been nearly completed, and the preparation of a final report is in progress.

The study of friction and wear of sliding surfaces in sodium environments has been continued with a mathematical analysis of the stick-slip friction traces obtained in the wear and friction apparatus. This analysis revealed that some viscous action is occurring during sliding in liquid sodium. Surface films are apparently exhibiting viscous behavior.

Two approaches which offer good possibilities for the determination of low concentrations of oxygen in sodium are the use of mass spectrometric techniques and coulometric techniques. The sensitivity of the mass spectrometer is being checked by using a known sample of $\mathrm{HgO}$. When the sersitivity checks are completed sodium 
samples will be analyzed for oxygen. Investigation of the coulometric technique for oxygen detection has been resumed with a review of aluminum-anodization techniques.

A program has been initiated toward the development of miniature electrical heating elements for application in power-balancing-type thermal-neutron flux detectors. A heater is required which will give controlled electrical characteristics and stable behavior in a reactor core. Two heater types will be examined, an imbedded-wire element and a film-conductance element.

\section{High-Pressure High-Temperature Solid-State Studies}

W. B. Wilson and C. M. Schwartz

An investigation is being conducted to determine the effects of ultrahigh pressure on the reactions of uranium oxide with various mixed oxides. Current work has been directed toward a detailed study of a pressure-induced reaction between $\mathrm{U}_{3} \mathrm{O}_{8}$ and $\mathrm{Al}_{2} \mathrm{O}_{3}$.

The $\mathrm{U}_{3} \mathrm{O}_{8}-\mathrm{Al}_{2} \mathrm{O}_{3}$ reaction has been investigated under varying conditions of temperature, pressure, and composition. Emphasis has been placed, however, on the examination of equimolar $\mathrm{UO}_{2} .67-\mathrm{Al}_{2} \mathrm{O}_{3}$ at a pressure of 60,000 atm. Transformation of the $\mathrm{UO}_{2} .67$ to the gamma high-pressure modification was observed to occur at lower temperatures to $1000 \mathrm{C}$. At temperatures near $1200 \mathrm{C}$ the conversion of gamma $\mathrm{Al}_{2} \mathrm{O}_{3}$ to alpha $\mathrm{Al}_{2} \mathrm{O}_{3}$ was observed. At $1300 \mathrm{C}$ a reaction compound is formed which is not produced at normal pressure.

$\mathrm{X}$-ray diffraction analyses have been undertaken to "index" the powder diffraction pattern. Reasonable agreement is obtained for a cubic structure with $a_{0}=13.20 \mathrm{~A}$. With this cell nearly all reflections are indexed on the basis of (hko) reflections with $\mathrm{h}=4 \mathrm{n}$ and $\mathrm{k}$ present in all orders. However, certain interplanar spacings appear to be shifted slightly from cubic indexing. Thus, the resulting structure has been tentatively indexed as tetragonal with $\mathrm{c} / \mathrm{a}=3.96$, where $\mathrm{c}=13.20 \mathrm{~A}$ and $\mathrm{a}=3.33 \mathrm{~A}$ and the $(00 \mathrm{l})$ reflections occur only with $\ell=4 \mathrm{n}$.

Samples known to contain the compound have been sectioned. Microstructural examination has shown that, at the temperature for compound formation, growth occurs with possible formation of single crystals. Several of these have been selected for examination by single-crystal techniques which, if successful, will permit unequivocal indexing.

Examination of the microstructure also has shown that excess $\mathrm{Al}_{2} \mathrm{O}_{3}$ was present for the equimolar composition of $\mathrm{UO}_{2} .67-\mathrm{Al}_{2} \mathrm{O}_{3}$. Thus, it would appear that the composition of the compound is nearer that of $\mathrm{UAlO}_{4}$ than $\mathrm{UAl}_{2} \mathrm{O}_{6}$. Further work will accordingly be undertaken to establish the composition. Both microstructural and diffraction examinations have shown that further reactions occur at still higher temperatures which ultimately result in growth of alpha $\mathrm{Al}_{2} \mathrm{O}_{3}$ crystals and dissociation of the uranium oxide to $\mathrm{U}_{4} \mathrm{O} 9$.

Work has also been undertaken on the system $\mathrm{U}_{3} \mathrm{O}_{8}-\mathrm{Cr}_{2} \mathrm{O}_{3}$ which by analogy to $\mathrm{Al}_{2} \mathrm{O}_{3}$ may also result in formation of a new compound. Early results indicate that 
reaction does occur under conditions similar to the $\mathrm{Al}_{2} \mathrm{O}_{3}$ reaction. The resulting diffraction pattern has not as yet been indexed and does not appear to be isostructural to its $\mathrm{Al}_{2} \mathrm{O}_{3}$ counterpart.

The investigation of $\mathrm{UO}_{2} .67-\mathrm{Al}_{2} \mathrm{O}_{3}$ and $\mathrm{U}_{3} \mathrm{O}_{8}-\mathrm{Cr}_{2} \mathrm{O}_{3}$ will be continued. Attempts will be made to obtain single crystals of the compounds for structural analysis; the density and stoichiometry must be established and the pressure and temperature existence regions further defined.

Irradiation-Surveillance Program on Type 347 Sta:inless Steel

W. E. Murr, F.. Leiberman, F. R. Shober, and R. F. Dickerson

The objective of this program is to determine the effects of fast-neutron irradiations (neutrons having energies of greater than $1 \mathrm{Mev}$ ) on the mechanical properties of AISI Type 347 stainless steel. The program consists of the irradiation and subsequent mechanical testing of specimens contained in 14 capsules, 10 of which are currently being exposed in core positions of the ETR. The types of specimens include subsize tensile, cyclic-strain fatigue, and impact bars which will be exposed over a range of about $5.0 \times 10^{21}$ to greater than $1.5 \times 10^{22} \mathrm{nvt}$ at temperatures of $120 \mathrm{~F}$ (process water) and $600 \mathrm{~F}$. Information obtained from postirradiation mechanical tests will be used for predicting in-reactor life for operating ETR loops constructed of this material.

At the present time, ten capsules are being irradiated in the $\mathrm{G}-13$ position of the ETR. Two capsules that were operating in the WTR were removed from test when the thermocouples became inoperative. An examination of the lead capsule indicated the thermocouple failure may have been caused by water which entered the capsule during storage. It is probable that these two capsules, and a third scheduled for WTRinsertion, will not be irradiated as planned. One Capsule, BMI-24-14, was discharged from the ETR following Cycle 28 at an estimated fast-flux exposure of $5.7 \times 10^{21}$ nvt. Results of mechanical tests on part of the specimens from this capsule have been previously reported.

Instantaneous fast-neutron flux data have been obtained from the analysis of dosimeter wires exposed in the G-13 position of the ETR during Cycle 32. This position has been occupied by the stainless steel surveillance capsules since their removal from the $K$ and $L$ positions at the end of Cycle 30 . The data, shown in Table $A-1$, indicate that the capsules are being exposed to a lower instantaneous fast flux in the G-13 position than they were when in the $K$ and L locations.

TABLE A-1. FAST-NEUTRON FLUX VALUES AS DETERMINED FROM IRON WIRES(a) EXPOSED IN ETR G-13 POSITION DURING CYCLE 32

\begin{tabular}{|c|c|c|c|c|c|c|c|c|c|c|}
\hline \multirow[b]{2}{*}{ Location in Capsule } & \multicolumn{10}{|c|}{ Fast Flux for Indicated Capsule in BMI -24 Series, $10^{14}$ nvt } \\
\hline & 2 & 4 & 6 & 8 & 10 & 12 & 16 & 18 & 20 & 22 \\
\hline Top & 2.0 & 1.4 & 1.9 & 1.75 & 1.75 & 1.4 & 1.6 & 1.7 & 1.5 & 1.1 \\
\hline Bottom & .1 .9 & 1.75 & 1.6 & 1.75 & 1.65 & 1.3 & 1.7 & 1.6 & 2.0 & 1.4 \\
\hline
\end{tabular}

(a) Technique involves the determination of manganese-54 produced in the reaction, $\mathrm{Fe}^{54}$ (n, p) $\mathrm{Mn}^{54}$. 
Using the experimentally determined values obtained for $\mathrm{G}-13$ during Cycle 32 , the total fast-neutron dosage was determined for the capsules during Cycles 31 , 32, and 33. Table A-2 lists the estimated accumulated exposures of all capsules up to the end of Cycle 33 (December 14, 1960).

It is planned to remove a capsule containing cyclic-strain fatigue and subsize tensile specimens for testing early in 1961.

Development of High-Strength Niobium-Base Alloys

J. A. De Mastry, F. R. Shober, and R. F. Dickerson

In order to operate the sodium-cooled Experimental Breeder Reactor, a fast reactor, at temperatures in excess of $725 \mathrm{C}$ (where the iron-uranium eutectic forms), the present cladding material, stainless steel, must be replaced. Niobium-base alloys are being considered for this application. The absence of an eutectic reaction between niobium and uranium up to $1000 \mathrm{C}$ and the superior strength of niobium alloys in this temperature range are the basis for this interest. Prior research performed at Battelle (BMI-1417) showed that additions of chromium, vanadium, and zirconium improve the elevated-temperature strength of niobium. However, an experimental study was needed to determine the magnitude of strengthening achieved.

Tensile tests have been completed on fully recrystallized binary niobium-base alloys containing $2.37 \mathrm{w} / \mathrm{o}$ chromium, $3.34 \mathrm{w} / \mathrm{o}$ zirconium, $5.21 \mathrm{w} / \mathrm{o}$ vanadium and on a ternary alloy containing $1.56 \mathrm{w} / 0$ zirconium and $1.09 \mathrm{w} / \mathrm{o}$ chromium. Very little decrease in yield-strength values was noted between 650 and $1000 \mathrm{C}$. On a weight basis, chromium was the most potent strengthener of the alloying additions being investigated. The tensile data were shwon in BMI-1469. Creep testing is being continued at 650,800 , and $1000 \mathrm{C}$.

The recrystallization temperatures of materials cold worked 95 per cent and given a 1-hr anneal are being determined. Specimens of each alloy have been annealed at 982, 1038, 1093, 1149, 1204, 1260, and $1316 \mathrm{C}$. Room-temperature hardness measurements of the above specimens indicate stress relief at about $1038 \mathrm{C}$ but show no further decrease in hardness. Selected specimens are being examined metallographically to determine the recrystallization temperature.

Investigation of the Creep Properties of Zircaloy-2 During Irradiation at Elevated Temperatures

F. R. Shober, P. B. Shumaker, and A. P. Young

An in-reactor creep experiment has been designed and an instrumented capsule constructed to investigate the effects of irradiation on the creep properties of Zircaloy2 at $650 \mathrm{~F}$. A flat specimen having three gage sections of different cross-sectional areas is to be loaded in each of two temperature-controlled capsules at stresses in the 14,000 to 20,000-psi range for $1000 \mathrm{hr}$ in fast-neutron fluxes of at least $1 \times 10^{14} \mathrm{nv}$. The irradiations are to be conducted at the Westinghouse Testing Reactor. A comparison 
TABLE A-2. CAPSULES PREPARED FOR THE TYPE 347 STAINLESS STEEL IRRADIATION-SURVEILLANCE PROGRAMI

\begin{tabular}{|c|c|c|c|c|c|c|}
\hline \multirow[b]{2}{*}{ Capsule } & \multirow{2}{*}{$\begin{array}{l}\text { Type of Specimen } \\
\text { in Capsule }\end{array}$} & \multirow{2}{*}{$\begin{array}{c}\text { Proposed } \\
\text { Irradiation } \\
\text { Temperature, } \\
\text { F }\end{array}$} & \multicolumn{2}{|c|}{$\begin{array}{c}\text { Total Exposure as of } \\
\text { December } 14,1960, \text { nvt }\end{array}$} & \multirow[b]{2}{*}{ Location } & \multirow[b]{2}{*}{ Remarks } \\
\hline & & & Top & Bottom & & \\
\hline BMI $-24-2$ & Tensile and fatigue & 120 & $7.013 \times 10^{21}$ & $7.536 \times 10^{21}$ & $\begin{array}{l}\text { ETR } \\
\text { G-13 }\end{array}$ & Being irradiated \\
\hline $\mathrm{BMI}-24-3$ & Tensile and fatigue & 600 & - & -- & BMII & - \\
\hline BMI $-24-4$ & Tensile and fatigue & 120 & $6.266 \times 10^{21}$ & $7.570 \times 10^{21}$ & $\begin{array}{l}\text { ETR } \\
\text { G-13 }\end{array}$ & Being irradiated \\
\hline BMI $-24-6$ & Tensile and fatigue & 120 & $7.899 \times 10^{21}$ & $6.590 \times 10^{21}$ & $\begin{array}{l}\text { ETR } \\
\text { G-13 }\end{array}$ & Being irradiated \\
\hline BMI - 24-8 & Tensile and fatigue & 120 & $6.570 \times 10^{21}$ & $7.386 \times 10^{21}$ & $\begin{array}{l}\text { ETR } \\
\text { G-13 }\end{array}$ & Being irradiated \\
\hline BNII-24-10 & Tensile and fatigue & 120 & $7.2 .59 \times 10^{21}$ & $6.325 \times 10^{21}$ & $\begin{array}{l}\text { ETR } \\
G-13\end{array}$ & Being irradiated \\
\hline BMI $-24-12$ & Tensile and fatigue & 120 & $8.429 \times 10^{21}$ & $7.973 \times 10^{21}$ & $\begin{array}{l}\text { ETR } \\
G-13\end{array}$ & Being irradiated \\
\hline BMI-24-14 & Impact & 120 & $5.736 \times 10^{21}$ & $5.811 \times 10^{21}$ & $\begin{array}{l}\mathrm{ETR} \\
\mathrm{K}-8-\mathrm{NW}\end{array}$ & $\begin{array}{l}\text { Removed for testing } \\
\text { at BMII }\end{array}$ \\
\hline BNII $-24-15^{(a)}$ & Impact & 600 & $3.5 \times 10^{20}$ & $1.28 \times 10^{20}$ & $\begin{array}{l}\text { W'TR } \\
L-7-6\end{array}$ & $\begin{array}{l}\text { Removed from WTR } \\
\text { because of faulty } \\
\text { thermocouple }\end{array}$ \\
\hline BMI-24-16 & Impact & 120 & $7.3835 \times 10^{21}$ & $6.362 \times 10^{21}$ & $\begin{array}{l}\text { ETR } \\
G-13\end{array}$ & Being irradiated \\
\hline BMI $-24-18$ & Tensile and fatigue & 120 & $2.982 \times 10^{20}$ & $3.986 \times 10^{21}$ & $\begin{array}{l}\text { ETR } \\
G-13\end{array}$ & $\begin{array}{l}\text { Being irradiated for } \\
\text { postirradiation } \\
\text { annealing studies }\end{array}$ \\
\hline BMI-24-19 $(a, b)$ & Tensile and fatigue & 600 & $4.53 \times 10^{20}$ & $4.33 \times 10^{20}$ & $\begin{array}{l}\text { WTR } \\
L-7-6\end{array}$ & $\begin{array}{l}\text { Fabricated to replace } \\
\text { BMII-24-17; removed } \\
\text { from WTR because of } \\
\text { faulty thermocouple }\end{array}$ \\
\hline B\II-24-20 & Tensile and fatigue & 120 & $2.956 \times 10^{21}$ & $4.584 \times 10^{21}$ & $\begin{array}{l}\text { ETR } \\
G-13\end{array}$ & $\begin{array}{l}\text { Being irradiated for } \\
\text { postirradiation } \\
\text { annealing studies }\end{array}$ \\
\hline BMI-24-22 & Tensile and fatigue & 120 & $3.300 \times 10^{21}$ & $4.736 \times 10^{21}$ & $\begin{array}{l}\text { ETR } \\
G-13\end{array}$ & $\begin{array}{l}\text { Being irradiated for } \\
\text { postirradiation } \\
\text { annealing studies }\end{array}$ \\
\hline
\end{tabular}

(a) Flux is reported as greater than $0.821 \mathrm{Mev}$; all other fluxes are greater than $1.0 \mathrm{Nev}$.

(b) Thermocouple-lead capsule. 
is to be made of total creep deformations obtained in and out of the reactor under similar conditions of stress and temperature. The possible occurrence of strain aging at $650 \mathrm{~F}$ during creep has been considered, and a study of strain aging in Zircaloy-2 is being made. Recent modifications to the capsule indicate that the heat-transfer properties of the capsule are satisfactory to obtain a $650 \mathrm{~F}$ test temperature during irradiation.

During December, thermal mock-up tests were completed, and assembly of the first in-pile capsule was started. Data from the mock-up experiments indicated that suitable heat transfer across the 70-mil heater block-to-capsule wall gap can be achieved with 15 equally spaced vertical copper tubes $(0.030-i n$, wall). These tubes, initially $1 / 8 \mathrm{in}$. in $O D$, are flattened by passing them through rolls having a separation of 69 mils. The final capsule heat-transfer scheme, in combination with the available electric heating, is tailored for maintaining the specimen temperature at $650 \mathrm{~F}$ with the irradiation conducted in a reactor position where the gamma-heating rate is approximately $12 \mathrm{w}$ per $\mathrm{g}$ (of aluminum). Recent information from the WTR indicates that a position having a quoted gamma flux of approximately $13 \mathrm{w}$ per $\mathrm{g}$, and a fast-neutron flux in the range 1 to $2 \times 10^{14} \mathrm{nv}$ will be available for the experiment. The final selection of space will be based on neutron-flux and gamma-flux data which should be obtained from current and future measurements. The capsule is tentatively scheduled for insertion for the reactor cycle beginning February 23, 1961.

A comparison of the deformation characteristics of Zircaloy- 2 is being made at room temperature and $650 \mathrm{~F}$. Examination by electron microscopy of thin sections of specimens deformed at $650 \mathrm{~F}$ in short-time tension tests showed somewhat different structures than those deformed at room temperature. Where material deformed at room temperature showed a striation apparently related to slip systems, the Zircaloy-2 deformed at $650 \mathrm{~F}$ did not. There were, however, still evidences that slip and twinning were occurring at the elevated test temperature. It does not seem likely that the differences noted would be related to a yield point previously observed in short-time tensile tests at this temperature.

\title{
$\underline{\text { Radiation Stability and Boron-Containing Powders }}$
}

\author{
R. A. Ewing and D. N. Sunderman
}

The objective of the program is to investigate the suitability of hafnium diborides as an alternate control material or burnable poison. No experimental work was conducted during the month. The desirability of determining the amount of helium retained in the severely radiation-damaged powders before completion of the experimental work is now being considered. This may be done if sufficient quantitites of the irradiated specimens are available and the determination can be made simply. 
Friction and Wear of Sliding Surfaces in

Sodium Environments

W. A. Glaeser and J. W. Kisse1

Research is being carried out to develop general principles which would be applicable to selection of materials and design of mechanical parts involving sliding surfaces in high-temperature molten sodium.

The friction and wear behavior of varous materials resistant to corrosion in liquid sodium is being studied by measuring the stick-slip friction characteristics of a ball sliding on a flat in liquid sodium and under a carefully controlled gaseous environment. Interpretation of stick-slip traces is supplemented by analysis of surface films formed during exposure to sliding in sodium.

The friction and wear behavior of molybdenum, tungsten, Inconel X, Stellite 3 , tungsten carbide, and titanium carbide have been investigated, and in each case, except for the two carbides, improved operation resulted when sodium was present between the rubbing surfaces. In the case of molybclenum sliding against itself, the improved behavior has been definitely correlated with the presence of a $\mathrm{Na}_{2} \mathrm{MoO}_{4} \mathrm{film}$. It was subsequently shown that formation of this film is thermodynamically feasible under any of the variety of temperature-environment conditions which might prevail during friction experiments. Thermodynamic analyses, when applied to the components involved in the various friction tests, indicated a favorable tendency toward formation for $\mathrm{Na}_{2} \mathrm{WO}_{4}$ and $\mathrm{Na}_{2} \mathrm{CrO}_{4}$, but a generally unfavorable tendency toward formation for $\mathrm{Na}_{2} \mathrm{CoO}_{3}$ and for $\mathrm{Na}_{2} \mathrm{C}_{2}$. These analyses suggest that the reason sodium does not appear to influence friction of the carbide cermet is that there is no chemical reaction between the sodium and the cermet.

Mathematical analysis of the stick-slip friction traces obtained in the Battelle wear and friction apparatus has revealed that some viscous action is occurring during sliding in liquid sodium. Surface films apparently are exhibiting viscous behavior. This approach holds promise for determination of the properties of reacted films which form during immersion of such materials as molybdenum, tungsten, and nickel-base alloys in liquid sodium.

Friction experiments will continue using materials selected for use in a sodium environment. New materials are being obtained and fabricated into friction specimens. Analysis of surface films formed during immersion in liquid sodium will continue with the objective of identifying those films which appear to influence sliding behavior in $=$ sodium.

Determination of Oxygen in Sodium at Concentrations Below 10 PPM

E. H. Hall, J. McCallum, and D. R. Grieser

A knowledge of the oxygen content of sodium-cooled-reactor heat-transfer systems at extremely low levels has grown in importance with the promotion of oxygen-sensitive 
materials for core and fuel-element structures. Previously developed methods do not appear adaptable to rapid monitoring of oxygen levels in the 0 to 10 -ppm range. Consequently, the present program is an investigation of the feasibility of applying new techniques to this problem.

At present two of the more promising approaches suggested during this program are being pursued. These are the application of mass spectrometric and coulometric techniques. Both promise selectivity of detection for oxygen in the presence of other impurities, and both are at present being evaluated for sensitivity.

A determination of the sensitivity of the mass spectrometer to oxygen has been made. A $0.002-\mathrm{g}$ sample of solid HgO was placed in the sapphire oven used for the sodium experiments and the system was evacuated. The oven was heated until decomposition occurred and the Mass 32 peak was observed throughout. The observed peak height was plotted as a function of time (minutes) and integrated to obtain the sensitivity. The result indicated that the quantity of oxygen expected from the sodium samples was near the lower limit of detection. This sensitivity measurement is now being repeated to determine the reproducibility of the result. The HgO composition was chosen for this study because the absence of hydrolysis makes it possible to get a more accurate sample weight, and to avoid the complication of possible hydrolysis by residual mois ture in the mass spectrometer.

A possible reason for the failure to observe oxygen from sodium samples is that the thermocouple placement has lead to observed temperatures higher than the actual sample temperature. If this were true, it is possible that the residue from the sodium sample was not heated to a high enough temperature to effect decomposition of the residual $\mathrm{Na} 2 \mathrm{O}$. To check this possibility, a second thermocouple was placed in contact with the inside bottom of the sapphire oven. With no sample present, the two thermocouples were compared up to $600 \mathrm{C}$. At this point, the temperature inside the oven was $20 \mathrm{C}$ lower than that indicated by the thermocouples used previously. This is not a large enough difference to explain the inability to obtain oxygen.

Work next month will include the completion of the second sensitivity determination and experiments using sodium samples having larger oxygen concentration in order to have quantities of oxygen further from the apparent detection limit. If oxygen peaks can be observed with these samples, lower concentrations will be studied.

Investigation of the coulometric technique for oxygen detection has been resumed with a review of aluminum-anodization techniques. Initial experiments in which attempts were made to form an impervious $\mathrm{Al}_{2} \mathrm{O}_{3}$ coating on commercial aluminum tubing proved unsuccessful. A direct electrical short developed immediately when the anode was inserted into sodium. Experiments now in progress in which high-purity aluminum wire have been substituted as the anode indicate more promise. An evaluation of anodization parameters is being made to determine the most satisfactory method for production of a durable, high-integrity coating. Several probes are now ready for insertion into the coulometric cell and evaluation in sodium.

The preliminary evaluation of the coating processes will be completed shortly, and if one or more of the probes prove to have suitable coatings preliminary feasibility data for evaluation of the technique will be obtained. A more rigorous evaluation will then be attempted by removing oxygen from the sodium completely using the coulometric 
anode as a getter and then observing the effect of specific additions of oxygen in the 0 to 10 -ppm range upon performance of the cell.

Development of Miniature Heating Elements for a PowerBalancing-Type Thermal--Neutron Flux Sensor

J. G. Buck, P. M. Steinback, D. R. Grieser, and W. H. Goldthwaite

A program has been initiated toward the development of miniature electrical heating elements for application in power-balancing-type thermal-neutron flux detectors. This type of detector is completely described in BMI-1083. Essential to this neutron-sensor operation is a miniature electrical heating element which can operate in a reactor-core environment at element temperatures up to $1500 \mathrm{~F}$. Preferable is a heater with an electrical resistance compatible with lead-wire and insulation characteristics. Previous attempts to fabricate semiconducting ceramic bodies as heater elements resulted in mixed success.

The present effort is divided between two heater designs. Each gives promise of controlled electrical characteristics and stable behavior. One approach is the incorporation of a small sheathed-wire resistance heater into a stainless steel-UO 2 matrix. The other is the production of a durable film-conductance heater on a uranium-containing ceramic insulator. The ultimate heater is to be approximately $1 / 2 \mathrm{in.}$ long and $1 / 8 \mathrm{in}$. in diameter, have long life, and be capable of sustaining frequent thermal cycling.

Imbedded-Wire Element

The initial effort in the development of an imbedded-wire heater has been the search for commercially available sheathed heater and the preliminary design of the element from the standpoint of fabrication processes and lead-wire attachment.

The preliminary design should be completed and materials ordered during the next report period.

\section{$\underline{\text { Film-Conductance Element }}$}

A review of published data has been made to aid in the choice of materials and procedures suitable for fabrication of conducting films to meet the flux-sensor requirements. Pyrolytic carbon and palladium have been chosen from a number of potential materials as possessing the most suitable characteristics for initial study. The equipment and materials needed for deposition are being assembled and checked. The design of a stainless steel envelope for enclosing the elements during life test has been started.

During the next month, four groups of resistors will be fabricated in preparation for life tests to be conducted at $1500 \mathrm{~F}$ in vacuum. 


\title{
STUDIES OF ALLOY FUELS (AEC-DRD)
}

\author{
R. F. Di.ckerson
}

The development of niobium rich-uranium alloys is continuing with current effort concentrating on the preparation of reasonably large homogeneous alloy heats which can be fabricated into tensile and creep specimens. The two irradiation capsules still await insertion into a test reactor.

The thorium compounds which have been chosen for study have been tested in $\mathrm{CO}_{2}$ at $1200 \mathrm{~F}$. The compounds most resistant to attack were the beryllides and the borides. The effect of uranium additions to $\mathrm{ThAl}_{2}, \mathrm{ThBe}_{13}, \mathrm{ThB}_{4}$, and $\mathrm{Th}_{3} \mathrm{Si}_{2}$ is a general increase in corrosion resistance. On the other hand, ThSi seems to be deleteriously affected by the uranium addition.

Since the binary niobium-base plutonium alloys are impractical as fuels because of the extremely low solubility of plutonium in aiobium, the system niobium-plutoniumsilicon has been considered. It is hoped that the plutonium and silicon will combine to form PuSiz. An alloy of niobium-25.6 w/o plutonium-6.1 w/o silicon has been examined by metallographic techniques and appears to have a two-phase structure. Hardness tests and $\mathrm{X}$-ray analyses are needed to definitely establish the structure. Niobiumplutonium-zirconium alloys have been cast and are being prepared for metallographic study. Results of initial studies of thorium-plutonium alloys indicate that the addition of $10 \mathrm{w} / \mathrm{o}$ zirconium to a thorium $-10 \mathrm{w} / \mathrm{o}$ plutorium alloy is more beneficial in increasing the strength than altering the plutonium content of the alloy. This alloy shows very little tarnish after several days of exposure to laboratory air. The study of $\mathrm{PuO}_{2}$ compatibility is continuing.

A study of the irradiation behavior of beta-phase uranium alloys has been undertaken for Nuclear Metals, Inc. Uranium with additions of $0.3 \mathrm{w} / 0$ chromium and $0.3 \mathrm{w} / \mathrm{o}$ chromium-0.3w/o molybdenum, variously heated to retain the beta phase, is being studied with the aim of determining if the metastable beta phase is stabilized by the rmal and displacement spikes during irradiation at temperatures of about $450 \mathrm{C}$. Design of the necessary irradiation capsules has been initiated.

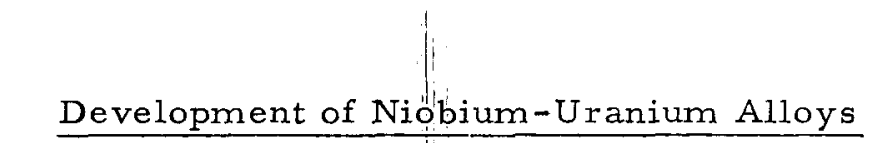

J. A. DeMastry, D. P. Moak, A. A. Bauer, and R. F. Dickerson

The properties of niobium-uranium alloys are being investigated in order to determine their potential as reactor fuels for ellevated-temperature applications.

A program concerned with the preparation of niobium-uranium-alloy ingots with structures amenable to fabrication is under way. The approach being investigated involves skull-melting techniques utilizing the consumable-electrode procedure. Ingots containing nominally $10,20,30,40$, and $50 \mathrm{w} / 0$ uranium and an ingot of unalloyed niobium will be cast. 
Initial attempts at pouring an unalloyed niobium casting indicated that metal recovery (ratio of casting to electrode weight) was less than anticipated and that this recovery may be dependent upon both power input and electrode configurations. Therefore, electrodes of the above-mentioned alloy compositions containing approximately 100 per cent overcharge are being prepared. By this means, it is expected that ample molten metal will be available to fill the mold cavity.

The mechanical properties (tensile and creep) of the alloys mentioned above will be determined as soon as specimens can be prepared.

Two capsules each containing 15 fuel pins made up of niobium-10, -20 , and $-30 \mathrm{w} / 0$ uranium alloys have been assembled and are ready for irradiation. These capsules will be irradiated to approximately 1 total a/o burnup at temperatures of 1600 and $1800 \mathrm{~F}$ as soon as suitable reactor space is available.

\section{Development of Uranium-Containing Thorium Compounds}

\section{S. Farkas, A. A. Bauer, and R. F. Dickerson}

Compounds of thorium and of a thorium-10 a/o uranium alloy are being investigated with the aim of developing a high-temperature fuel suitable for use in a thermal breeder reactor. Low thermal-neutron cross section, high melting point, and a high thorium (uranium) density were the criteria used to choose compounds for study. The compounds are $\mathrm{ThB}_{4}, \mathrm{ThC}, \mathrm{ThC}_{2}, \mathrm{ThN}, \mathrm{Th}_{3} \mathrm{P}_{4}, \mathrm{ThS}, \mathrm{Th}_{3} \mathrm{Si}_{2}$, and $\mathrm{ThSi}$ and the se same compounds with 10 a/o additions of uranium.

Oxidation tests in $\mathrm{CO}_{2}$ at $1200 \mathrm{~F}$ have been completed, and the results are presented in Table B-1. As in the case of air oxidation at $1200 \mathrm{~F}$ the compounds most resistant to attack by $\mathrm{CO}_{2}$ were the beryllides and borides. The high corrosion rates exhibited by the other compounds investigated indicates their application is limited where exposure to high-temperature $\mathrm{CO}_{2}$ is possible. Slight deviations in stoichiometry may affect $\mathrm{CO}_{2}$ corrosion rates. The effect of uranium on the corrosion rates in $\mathrm{CO}_{2}$ was as follows: the replacement of $10 \mathrm{a} / 0$ thorium with uranium in $\mathrm{ThAl}_{2}, \mathrm{ThBe}_{13}, \mathrm{ThB}_{4}$, and $\mathrm{Th}_{3} \mathrm{Si}_{2}$ increased corrosion resistance, while ThSi was deleteriously affected by the uranium addition. Results of tests of the se aluminides, beryllides, borides and silicides in water at $90 \mathrm{C}$ indicated that negligible changes occurred and that they were essentially corrosion resistant for 1 day under these conditions.

Presently air-oxidation tests on thorium and thorium-uranium carbides are being performed. Studies planned for the future include determination of the thermalexpansion, the rmal-conductivity, and strength characteristics of the most promising compounds. 
T ABLE B-1. OXIDATION OF THORIUM AND THORIUM-URANIUM COMPOUNDS IN $\mathrm{CO}_{2}$ AT $1200 \mathrm{~F}$

\begin{tabular}{|c|c|c|}
\hline Compound & $\begin{array}{c}\text { Test Period, } \\
\text { hr }\end{array}$ & $\begin{array}{c}\text { Average Weight } \\
\text { Gain During Test } \\
\text { Period, } \mathrm{mg} /\left(\mathrm{cm}^{2}\right)(\mathrm{hr})\end{array}$ \\
\hline $\mathrm{Th}_{2} \mathrm{Al}$ & 0.33 & 200 \\
\hline$(\text { Thgu })_{2} \mathrm{Al}$ & 0.33 & 125 \\
\hline $\operatorname{ThBe}_{13}$ & 16 & 1.35 \\
\hline (ThgU)Be 13 & 15.5 & 0.048 \\
\hline $\mathrm{ThB}_{4}$ & 7.75 & 0.082 \\
\hline$\left(\mathrm{Th}_{9} \mathrm{U}\right) \mathrm{B}_{4}$ & 17 & 0.029 \\
\hline ThSi(a) & 0.16 & 480 \\
\hline (ThgU)Si & 0.16 & 690 \\
\hline $\mathrm{Th}_{3} \mathrm{Si}_{2}$ & 0.16 & 512 \\
\hline$\left(\text { Thg }_{9} \mathrm{U}\right)_{3} \mathrm{Si}_{2}$ & 0.16 & 117 \\
\hline
\end{tabular}

(a) Average of two tests.

\section{A Study of Plutonium-Ciontaining Fuel Alloys}

V. W. Storhok, A. A. Bauer, and R. F. Dickerson

An investigation aimed at developing irradiation-resistant plutonium-bearing alloys is being conducted. The alloys selected for study, chosen on the basis of the irradiation behavior of similar uranium-containing alloys, include niobium-base, thorium-base, uranium-molybdenum base, and uranium-niobium-base alloys. Metallographic examination and hardness testing are the principal means by which these alloy systems are being evaluated initially.

Metallographic examination of a niobium-25.6 w/o plutonium-6. 1 w/o silicon alloy showed the as-cast structure to be two-phase. Whether these phases were $\mathrm{PuSi}_{2}$ and niobium, as expected, was not definitely established. However, microhardness measurements of segregated areas revealed a diamond-pyramid hardness of 249 in areas containing a large amount of matrix phase and a diamond-pyramid hardness of 276 where less matrix phase was present. These data suggest that the apparently softer matrix phase may be niobium, while the harder discontinuous phase is a compound. X-ray diffraction analysis will be necessary to substantiate this conclusion. In the meantime, a similar alloy theoretically consisting of niobium-20/w $/ 0 \mathrm{PuSi}_{2}$ will be melted and cast for study.

Other niobium-base alloys, niobium-10 w/o plutonium-10 w/o zirconium and niobium-10 w/o plutonium-30 w/o zirconium, have been cast and will be studied metallographically. It is hoped that the addition of zirconium will increase the solubility of plutonium in niobium or the plutonium will be alloyed with zirconium to form a higher melting phase than unalloyed plutonium.

Data obtained from examination of thor.um-base alloys indicated that the ternary addition of $10 \mathrm{w} / 0$ zirconium to a thorium-10 w/o plutonium alloy was more beneficial in increasing strength than altering the plutonium content of the binary alloy. An essentially single-phase thorium-10 w/o plutonium-10 w/o zirconium alloy exhibited a 
diamond-pyramid hardness of 89 as compared with respective hardnesses of 48,53 , and 74 for thorium $-5,-10$, and $-30 \mathrm{w} / \mathrm{o}$ plutonium alloys. In addition, zirconium apparently improved the resistance of the alloys to oxidation by room-temperature air. A thorium$10 \mathrm{w} / 0$ plutonium-10 w/o zirconium metallographic specimen showed very little tarnish when allowed to stand in laboratory air for several days. Binary thorium-plutonium alloys similarly exposed to laboratory air tarnished badly. The effect of heat treatment on the se alloys is being investigated.

Other alloys to be investigated include uranium-10 and $-15 \mathrm{w} / 0$ molybdenum -5 , $-10,-15$, and $-20 \mathrm{w} / \mathrm{o}$ plutonium and uranium $-20 \mathrm{w} / \mathrm{o}$ niobium $-5,-10,-15$, and $-20 \mathrm{w} / \mathrm{o}$ plutonium. It is hoped that the plutonium additions will not substantially alter the properties of the binary base alloys.

Alloys appearing promising on the basis of hardness and microstructure will be studied further.

\section{Compatibility of $\mathrm{PuO}_{2}$}

S. J. Paprocki, D. L. Keller, and W. M. Pardue

The purpose of this program is to study the compatibility of $\mathrm{PuO}_{2}$ with various metallic and ceramic materials. Heat treatments of powder mixtures and abutted surfaces of $\mathrm{PuO}_{2}$ with the material in question will be conducted. The appearance of new phases will be followed by X-ray diffraction measurements, metallographic examination, and changes in the physical condition of the compacts.

The results of a preliminary screening procedure using calculations of standard free energies to indicate metal $\mathrm{PuO}_{2}$ reactions were summarized in BMI- 1455 .

The as-received $\mathrm{PuO}_{2}$ particles average $9.4 \mu$ in diameter with generally submicroscopic grain size and are spherical in shape. Ten volume per cent of an extraneous phase was identified tentatively as $\mathrm{Pu}_{2} \mathrm{O}_{3}$.

Sinterability studies showed that as-pressed green density increased with compacting pressure to a maximum of 60 per cent of theoretical at $100 \mathrm{tsi}$. Sintering in argon for $1 \mathrm{hr}$ at a temperature in excess of $1600 \mathrm{C}$ increased the density to 90 per cent of theoretical. Sintering in argon or hydrogen at $1700 \mathrm{C}$ for $1-1 / 2 \mathrm{hr}$ caused melting and alloying of individual pellets placed on trays of molybdenum, tantalum, tungsten, $\mathrm{Al}_{2} \mathrm{O}_{3}$, $\mathrm{ZrO}_{2}, \mathrm{BeO}$, and $\mathrm{MgO}$. The argon atmosphere gave slightly less drastic reactions, and $\mathrm{MgO}$ appeared to be the most compatible material with $\mathrm{PuO}_{2}$ at $1700 \mathrm{C}$.

It appears that either a chemical reduction to $\mathrm{Pu}_{2} \mathrm{O}_{3}$ or a the rmal decomposition is occurring. The melting point of $\mathrm{Pu}_{2} \mathrm{O}_{3}$ is $1610 \mathrm{C}$ or below the sintering temperature involved when melting takes place.

During the past month, some loose as-received $\mathrm{PuO}_{2}$ was air oxidized at $800 \mathrm{C}$ for $1-1 / 2 \mathrm{hr}$. During this treatment, sparking was observed which was interpreted as $\mathrm{Pu}_{2} \mathrm{O}_{3}$ transforming to $\mathrm{PuO}_{2}$. One pellet was prepared from this oxide and one from the "Glassner, A., "The Thermochemical Properties of the Oxides, Fluorides, and Chlorides to 2500K", ANL-5750 (1957). 
as-received material. Both were sintered at $1180 \mathrm{C}$ in air for $16 \mathrm{hr}$. The as-received powder showed a slightly smaller percentage weight loss and is thus believed to have picked up oxygen during sintering. The weight loss is attributed to binder and water volatilization. Sintered densities were approximately 75 per cent of theoretical.

Petrographic examination of the air-oxidized powder showed elimination of the hexagonal phase found in the as-received material. Average particle diameter had increased to $13.1 \mu$, and it is assumed that the grain size increased also, but internal structures could not be resolved.

Density of the melted material previously obtained during hydrogen sintering was determined to be $8.23 \mathrm{~g}$ per $\mathrm{cm}^{3}$. This more nearly approximates the density of $10.6 \mathrm{~g}$ per $\mathrm{cm}^{3}$ attributed to plutonium hydride than any other reported compound.

Upon completion of two new sintering furnaces next month, actual compatibility runs will be undertaken.

\section{Ir radiation Study of Metastable Beta-Phase Uranium Alloys}

M. S. Farkas, D. B. Hamilton, A. A. Bauer, and R. F. Dickerson

A study of the irradiation behavior of beta-phase uranium alloys has been undertaken for Nuclear Metals, Inc. Uranium, with additions of $0.3 \mathrm{w} / 0$ chromium and $0.3 \mathrm{w} / \mathrm{o}$ chromium-0.3 w/o molybdenum, variously heat treated to retain the beta-uranium phase, is being studied with the aim of determining if the metastable beta phase is stabilized by thermal and displacement spikes during irradiation at temperatures of about $450 \mathrm{C}$.

Preliminary studies are being made on the design of two temperature-controlled irradiation capsules, each containing nine 1/4-in.-diameter pin-type fuel specimens with nominal characteristics as shown in Table $\mathrm{B} \cdot-2$.

TABLE B -2. SPECIMENS FOR IRRADIATION-CAPSULE STUDY OF MET AST ABLE BETA -PHASE URANIUM ALLOYS(a)

\begin{tabular}{ccclc}
\hline Specimen & $\begin{array}{c}\text { Composition } \\
\text { (Balance Uranium), } \\
\text { w/o }\end{array}$ & $\begin{array}{c}\text { Uranium } \\
\text { Enrichment, } \\
\text { a/o }\end{array}$ & Heat Treatment & Cladding \\
\hline 1 & $100 \mathrm{U}$ & 10 & Beta quench & None \\
2 & $0.3 \mathrm{Cr}$ & 10 & Beta quench & None \\
3 & $0.3 \mathrm{Cr}$ & 10 & Gamma quench & None \\
4 & $0.3 \mathrm{Cr}-0.3 \mathrm{Mo}$ & 10 & Beta quench & None \\
5 & $0.3 \mathrm{Cr}-0.3 \mathrm{Mo}$ & 10 & Gamma quench & None \\
6 & $0.3 \mathrm{Cr}-0.3 \mathrm{Mo}$ & 10 & Beta quench, & None \\
7 & $0.3 \mathrm{Cr}-0.3 \mathrm{Mo}$ & 10 & alpha transform & Zircaloy -4 \\
8 & $0.3 \mathrm{Cr}-0.3 \mathrm{Mo}$ & 10 & Gamma quench & None \\
9 & $0.3 \mathrm{Cr}-0.3 \mathrm{Mo}$ & Natural & &
\end{tabular}

(a) Specimens prepared by Nuclear Metals, Inc. 
The capsule design is governed by three requirements: (1) a specimen center-line temperature of $450 \mathrm{C}$, (2) close temperature control, and (3) a specimen-effective thermal-neutron flux of about $10^{13} \mathrm{nv}$ to produce the desired fission rate. Based on the se criteria, a double-walled capsule has been designed in which the nine specimens are aligned on the axis and immersed in NaK. Temperature control is achieved by variation of the thermal conductance of the annulus between the inner and outer containment cylinders. Currently, a thermal mock-up is being run to check potentially useful schemes for achieving the temperature control desired.

Specimens are to be irradiated in two capsules. The first set will be irradiated to a burnup of between 0.01 and $0.05 \mathrm{a} / \mathrm{o}$, and postirradiation tests will be designed primarily to determine whether the beta phase is retained after irradiation. The second set of specimens will be irradiated to a burnup of 0.3 to 0.4 a/o to establish the radiation stability of the alloys.

Flux-perturbation characteristics of the capsules will be determined by nuclear mock-up experiments in the Battelle Research Reactor. A determination of the flux attenuation by the capsule and its contents is required in order to determine capsule location.

According to the present schedule, fabrication of both capsules will be completed by the end of February. Irradiations will commence as soon thereafter as reactor space becomes available.

A study is also being made of the effect of cutting operations, which will be required during postirradiation examination, on transformation of the metastable beta phase. Specimens of two alloys which transform most readily from beta to alpha uranium have been cut under conditions similar to those which would be used in the hot cell. After suitable grinding and polishing operations to remove the surface worked metal, the specimens will be examined in an X-ray diffractometer to determine if transformation occurred. 


\title{
FISSION-GAS RELEASE FROM REFRACTORY FUELS (AEC-DRD)
}

\author{
J. B. Melehan, S. G. Epstein, M. Kangilaski, and F. A. Rough
}

The objective of this program is to gain an understanding of the important causes of fission-product release in $\mathrm{UO}_{2}$ and other important refractory fuels and to collect data needed for design of fuel elements. Studies in progress during December centered on the continuous release of fission product:s during irradiation of sintered materials.

In-Pile Studies

To carry out the program objective, ramely, the study of in-pile fission-gas release from $\mathrm{UO}_{2}$, apparatus and procedures have been developed for the production of fission gases in samples and for their collection and radiochemical analysis as they are released.

No additional fission-gas release experiments were performed during December, but analysis of experiments discussed in the November report (BMI-1480) was continued. No significant change in the interpretation of the experimental data was warranted, but progress was made toward more precise determination of fission krypton and xenon released during irradiation. The principal problem involved in determination of the fission-gas mixtures is the separation of contributions of the individual isotopes to the total radioactivity of the mixtures. It has been possible to measure with sufficient confidence the $0.41-$ Mev gamma decay of krypton-87 in freshly collected gas mixtures. However, krypton-85m, krypton-88, xenon-133, xenon-133m, and xenon-135, with gamma radioactivity in the range 0.08 to $0.25 \mathrm{Mev}$, generate decay spectra from which it is difficult to separate the individual isotcpe activities. It has been necessary to permit radioactive decay of the short-lived krypton-85m, krypton- 87 , and krypton-88 in the mixtures in order that the spectra for the longer lived xenon-133 and xenon-135 be more distinct for reliable measurement.

Modifications of the in-pile induction furnace are being made to permit operation at temperatures up to and above $3000 \mathrm{~F}$. No additional in-pile gas-release experiments are planned until the redesigned furnace has been tested. 


\title{
GENERAL FUEL-ELEMENT DEVELOPMENT (AEC-DRD)
}

\author{
S. J. Paprocki
}

Techniques have been developed for the fabrication of cermet fuels embodying 80 volume per cent $\mathrm{UO}_{2}$ and 20 volume per cent of a refractory metal. Physical and mechanical properties have been determined, and, on the basis of results of this study, test specimens are being prepared for irradiation.

Studies are now in progress to develop UN cermet fuel materials. Compatibility tests of UN with iron, molybdenum, tantalum, titanium, tungsten, and zirconium are being conducted, and techniques for fabrication are being developed. The UN appears to be more refractory than $\mathrm{UO}_{2}$ or $\mathrm{UC}$, and, consequently, it is more difficult to densify. This may be indicative of excellent high-temperature potential as a fuel material.

Techniques are being developed for the fabrication of single and multiple thinwalled tubular fuel elements consisting of a stainless steel cladding and stainless $-\mathrm{UO}_{2}$ fuel core. The objective of the study is to develop low-cost fabrication processes that will produce a product of acceptable quality. Although the study is directed at development of a stainless system, the process should be applicable to other material systems with a minimum of development.

A study of the kinetics and mechanism involved in the solid-phase bonding of copper by the use of temperature and pressure has been concluded. The study is being continued to include metals other than coppe: to determine if the same relationship between bonding parameters and properties of the metal exists as with copper.

\section{Fabrication of Cermet Fuel Elements}

S. J. Paprocki, D. L. Keller, G. W. Cunningham, and D. E. Kizer

Investigations of fabrication techniques for producing 60 to 90 volume per cent UN cermets to 90 per cent of theoretical density or greater are being made. Gas-pressure bonding is currently being evaluated as a fabrication technique as well as a method for preparing dense cermets for compatibility studies.

To obtain information on compatibility, green-pressed cores of $20 \mathrm{w} / \mathrm{o} U \mathrm{~N}$-iron -molybdenum, -tantalum, -titanium, -tungsten, and-zirconium have been heated in a vacuum for $4 \mathrm{hr}$ at $2250 \mathrm{~F}$. Also a $20 \mathrm{w} / \mathrm{O} \mathrm{UN}$-nickel compact has been vacuum heated for $4 \mathrm{hr}$ at $1350 \mathrm{~F}$. Microscopic examination of the cores indicated no reaction of $U N$ with iron, molybdenum, nickel, tantalum, or tungsten under the conditions tested. A visible reaction was noted between UN-titanium and UN-zirconium. In view of the difficulty in evaluating compatibility on low-density cores, microscopic examinations have also been made on high-density cermet is containing 80 volume per cent UN. Matrix metals were chromium, molybdenum, niobium, and Type 347 stainless steel. Specimens were densified to 81 per cent of theoretical clensity or greater by gas-pressure bonding for $3 \mathrm{hr}$ at $2200 \mathrm{~F}$ under a helium gas pressure of $10,000 \mathrm{psi}$. No reaction could be detected between the UN and chromium, molybdenum, or stainless steel matrices; however, a reaction between the UN and niobium was indicated. 
Vacuum sintering has been investigated as a method of producing dense UN cermets and also for evaluating compatibility. Table $\mathrm{D}-1$ is a tabulation of cermets sintered to date. Fuel loadings were 60 volume per cent in all cases. Minus 100-mesh UN and minus 325-mesh metal powder was used in preparing the green compacts. All specimens sintered shrank in both the diameter and length except the molybdenum cermet sintered for $2 \mathrm{hr}$ at $3000 \mathrm{~F}$, which shrank in diameter and expanded in length. The weight loss generally increased with longer times at temperature or increased sintering temperature without an accompanying shrinkage. All specimens sintered were compatible under microscopic examination except the niobium-containing cermets. Sintering UN-niobium for $1 \mathrm{hr}$ at $3000 \mathrm{~F}$ resulted in a structure indicating reaction without evidence of molten metal. However, when the sintering time was increased to $2 \mathrm{hr}$, the reaction was more severe and resulted in the formation of an estimated 10 to 15 volume per cent molten phase, accounting for the high density achieved. As indicated by the data presented in Table D-1, vacuum sintering UN cermets to high density appears to be an infeasible method for producing dense cermets and will be dropped from further investigation.

TABLE D-1. DENSITIES ACHIEVED BY VACUUM SINTERING 60 VOLUME PER CENT UN CERMETS

\begin{tabular}{|c|c|c|c|c|c|}
\hline \multirow[b]{3}{*}{ Matrix Metal } & \multicolumn{2}{|c|}{ Sintering Conditions } & \multirow{2}{*}{\multicolumn{2}{|c|}{$\begin{array}{c}\text { Density, per cent of } \\
\text { theoretical }\end{array}$}} & \multirow{3}{*}{$\begin{array}{c}\text { Weight Loss } \\
\text { per cent }\end{array}$} \\
\hline & \multirow{2}{*}{$\begin{array}{c}\text { Time, } \\
\text { hr }\end{array}$} & \multirow{2}{*}{$\begin{array}{c}\text { Temperature, } \\
\text { F }\end{array}$} & & & \\
\hline & & & Green & Sintered & \\
\hline \multirow[t]{4}{*}{ Chromium } & 2 & 2400 & 69.4 & 66.9 & 4.3 \\
\hline & $1 / 2$ & 2600 & 64.1 & 64.1 & 1.2 \\
\hline & 2 & 2600 & 68.5 & 65.0 & 8.6 \\
\hline & 2 & $2600(a)$ & 67.1 & 65.1 & 3.2 \\
\hline \multirow[t]{4}{*}{ Type 347 stainless steel } & 2 & 2400 & 65.7 & 68.4 & 0.3 \\
\hline & 2 & 2400 & 73.2 & 69.5 & 5.1 \\
\hline & $3-1 / 2$ & 2400 & 67.9 & 67.8 & 2.6 \\
\hline & $1 / 2$ & 2600 & 71.4 & 71.9 & 4.3 \\
\hline \multirow[t]{2}{*}{ Molybdenum } & 1 & 3000 & 70.6 & 69.8 & 2.3 \\
\hline & 2 & 3000 & 74.8 & 74.8 & 5.5 \\
\hline \multirow[t]{2}{*}{ Niobium } & 1 & 3000 & 71.5 & 71.6 & 1.6 \\
\hline & 2 & 3000 & 70.5 & 99.5 & Melted \\
\hline
\end{tabular}

(a) Sintered under $1 \mathrm{~atm}$ of argon.

Additional 80 volume per cent UN cermets have been gas-pressure bonded for $3 \mathrm{hr}$ at $2300 \mathrm{~F}$ and $2400 \mathrm{~F}$ to determine densities obtainable and to prepare additional compatibility specimens. Chromium, molybdenum, niobium, and Type 347 stainless steel were used as matrix metals. Densities obtained at $2300 \mathrm{~F}$ were, respectively, 90.5 , $86.4,96.2$, and 91.0 per cent of theoretical, a 1 to 8 per cent increase over densities previously obtained at $2200 \mathrm{~F}$. Microscopic examinations are not complete as yet. The $2400 \mathrm{~F}$ specimens are being machined for density measurements and microscopic examination. In addition, UN-chromium, -molybdenum, -niobium, and -Type 347 stainless steel cermets containing 60 to 90 volume per cent $U N$ have been pressure bonded to determine the effect of fuel loading on final densities.

As results on pressure-bonded densities and compatibility studies are obtained, materials for the preparation of UN cermet specimens for the measurement of thermal conductivity and mechanical properties will be made. 


\title{
Irradiation of Cermet Fuels
}

\author{
S. J. Paprocki, G. W. Cunningham, D. E. Lozier, and E. O. Fromm
}

Two capsules containing clad (with $35 \mathrm{mils}$ of Type 430 stainless steel) cylindrical specimens of $\mathrm{UO}_{2}$-refractory metal fuels are being prepared for high-temperature highheat-flux irradiations at the Engineering Testing Reactor. Three refractory metal matrices, chromium, molybdenum, and niobium, are involved, each combined with 80 volume per cent $\mathrm{UO}_{2}$ enriched to 20 per cent. Each capsule will contain six specimens, two each of the three materials indicated abcve. While the irradiations will be conducted in similar neutron-flux levels, different specimen burnup levels (approximately 2 and 5 per cent of the total uranium present) will be achieved by appropriate regulation of the in-pile time.

Table D- 2 presents various parameters which have been selected for the irradiations. The primary specifications are (1) sfiecimen heat fluxes of approximately $1 \times 106$ $\mathrm{Btu} /(\mathrm{hr})\left(\mathrm{ft}^{2}\right),(2)$ specimen center-line temperatures in the neighborhood of 0.7 of the melting points of the respective refractory metals, and (3) the following thermalconductivity values: $14.5 \mathrm{Btu} /(\mathrm{ft})(\mathrm{hr})(\mathrm{F})$ for molybdenum-UO $2,5.5 \mathrm{Btu} /(\mathrm{ft})(\mathrm{hr})(\mathrm{F})$ for niobium-UO2, and $11.0 \mathrm{Btu} /(\mathrm{ft})(\mathrm{hr})(\mathrm{F})$ for chromium-UO $\mathrm{U}_{2}$. The major dependent parameters are specimen diameter and neut:on flux. The fluxes indicated in Table D- 2 will be obtained by locating the specimen pairs in each capsule at vertical positions selected on the basis of the normal axial flux profile in the facilities to be occupied.

TABLE D-2. PARAMETERS FOR IRRADIATICIN OF UO 2 -REFRACTORY METAL CERMETS

\begin{tabular}{|c|c|c|c|}
\hline & Molybdenum $-\mathrm{UO}_{2}$ & Niobium- $\mathrm{UO}_{2}$ & Chromium- $\mathrm{UO}_{2}$ \\
\hline Enrichment, per cent & 20 & 20 & 20 \\
\hline Specimen Center-Line Temperature, F & 2640 & 2600 & 2370 \\
\hline Temperature at Cladding-Fuel Interfaces, F & 1700 & 1700 & 1700 \\
\hline Temperature at Cladding Surface(a), F & 1469 & 1560 & 1540 \\
\hline Fuel-Cylinder Diameter, in. & 0.400 & 0.246 & 0.300 \\
\hline Fuel-Cylinder Length, in. & $3 / 4$ & $3 / 4$ & $3 / 4$ \\
\hline Specimen Heat Flux, Btu/(hr) $\left.\mathrm{ft}^{2}\right)$ & $1.4 \times 10^{6}$ & $0.8 \times 10^{6}$ & $0.9 \times 10^{6}$ \\
\hline Specimen Effective Flux, $10^{14} \mathrm{nv}$ & 0.33 & 0.34 & 0.33 \\
\hline Burnup Per 25-Day Reactor Cycle, per cent & 1 & 1 & 1 \\
\hline
\end{tabular}

(a) The capsules will contain thermocouples which will be in close proximity to the specimen surfaces. 
According to present plans, the irradiation will commence at the ETR during April. To adhere to this schedule, it will be necessary that the capsule-assembly phase be completed early in March.

The specimens prepared for the cladding-material study have been pressure bonded $3 \mathrm{hr}$ at $2300 \mathrm{~F}$ and examined. The Hastelloy X-clad specimens failed during the bonding operation in the autoclave; however, the Type 430 stainless steel specimens appear satisfactory. The specimens represented alternate methods of incorporating void space to absorb fission gases at the ends of the fuel and within the cladding. The pressed $\mathrm{Al}_{2} \mathrm{O}_{3}$ powder densified to a greater extent than was anticipated and was rejected. The fused alumina containing four drilled holes cannot be used since the stainless steel end plugs extruded completely through the 1/8-in. -long holes and bonded to the fuel core. The void space will, however, be incorporated into the specimens by inserting two end plugs into each end of the tubing containing the green-pressed cores and pressure bonding. Both ends can than be drilled to the core and single end plugs electron-beam welded flush to the ends of the specimen cladding.

Continuous bonding was observed between the core and cladding by metallographic examination after pressure bonding. Thermally cycling a specimen between $1850 \mathrm{~F}$ and $200 \mathrm{~F}$ for 25 times did not result in any defects in the cladding, core, or interface.

\section{Development of Low-Cost Tubular Fuel Elements}

S. J. Paprocki, R. J. Carlson, and E. G. Smith, Jr.

The objective of this program is to develop techniques for fabricating low-cost tubular elements of consistent quality. Techniques under consideration at present include the consolidation of concentric components, the expansion of seam-welded or otherwise bonded flat-plate assemblies into a multiple-tube configuration, and a modification of a commercial process for producing thin-walled tubing which consists of flat rolling heavy-walled tubing and subsequently expanding it to a finned tubular shape.

Studies concerned with the shaping of powder mixtures containing a cold-binder plastic have continued. Acryloid has been chosen for further study because its forming properties are the best of the best of the plastics considered. A rather large amount $(20 \mathrm{w} / 0)$ of binder has been found necessary to maintain the desired shaping properties of the mixtures. Attempts to use solvents to dilute the mixture result in loss of these properties.

A mixture of stainless steel powder and Acryloid has been cold rolled to a thickness of $0.025 \mathrm{in}$. and can be formed into any shape when properly wetted. A tubular specimen has been assembled using a cold-rolled powder mixture. This sheet was formed around an inner stainless tube, and another larger stainless tube was placed over the sheet. The assembly was then heated at $1600 \mathrm{~F}$ for $1 \mathrm{hr}$ in hydrogen and then sealed off by electronbeam welding. Explosive techniques will be used to densify the core material and at the same time size the tubular shape.

Further investigation of a commercial process for producing thin-walled tubing has been concerned with hot rolling of tubular specimens. The annulus between two concentric stainless tubes is filled with a $\mathrm{UO}_{2}$-stainless steel powder dispersion. The 
assembly is then flattened and hot rolled. Considerable difficulty has been found in rolling these tubular specimens. Nonuniform loading of the core powder results in splitting of the thin-walled tubing in the thicker parts of the specimens.

To establish the feasibility of an expanded multiple-tube assembly, two specimens have been prepared. One consists of two $\mathrm{UO}_{2}$-stainless steel fuel plates fabricated in a conventional manner. Each plate contains two fuel sections. These plates will be subsequently bonded together. Spot welding was used to bond the plates together in the initial specimens. The fuel sections were then opened up into a tubular shape by drawing a series of mandrels through each core section in a drawbench operation.

To produce a multiple-tube element as described above, it would be desirable from cost considerations to employ a rolling operation to both roll the fuel plates and at the same time bond them together. This would require the use of a parting compound to prevent bonding between the core sections. An investigation of several parting compounds for this purpose is to be initiated. In addition, the possibility of using a welding operation to bond the rolled fuel plates together will be considered.

\section{Factors Affecting Pressure Bonding}

D. C. Carmichael, G. W. Cunningham, and J. W. Spretnak

The mechanism of solid-phase bonding of metal components under the application of heat and pressure is being studied. A broad study of the mechanism of pressure bonding has been made utilizing pure copper. Investigations have been initiated to examine the mechanism in more detail and in other metals than copper.

The relationship between required pressure for intimate contact and hot hardness which has been determined for copper is being tested for other selected metals, such as aluminum and tantalum. Also, since minimization of the number of voids in a bond is important in order to permit complete grain growth across the bond region, the availability of vacancy sinks in other metals than copper will be considered. The bonding behavior will be investigated for metals such as aluminum in which dislocations are known to be more effective vacancy sinks than they are in copper. 


\title{
GAS-PRESSURE BONDING OF CERAMIC, CERMET, AND DISPERSION FUEL ELEMENTS (AEC-FUEL CYCLE)
}

\author{
S. W. Porembka
}

This program concerns the application of the gas-pressure-bonding process to the fabrication of low-cost ceramic, cermet, and dispersion fuel elements. With the unique capability of densifying and cladding the fuel in a single bonding operation, the process offers promise in producing quality fuel elements at a reduced cost. The major emphasis to date has been placed on the ceramic fuel system as clad with Type 304 stainless steel. Past efforts have involved studies of initial oxide compacting techniques, characteristics of pressure-bonded oxides, and various basic fuel-element geometries.

The behavior of various commercially available types of uranium dioxide has been evaluated in both cold-compacting and subsequent pressure-bonding operations. Mixtures of fused and ceramic oxides have demonstrated the best characteristics for successful pressure bonding; consequently, all present work is concentrated on such mixtures. The optimum conditions necessary for high-integrity stainless steel bonds, consistent with good oxide-densification behavior, have also been defined. Current studies involve establishing preliminary prccess specifications for the most promising fuel elements.

\section{Uranium Dioxide Compaction Studies}

S. J. Paprocki, D. L. Keller, and J. B. Fox

Investigations of various uranium dioxide powders have been directed toward achieving high-density green cores which attain high final densities on pressure bonding with good dimensional control. In view of the desirable characteristics of fused and ceramic mixtures, current efforts have concerned a more detailed study of such mixtures with particular regard to defining preliminary process specifications. The effectiveness of different binder additions, fused oxide particle size, and vibratory packing are presently under consideration.

A coarse-particle fused oxide (minus 6 mesh as received) was characterized for comparison with the minus 20-mesh fused oxide utilized in recent studies. The coarse material exhibited a tap density of 57.1 per cent of theoretical and cold pressed to a maximum density of 87.3 per cent of theoretical. A mixture of minus 6-mesh fused oxide with $25 \mathrm{w} / \mathrm{o}$ ceramic oxide (minus 325 mesh) yielded cold-pressed compacts of 80.9 per cent of theoretical. In general, the coarse oxide has permitted slightly higher densities than the minus 20-mesh fused material. 
Investigations to develop preliminary process specifications for the fabrication of several basic Type 304 stainless steel-clad $\mathrm{UO}_{2}$ fuel-element shapes by the gaspressure-bonding technique are being continued.

Two rod-type elements approximately $2 \mathrm{ft}$ long have been pressure bonded with very encouraging results. These rods contained green-pressed oxide pellets of a $60 \mathrm{w} / \mathrm{o}$ fused-40 w/o ceramic $\mathrm{UO}_{2}$ as-received mixture with a Ceremul " $\mathrm{C}$ " binder. The green-pressed pellets were loaded into Type 304 stainless steel 0.023-in. -wall tubes measuring $0.542 \mathrm{in.}$ in ID by $26 \mathrm{in.} \mathrm{long.} \mathrm{A} \mathrm{rod} 0.539 \mathrm{in}$. in diameter was used to force each pellet into position to insure intimate contact. The preliminary results obtained from these two rods are given in Table $\mathrm{E}-1$.

The investigation of the effects of different binders and methods of binder removal upon the final characteristics of the pressure-bonded oxide is being continued to help establish final process specifications for the green-pressed oxide cores. The results obtained from pressure bonding pellets using a $60 \mathrm{w} / 0$ fused $-40 \mathrm{w} / 0$ ceramic $\mathrm{UO}_{2}$ mixture made by the slurry method are given in Table E-2. Slightly higher coldcompacting densities are obtained when the slurry method for preparing the $\mathrm{UO}_{2}$ is used. There appears to be little difference in the final characteristics of the pressurebonded $\mathrm{UO}_{2}$ between this and the other methods of binder addition; however, the higher starting density minimizes the effects of densification upon the element shape. Further studies are being made to determine the optimum binder and method of binder addition.

Additional flat-plate specimens containing pressed and sintered stainless powder frames and green-pressed $\mathrm{UO}_{2}$ cores have been pressure bonded. These specimens contained pressure plates inserted next to the claddings to help overcome densification irregularities. Preliminary examination of these specimens indicate the use of these pressure plates has improved the uniformity of these specimens.

The subassembly measuring 1 by $2-1 / 4$ by 6 in. has been sectioned and a complete dimensional study is being made. The objective of this investigation is to define the degree of dimensional control that can be achieved with compartmented flat-plate assemblies. 


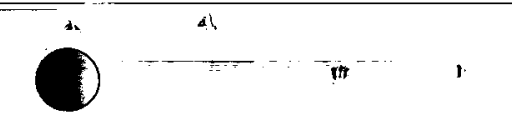

TABLE E-1. RESULTS OF AN EXAMINATION OF TWO GAS-PRESSURE-BONDED ST AINLESS STEEL-CLAD UO 2 ROD-TYPE ELEMENTS

\begin{tabular}{|c|c|c|c|c|c|c|c|c|c|c|}
\hline \multirow[b]{2}{*}{ Tube } & \multirow{2}{*}{$\begin{array}{l}\text { Starting } \\
\text { Core } \\
\text { Length, } \\
\text { in. }\end{array}$} & \multirow{2}{*}{$\begin{array}{l}\text { Final } \\
\text { Core } \\
\text { Length, } \\
\text { in. }\end{array}$} & \multirow{2}{*}{$\begin{array}{l}\text { Starting } \\
\text { Tube OD, } \\
\quad \text { in. }\end{array}$} & \multicolumn{2}{|c|}{$\begin{array}{c}\text { Final } \\
\text { Tube } O D_{\text {, }} \text { in. } \\
\end{array}$} & \multirow{2}{*}{$\begin{array}{c}\text { Final } \\
\text { Tube-Wall } \\
\text { Thickness, } \\
\text { in. }\end{array}$} & \multicolumn{2}{|c|}{$\begin{array}{l}\text { Average Density, } \\
\text { g per } \mathrm{cm}^{3} \\
\end{array}$} & \multirow{2}{*}{$\begin{array}{c}\text { Average Final } \\
\text { Stoichiometry } \\
\text { (Oxygen/Uranium) }\end{array}$} & \multirow[b]{2}{*}{ Comments } \\
\hline & & & & Maximum & Minimum & & Starting & Final & & \\
\hline 118 & 25.375 & 23.204 & 0.588 & 0.547 & 0.542 & 0.026 & 8.0 & $\begin{array}{l}10.51^{(a)} \\
10.6(b)\end{array}$ & 2.01 & $\begin{array}{l}\text { The tube was very uniform except for two } \\
\text { indentations, } 10 \text { mils deep, where the } \\
\text { cladding flowed in between two pellets; } \\
\text { a bow of approximately } 1 / 16 \text { in. over } \\
\text { a } 1 \text {-ft length was observed }\end{array}$ \\
\hline 119 & 25.375 & 22.985 & 0.588 & 0.547 & 0.542 & (c) & 7.7 & $10.45^{(a)}$ & (c) & $\begin{array}{l}\text { Very uniform tube except for one } \\
\text { indentation, which had been noted in a } \\
\text { radiograph before bonding as a poorly } \\
\text { loaded core; very straight after bonding, } \\
\text { less than a } 1 / 32-\text { in. bow over the tube } \\
\text { length }\end{array}$ \\
\hline
\end{tabular}

\footnotetext{
(a) Calculated density.

(b) Pycnometer measurement.

(c) Tube 119 has not been sectioned for these measurements.
} 
TABLE E-2. COMPACTING ${ }^{(a)}$ AND PRESSURE-BONDING ${ }^{(b)}$ CHARACTERISTICS OF 60 w/o FUSED-40 w/o CERAMIC UO 2 MIXTURE MADE BY THE SLURRY METHOD(c)

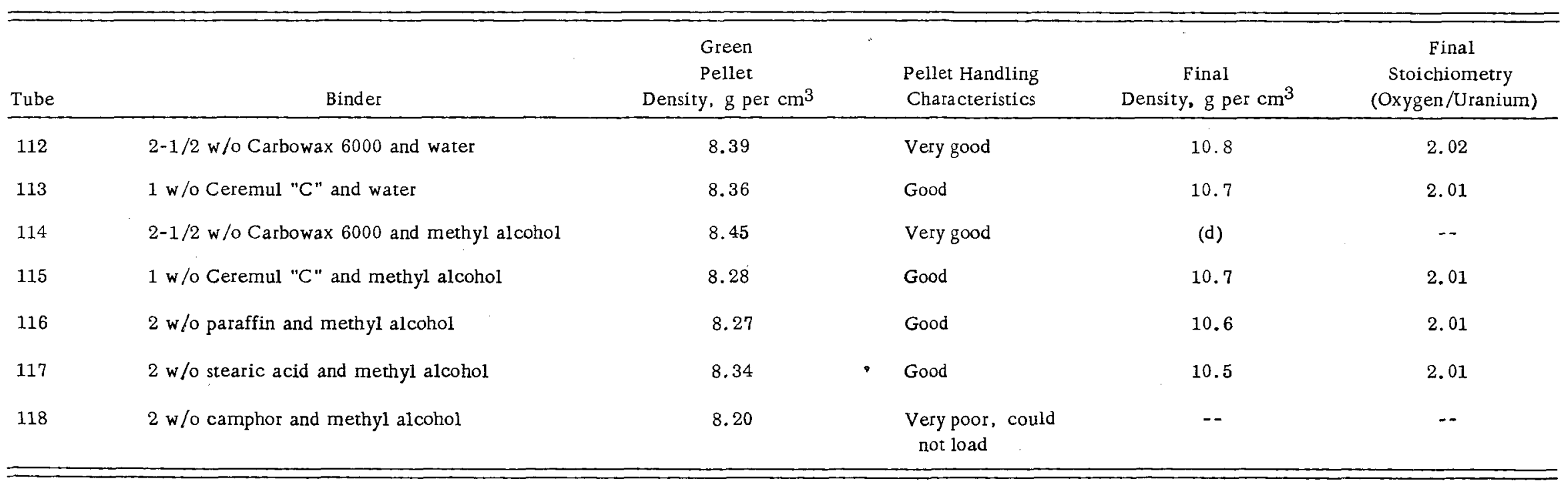

(a) Pressed at 50 tsi.

(b) The tubes with the exception of 118 were debindered under vacuum at $1200 \mathrm{~F}$ for $1-1 / 2 \mathrm{hr}$. After evacuation down to $5 \mu$, they were sealed and pressure bonded at $2100 \mathrm{~F}$ for $3 \mathrm{hr}$ at 10,000 psi.

(c) The fused $\mathrm{UO}_{2}$ powder was minus 20 mesh; the ceramic $\mathrm{UO}_{2}$ was minus 325 mesh.

(d) Weld failed during pressure bonding. 


\title{
DEVELOPMENT OF URANIUM CARBIDE (AEC-FUEL CYCLE)
}

\author{
F. A. Rough and W. Chubb
}

Uranium carbides and their alloys are being developed for the $A E C$ as a part of the Fuel-Cycle Development Program. The objective of this program is to lower the cost of power produced from nuclear energy by lowering the costs of manufacturing, using, and reprocessing reactor fuels. Foremost amorg the various ways in which these costs can be reduced are: (1) lowering the cost of fabricating the fuel, (2) increasing the temperature at which the reactor coolant and fuel operate, (3) increasing the life of the fuel in the reactor, and (4) decreasing the cost of reprocessing the fuel. Uranium carbides seem capable of producing dramatic savings in cornection with the second and third of these items, and the costs of fabricating and reprocessing of fuel elements using uranium carbides will probably be quite similar to the costs of fabricating and reprocessing fuel elements containing uranium oxide or uranium metal.

To assist in the accomplishment of the aforementioned objective, an integrated program of research on the preparation and properties of bulk uranium carbides is in progress at Battelle. This program includes: (1) studies of the properties of hotpressed uranium carbide powders, (2) development of skull-melting and casting techniques for carbides, (3) determination of the mechanical, physical, and chemical properties of uranium carbides at room and elevated temperatures, (4) measurements of the rates of diffusion of uranium and carbon in uranium carbides, and (5) irradiations designed to produce basic information on the nature of radiation-damage processes in the structure and upon the integrity of uranium carbides. These studies have now been in progress for over a year and a half. During this time the emphasis in the research effort has been in the first four areas menticned above. During the next year, emphasis will be shifted gradually toward property studies and toward analysis of the nature of radiation-damage processes in uranium carbides.

During the last month, additional studies of the hot-pressing technique for preparing shapes of uranium carbide demonstrated that the technique is capable of producing a 93 per cent dense product containing no uranium metal in a consistent and reproducible fashion.

The skull-casting furnace has now produced five successive casting seighing from 6 to $8 \mathrm{~kg}$, all having analyses in the range from 4.52 to $4.66 \mathrm{w} / 0$ carbon $(4.59 \pm$ $0.07 \mathrm{w} / 0$ carbon). This result was achieved by outgassing commercial graphite at $1800 \mathrm{C}$ in a vacuum prior to charging it in the skull-casting furnace.

Studies of the transformation of cast uranium-7 w/o carbon alloys into the $\mathrm{U}_{2} \mathrm{C}_{3}$ structure have suggested that this process will occur in less than 15 min at temperatures between 1500 and $1700 \mathrm{C}$.

The results of a single hot-hardness run on uranium carbide (5.0 w/o carbon) show that the hardness of the carbide begins to decrease rapidly above $1000 \mathrm{C}$. A hardness of about $22 \mathrm{DPH}$ was measured at $1500 \mathrm{C}$. 
$F-2$

Alternate Fabrication Methods for UC

S. J. Paprocki, D. L. Keller, and J. M. Fackelmann

A study of solid-phase fabrication methods for uranium carbide and of the properties of such bodies is being conducted.

Isostatic hot pressing of UC compacts for $3 \mathrm{hr}$ at temperatures from 1300 to $1430 \mathrm{C}$ under a 5-tsi pressure has resulted in compact densities of 85 to 99 per cent of theoretical. The microstructure of the densest compacts contained relatively large amounts of oxygen present as the $\mathrm{UO}_{2}$ phase. The heaviest concentration of $\mathrm{UO}_{2} \mathrm{ob}-$ served amounted to approximately 5 volume per cent. In attempting to eliminate $\mathrm{UO}_{2}$ and at the same time permit simpler powder-handling procedures, coarser UC powder is being investigated. In the past particles finer than $44 \mu$ have been used. In recent studies, the core densities obtained from UC powder prepared by crushing arc-melted buttons ranged from 12.6 to $12.8 \mathrm{~g}$ per $\mathrm{cm}^{3}$ after hot pressing $3 \mathrm{hr}$ at $1480 \mathrm{C}$ with $5 \mathrm{tsi}$ of pressure. An average value of $12.7 \mathrm{~g} \mathrm{per} \mathrm{cm}^{3}$ represents 93 per cent of the theoretical density. Minus 80 to minus 325 -mesh fractions were used in this series as indicated in Table F-1. The density measurements referred to above were obtained by buoyancy measurements of the niobium-UC capsules. Corrections were made for the niobium cladding present. These results are compared with the values estimated from radiographic measurements in Table $F-1$. It can be noted that increasing the particle size did reduce the densities obtained.

TABLE F-1. PRELIMINARY DENSITY MEASUREMENTS OF ISOST ATIC HOT -PRESSED URANIUM CARBIDE COMPACTS

\begin{tabular}{|c|c|c|c|}
\hline & Particle & Green Density, & Hot-Pressed Density, g per $\mathrm{cm}^{3}$ \\
\hline Type Powder & Size, mesh & $\mathrm{g}$ per $\mathrm{cm}^{3}$ & Buoyancy $\quad$ Radiograph \\
\hline
\end{tabular}

Hot Pressed $3 \mathrm{Hr}$ at $1480 \mathrm{C}$ and $5 \mathrm{TSI}$

Crushed arc-melted buttons

Vitro shot

Crushed arc-melted buttons

Vitro shot

$\begin{array}{lr}-80 & 10.6 \\ -100 & 10.7 \\ -200+325 & 10.1 \\ -325 & 9.7 \\ -80 & 10.6 \\ -200+325 & 10.2 \\ -325 & 10.4\end{array}$

Hot Pressed $6 \mathrm{Hr}$ at $1430 \mathrm{C}$ and $5 \mathrm{TSI}$

$\begin{array}{cc}-100 & 10.4 \\ -100 & 10.6 \\ -325 & 9.7^{(a)} \\ -325 & 9.6^{(a)} \\ -100 & 10.6 \\ -100 & 10.1\end{array}$

$\begin{array}{ll}12.7 & 12 \\ 12.8 & 12 \\ 12.6 & 13 \\ 12.7 & 13 \\ 12.2 & 12 \\ 12.2 & 12 \\ 12.1 & 13\end{array}$

13

(a) Compacts sintered in static argon to a density of about 70 per cent of theoretical. All other compacts were hot pressed in the as-compacted condition. 
A similar series of capsules contained compacts of commercial uranium carbide obtained from Vitro Laboratories. This material was crushed to the appropriate size in argon, compacted, vacuum sealed in niobium capsules, and hot pressed under the same conditions described above. Again no particle-size effect was noted, but the average density of $12.2 \mathrm{~g}$ per $\mathrm{cm}^{3}$ was significantly lower than for the corresponding cores prepared from the reference arc-melted and crushed powder.

Hot-pressing time was increased from 3 to $6 \mathrm{hr}$ at a temperature of $1430 \mathrm{C}$ for compacts prepared from the arc-melted and crushed powder as well as the crushed Vitro shot to determine the effect of time on densification. Densities similar to those observed at $1480 \mathrm{C}$ were obtained.

Presintered compacts with intentional jmpurity additions have also been hot pressed. The presintered compacts had been surrounded by compacted powder before encapsulating so metallographic analysis will. be required for a complete interpretation of these results.

Metallographic analysis of all the cores described in Table F-1 is in progress.

Melting and Casting Techniques for Uranium-Carbon Alloys

B. C. Boesser, E. L. Foster, and R. F。 Dickerson

In the interest of developing techniques for the production of high-quality cast shapes, efforts are being devoted to the problem of controlling purity and composition of large volumes of uranium carbide prepared by skull melting and casting. The determination of the effects of various grades of graphite upon final composition continues to be of interest.

Usually a variation of $\pm 0.3 \mathrm{w} / \mathrm{o}$ carbon from the desired composition is experienced in alloying uranium under constant melting conditions with commercial electrode-grade graphite, the same grade of graphite being usied as the electrode-tip material. Two melts were made under the usual conditions excepting that vacuum-degassed commercial graphite was used as the electrode and charge. Less splashing of metal and less erosion of the tip occurred. The variation in carbon content between these two melts was only $0.1 \mathrm{w} / \mathrm{o}$.

During this report period, seven additional melts were made at higher than normal power input using vacuum-outgassed $(1800 \mathrm{C})$ commercial electrode-grade graphite as the electrode tip and alloying agent. The installation of additional rectifiers to the furnace circuit allowed the use of $5000 \mathrm{amp}$ instead of the usual $3600 \mathrm{amp}$ as the arc current. After a new skull was built up, charges of uranium-4 w/o outgassed graphite were added to the skull and melted for $30 \mathrm{~min}$. As with the lower power input, less splashing of the melt was observed with the outgassed graphite. The seven new castings contained 4.17 , $4.29,4.66,4.52,4.61,4.65$, and $4.59 \mathrm{w} / 0$ carbon, respectively. The latter five values were obtained in castings poured after the initial buildup of the skull, and the castings varied less than $\pm 0.1 \mathrm{w} / \mathrm{o}$ carbon at this power level. Sound castings were produced which weighed from 6 to $8 \mathrm{~kg}$.

Preparations are being made to study the use of vacuum-degassed AGOT and TSF reactor-grade graphites as electrode and alloying agents by observing carbon fluctuation: of the cast UC prepared under the same high-power-input melting conditions. 
$\mathrm{F}-4$

Mechanical and Physical Properties of Uranium Monocarbide

G. G. Chesmar, R. W. Endebrock, E. L. Foster, and R. F. Dickerson

Uranium monocarbide offers promise as a nuclear fuel capable of operation at elevated temperatures. To fully evaluate the usefulness of this fuel, however, hightemperature properties such as strength, hardness and thermal conductivity must be determined. An additional objective of this phase of the research is to determine the effect of alloying, coating and heat treating on UC properties.

A series of hot-hardness measurements in the 1000 to $1500 \mathrm{C}$ temperature range was obtained on one uranium-5 w/o carbon specimen. These measurements are given in Table F-2. When temperature is plotted against the logarithm of the hardness, two straight lines result with a significant change in slope occurring at a temperature of $1000 \mathrm{C}$. This change in slope is interpreted as the beginning of softening of the material; however, more data are necessary for confirmation.

T ABLE F -2. HOT HARDNESS OF URANIUM -5 W/O CARBON ALLOY

\begin{tabular}{cc}
\hline \hline Temperature, C & Hardness, DPH \\
\hline RT & 1000 \\
1000 & 780 \\
1100 & 270 \\
1200 & 130 \\
1300 & 70 \\
1400 & 40 \\
1500 & 22 \\
\end{tabular}

Specimens of uranium $-7 \mathrm{w} / \mathrm{o}$ carbon alloy were subjected to various heat treatments $(1400,1500,1600,1700 \mathrm{C}$ for $1 / 4,1 / 2$, and $1 \mathrm{hr})$. The treated specimens were examined by metallography and by hardness tests in an effort to further define the rate of transformation of the as-cast $U C-U_{2}$ structure to $\mathrm{U}_{2} \mathrm{C}_{3}$. Although there were some differences in the appearances of the microstructures and there was a slight scatter in the room-temperature hardness measurements, the results indicated complete transformation of all specimens, suggesting that transformation is quite rapid at these temperatures. Heat treatments for shorter times are planned.

During this period, some UC-molybdenum alloys were prepared in an attempt to find an alloy with greatly improved properties. These alloys are currently being examined.

High-temperature property measurements of $\mathrm{UC}, \mathrm{U}_{2} \mathrm{C}_{3}$, and $\mathrm{UC}_{2}$ will continue. Specimens of all three compositions have been prepared and are ready for examination by hot-hardness measurements. Additional heat treatments are planned in a study of the transformation rate of the cast $U C-U C_{2}$ structure to that of $U_{2} C_{3}$. The preparation of a 3-in. -diameter by 1 -in. -thick specimen for thermal-conductivity tests is in progress. 
Uranium Monocarbide: Diffusion Studies

W. Chubb, R. W. Getz, and F. A. Rough

Diffusion rates in uranium monocarbide are of interest in predicting the elevatedtemperature behavior of this material. The interdiffusion of uranium and carbon has been determined for temperatures from 1600 to $2000 \mathrm{C}$ by measuring the rate of growth of the carbide layers formed between molten uranium saturated with carbon and graphite. The rate of self-diffusion of uranium in uranium monocarbide for temperatures from 1600 to $2100 \mathrm{C}$ was measured by diffusing uranium-235 atoms from a foil of enriched uranium into two lengths of depleted uranium monocarbide, one on either side of the foil, and counting the gross gamma activity of samples ground from the couple. The rate of self-diffusion of carbon in uranium monocarbide will now be determined for temperatures from 1600 to $2000 \mathrm{C}$ by diffusing carbon-14 from a length of uranium monocarbide made with carbon-14 into a length of uranium. monocarbide made of natural carbon.

Analyses for carbon-14 will be made by counting the beta activity of an exposed surface perpendicular to the axis of the specimen as successive slices are ground away.

In the study of the rate of self-diffusion of uranium, the final couple, annealed for $480 \mathrm{~min}$ at $2000 \mathrm{C}$, was analyzed for enrichment using the 0.184-Mev gamma-ray activity. The diffusion coefficient for the self-diffusion of uranium in this couple was calculated to be $1.9 \times 10^{-8} \mathrm{~cm}^{2}$ per sec. A linal calculation of the activation energy and of the diffusion constant is being made.

Uranium monocarbide with $4.85 \mathrm{w} / \mathrm{o}$ carbon and a specific beta activity of about $100 \mathrm{mc}$ per $\mathrm{g}$ from carbon- 14 was drop cast into a graphite mold $0.5 \mathrm{in}$. in diameter and $1.5 \mathrm{in}$. in length for studying the rate of self-diffusion of carbon. The diffusion couples will be prepared by placing a foil of natural uranium between two rods of uranium monocarbide, one of which contains carbon-14. These will be bonded using the same procedures employed in the determination of the rate of self-diffusion of uranium. It is planned to anneal the first couple for $120 \mathrm{~min}$ at $2000 \mathrm{C}$. This anneal is expected to produce a diffusion zone approximately $0.035 \mathrm{in.} \mathrm{thick.}$

Future work will include the final calculations in the study of the self-diffusion of uranium in uranium monocarbide and the preparation of couples for the study of the selfdiffusion of carbon in uranium monocarbide.

\section{Effects of Radiation on UC} and F. A. Rough

The study of the radiation stability of three types of 10 per cent enriched uraniumcarbon fuel material is continuing. Specimens of uranium-5. $0 \mathrm{w} / 0$ carbon, uranium$6.7 \mathrm{w} / 0$ carbon, and uranium $-8.5 \mathrm{w} / 0$ carbon are presently being irradiated in the BRR. Because of a lower than anticipated neutron flux encountered during the first reactor cycle, specimen temperatures were several hundred degrees lower than the design temperatures. However, by incorporating mixtures of inert gases into the outer annuli of the capsules, temperatures in excess of $1400 \mathrm{~F}$ have been attained. During the 
$F-\underline{6}$

startup of Cycle 148, fission products detected in the reactor coolant were traced to Capsule 4, which therefore necessitated its discharge. This capsule contained four uranium $-5 \mathrm{w} / \mathrm{o}$ carbon specimens, two of which had been heat treated to relieve casting stresses, and two heat-treated specimens of uranium- $6.7 \mathrm{w} / 0$ carbon. It is estimated that these specimens had experienced a uranium burnup of approximately 0.1 a/o at the time of their discharge. The irradiation of the remaining three capsules is continuing as scheduled. 
PHYSICAL RESEAR.CH (AEC-DR)

\author{
F. A. R.ough
}

A research program directed toward the development of high-quality single crystals of $\mathrm{UO}_{2}$ is under way. This study is being supported by the AEC Division of Research.

Growth of $\mathrm{UO}_{2}$ Single Crystals

J. D. Jackson and I. A. Alexander

The objective of this program is to prepare large single crystals of $\mathrm{UO}_{2}$. Hightemperature sources are being used to melt $\mathrm{UO}_{2}$ (melting point about $2760 \mathrm{C}$ ) and to control its solidification to form large single: crystals. The following fusion methods have been investigated in the program:

(1) Electron-beam melting

(2) Resistance heating

(3) Arc melting

(4) Plasma-jet impingement

(5) Induction heating

(6) Radiation heating from resistance element.

Most of the experimental program has employed the last three methods. The resistance furnace with a tungsten heating element appears to give the greatest promise for success, and the present objective is to improve the furnace to reach and maintain a temperature of $2800 \mathrm{C}$.

Considerable effort was expended in December in devising and fabricating satisfactory tungsten resistance elements. Because these elements work almost to their melting point, the utmost care was required to cut, form, and mount the crystallized tungsten.

During one experiment this month, the temperature of the system was raised very near the melting point of $\mathrm{UO}_{2}$. In fact, a thin film of molten $\mathrm{UO}_{2}$ was formed on the wall of the crucible, and the remaining $\mathrm{UO}_{2}$ became sintered and glazed. The temperature of the crucible could not be measured because of a dense smoke which formed above $2200 \mathrm{C}$. This smoke was traced to a krass mounting ring on the crucible which later collapsed and ended the experiment after only $15 \mathrm{~min}$ at temperature.

The high-temperature experiments will be continued in the resistance furnace during the coming month. 
In addition, consideration is being given the use of molten oxide systems in which the components are miscible in the liquid phase, but form no solid solutions. Investigation of existing phase diagrams indicate three systems of potential interest, the $\mathrm{UO}_{2}-$ $\mathrm{MgO}, \mathrm{UO}_{2}-\mathrm{BeO}$, and $\mathrm{UO}_{2}-\mathrm{Al}_{2} \mathrm{O}_{3}$ systems. Of these, the $\mathrm{UO}_{2}-\mathrm{Al}_{2} \mathrm{O}_{3}$ appears most promising, since temperatures as low as $2000 \mathrm{C}$ may be employed with this system. It appears from available information that complete segregation occurs in this system, and the $\mathrm{UO}_{2}$ is precipitated in a fused homogeneous mass.

Use of such a system is advantageous from two standpoints. First, the lower temperatures are readily obtained in the resistance furnace. A second and quite important advantage is that the presence of the molten alumina would be of great help in effectively transferring the heat to the $\mathrm{UO}_{2}$, since the thermal conductivity of $\mathrm{UO}_{2}$ is very low at temperatures in the neighborhood of its melting point. 


\title{
RADIOISOTOPE AND RADIATIOIN APPLICATIONS (AEC-OID)
}

\author{
D. N. Sunderman
}

Two research programs are under way at Battelle as a part of the program of the Office of Isotopes Development. The first is concerned with the use of intrinsic radioactive tracers in industrial process control and the second is a study of the influence of molecular structure on radiation-induced graft polymerization.

Current experiments in utilization of intrinsic tracers are centered upon the purification of process water. Manganese is a common impurity whose concentration is critical in a number of industrial applications. It is usually removed by coprecipitation with iron, also present in low concentrations. Intrinsic tracers may be of value in the control of this separation process, and experiments are under way to evaluate their use. Results of initial experiments will be reported next month.

Molecular mobility appears of major importance in determining the stability of radiation-induced free-radical sites. Experiments with polymethylmethacrylate and polymethylacrylate indicate that active sites formed in the less rigid PMMA are readily destroyed by low molecular weight-high mobility products, while sites in the more highly cross-linked PMA are longer lived as the result of the lower molecular mobility. Critical experiments are under way to evaluate this hypothesis.

The mechanism of radiation-induced reactions in polymethyl- $\alpha$-chloroacrylate was described on the basis of infrared, gas chrornatographic, and mass-spectrometric analyses of reaction products. Results with this material are consistent with earlier work on polybutylmethacrylates.

\section{Use of Intrinsic Radioactive Tracers for Process Control}

J. L. McFarling, P. Gluck, J. F. Kircher, and D. N. Sunderman

The intrinsic-radiotracer program has been continued along the lines described last month in BMI-1480.

The previously completed experimental study demonstrated the application of radiotracers control to the removal of iron by precipitation. The present experimental program will extend the scope of the demonstration through the application of different intrinsic radiotracers in other precipitation-filtration systems.

The system now being studied is the removal of manganese from industrial processing water by precipitation at a high $\mathrm{pH}$. Manganese -54 is being used as the intrinsic radiotracer in this instance.

Although manganese does not ordinarily occur in concentrations greater than a few parts per million in untreated feed water, its concentration must be reduced in many cases, e.g., pulping operations and brewing of beer, to less than $0.1 \mathrm{ppm}$. Iron is commonly removed along with manganese, the iron hydroxide serving to help carry down the manganese dioxide formed. Since the method of removing low-concentration 
impurities by coprecipitation is used very widely in industry, it was felt that the demonstration of the use of an intrinsic radiotracer in the process would be valuable for this program.

The possible hazards associated with the occurrence of residual intrinsic radiotracers in consumer products are being evaluated. The steel industry is being used as an example of a commercial operation which might use a variety of radiotracers and which produces widely used consumer products.

The criteria being used as a basis of comparison in the evaluation are as follows:

(1) AEC maximum permissible dose levels for occupational exposure

(2) AEC maximum permissible dose levels for nonoccupational exposure

(3) Average exposure levels from ordinary environmental radiation.

The approach being used is to estimate the maximum dose which could be received from continuous exposure to residual radioisotopes if they were present in the maximum concentrations allowed. This "worst case" will then be compared with the abovementioned criteria and also with average exposures which might accrue to steel users.

Next month both the hazards evaluation and manganese-removal study will be continued. In addition, other processes will be examined for possible use as demonstrations of intrinsic-tracer control of the precipitation-filtration principle.

Graft-Polymerization Studies

F. A. Sliemers, W. B. Gager, J. F. Kircher, and $R$. I. Leininger

The investigation of the influence of total dose on site formation for polymethylacrylate (PMA) was continued. Earlier in the program, samples of PMA were irradiated to total doses in the range $3 \times 10^{5}$ to $3 \times 10^{7}$ rads. No evidence of site formation was obtained by EPR measurements below approximately 107 rads. The present work has extended the investigation to doses as high as $1.4 \times 10^{8}$ rads. At these higher doses, EPR data indicate that considerable numbers of sites have been formed. How ever, the results further show that an unidentified reaction takes place within the irradiated polymer, resulting in a diminution of the total number of sites with time.

A comparison of the behaviors with increasing dosage of PMMA and PMA with respect to (1) total site formation and (2) molecular-weight changes indicates that molecular mobility is of considerable importance in the production of long-lived free radicals. The irradiation of PMMA results in the formation of measurable numbers of sites even at very low doses $\left(\sim 10^{5} \mathrm{rads}\right)$. In addition, a decrease in molecular weight occurs as the dose is increased and, consequently, molecular mobility increases. The decrease in total number of sites at doses in excess of some critical value can be explained in terms of this increased mobility. At this point, the production of free radicals can no longer compete with the destruction of sites by scavenger effects of the low-molecular-weight by-products of the reaction and the more mobile polymer itself. 
On the other hand, in the irradiation of PMA, doses of the order of $10^{7}$ rads are required to produce measurable numbers of free radicals. The cross-linking nature of this material results in a continuous increase in molecular weight with dose. Thus, the polymer becomes more and more rigid. At some intermediate rigidity, the polymer still has the mobility to destroy sites, but much more slowly. This behavior probably accounts for the gradual decay noted above. Finally, a network is built up in which molecular mobility has been reduced to the point where relatively stable free radicals are produced by further irradiation.

To test this hypothesis, samples of PMA are now being irradiated to doses of the order of $10^{8}$ rads. Following the determination of the total number of sites, these materials will be heated to $100 \mathrm{C}$ to destroy the sites and reirradiated to lower total doses. An immediate buildup of sites would lend support to the hypothesis. An alternative approach would be the use of low total doses at reduced temperatures. This work will be reported in the report for January.

The volatile products from the irradiation of polymethyl-a-chloroacrylate were quantitatively measured by means of mass spectrometry and vapor-phase chromatography. All compounds detected were identified and are listed in Table $\mathrm{H}-1$.

TABLE H-1. COMPOUNDS FORMED DURING IRRADIATION

OF POLYMETHYL- $\alpha$-CHLOROACRYLATE

\begin{tabular}{lc}
\hline \multicolumn{1}{c}{ Compound } & Concentration, microliters \\
\hline & \\
Carbon monoxide & 900 \\
Carbon dioxide & 3100 \\
Methyl chloride & 3000 \\
Hydrogen & 350 \\
Methane & 200 \\
Methanol & 5 \\
Methyl formate & 0.1 \\
Methyl acetate & 0.1 \\
& \\
\hline
\end{tabular}

It should be mentioned that analysis revealed no water, hydrogen chloride, or chlorine.

Analysis of the above data indicates, in agreement with earlier findings, that free-radical formation takes place by ester chain scission. Either $\mathrm{CO}_{2}$ or $\mathrm{CO}$ is eliminated. If $\mathrm{CO}_{2}$ is formed, the free methyl radical reacts with either a chlorine or hydrogen atom on the polymer chain to form methyl chloride or methane. Methyl chloride appears to be formed about 90 per cent of the time. If CO is formed, the data indicate that the methoxy radical recombines with the chain free radical with no apparent net gain in free-radical concentration. This recombination was also noted in the work with the polybutylmethacrylates.

During January, work will be continued in the areas outlined in the November report (BMI-1480). 


\title{
ASSISTANCE TO AEC-EURATOM PROGRAM
}

\author{
H. M. Epstein and D. L. Keller
}

Studies concerned with obtaining information on void-content and heat-transfer relationships in forced-convection subcooled boiling water and with the development of uranium mononitride as a possible fuel material are under way for the Joint US-Euratom Research and Development Board. Both programs are directed toward obtaining data that will be useful in efforts to achieve more economical nuclear power.

\section{VOID-DIST RIBUTION AND HEAT - TRANSFER STUDIES}

R. O. Wooton, F. G. Peter, J. J. Foglia, H. M. Epstein, and J. W. Chastain

The objective of this program is to investigate axial void distribution and heat transfer for rectangular coolant passages over a range of experimental conditions of interest in light-water reactors. In the experimental program, a positive displacement pump is used to circulate distilled water in a closed, pressurized loop consisting of piping, test section, preheater, condenser, sump, and accumulator. The void distribution in the test section is measured using a beta-ray attenuation technique. The experimental void fractions are correlated in terms of the significant heat-transfer parameters, such as mass flow rate, fluid temperature, heat flux, slip ratio, and quality.

During the past months, special experimental conditions have been investigated. A correlation of the Bankoff flow parameter, $\mathrm{K}$, in terms of the Reynolds number was developed, and tests were made which confirmed the behavior of the correlation at low Reynolds numbers $(45,000)$. Several runs taken at pressures around 900 psi to reexamine the variation in the slip ratio indicated that the slip ratio exhibits an oscillation of \pm 25 per cent with a-c power on the test section.

A $40-k w$ direct-current motor-generator was installed last month to investigate the influence of $a-c$ versus $d-c$ power on the test section. Tests were made which show that deflection of the beta beam by the direct current in the test section will not be a serious problem. The calibration procedures have been nearly completed so that preliminary test runs can be made next month.

Void-fraction measurements will be taken at pressures between 800 and 1200 psi using different mass flows to examine the behavior of the slip ratio in this pressure range. 
The feasibility of uranium mononitride as a fuel for power reactors is being determined. Fabrication studies are being conducted to provide dense UN bodies for both physical- and mechanical-property determinations as well as for irradiation studies. Sintering, hot pressing, hot swaging, and melting and casting are each being investigated as methods of fabricating UN. Initial capsule-design studies are under way.

\title{
Powder-Metallurgy Studies
}

\author{
S. J. Paprocki, D. L. Keller, E. O. Speidel,
} and J. Stocker

Microscopic examination of minus $80-$ mesh UN powder produced by the method outlined in BMI-1365 revealed that the powder is 97 to 99 volume per cent UN. Small quantities of both a higher nitride and a uranium phase were observed. The uranium phase was estimated to be about 0.1 volume per cent of the sample, while the higher nitride, which appears light blue under a bright light, was estimated to represent about 2 volume per cent of the observed sample and was present as homogeneous particles. The average grain diameter of the UN was about $6 \mu$ and ranged from 3 to $18 \mu$.

The highest density to date by vacuum sintering at a temperature low enough to impede decomposition has been obtained from a sample of minus 400-mesh powder produced by decomposing $\mathrm{UH}_{3}$ under an atmosphere of nitrogen. This powder nitrided and also reverted from the higher nitride to UN at somewhat lower temperatures than usually observed in the regular production process, indicating the possibility of a more active powder. A compact green pressed to 70 per cent of theoretical density was vacuum sintered at $1650 \mathrm{C}$ for $6 \mathrm{hr}$ to 79 per cent of theoretical density, and an additional $4 \mathrm{hr}$ at the same temperature increased the density to 80 per cent of theoretical.

A thermodynamic evaluation of alternate methods of producing UN powder is being conducted in the search for a more active and sinterable powder.

In initial attempts to densify UN powder by rotary swaging, cold-pressed compacts of minus 100-mesh UN powder coated with Carbowax 6000 were loaded into Type 304 stainless steel tubes having a 32-mil wall thickness. Evacuation stems and mild-steel end plugs were welded in place prior to degassing the compacts to remove the protective coating. Two of these packs were swaged, one cold and one at $800 \mathrm{C}$, through about 70 per cent reduction in area before failure occurred due to either splitting of the tube or UN powder working though the tubing. However, in most cases, failure of the weld and extrusion of the mold-steel end plugs out of the tubing occurred at about 40 per cent reduction in area for both the hot- and cold-swaged packs.

From observations on this initial series of swaged packs, it appears that: 
(1) For a given die size, there is slightly more reduction in area imparted to the compact by hot swaging.

(2) Initially, the tube reduces in area with a slight thickening of the wall and very little elongation. Further swaging results in thinning of the wall and elongation of the compact and tubing.

(3) There is no bonding of the mild steel end plugs to the stainless tubing, and UN powder is extruded between the plugs and tubing as well as into the evacuation stems.

(4) There is fracturing of the larger UN particles but little relative movement of the fragments, the fractured surfaces remaining essentially in contact.

(5) After some degree of reduction, cracks are imparted to the UN cores which appear somewhat circular when observed on a transverse section.

(6) There is only slight bonding of the UN particles during swaging, indicating the probable need of a subsequent heat treatment of the core to effect interparticle bonding.

(7) The amount of densification which can be achieved is apparently directly related to the yield strength of the tubing.

(8) Regardless of the previously mentioned difficulties of weld failure and leakage, some of the cores have been estimated metallographically to be about 85 per cent of theoretical density, with areas of these cores appearing even more dense.

A second series of packs has been made by preswaging one end of the tubes before insertion of end plugs to eliminate swaging of the welds. Plugs were inserted between the cores and evacuation stems to prevent extruding of the powder into the stems. This series contains cores of minus $100-$ mesh powder as well as cores of minus 60 plus 200mesh powder. Packs of these series have been cold swaged, hot swaged at $980 \mathrm{C}$, and cold swaged with intermittent anneals under more vigorously controlled conditions. Prior difficulties which caused failure were not encountered, and preliminary results are promising. Results of this series are being evaluated to relate amount of reduction as well as temperature and particle size to the densities obtained.

Varied mesh fractions of UN powder have been isostatically hot pressed at 5 tsi and $1260 \mathrm{C}$ after being cold compacted to about 72 per cent of theoretical density and sealed under vacuum in stainless steel capsules. Conservative density measurements of the cores after hot pressing gave values of 11.5 to $12.2 \mathrm{~g} \mathrm{per} \mathrm{cm}^{3}$ or 83 to 85 per cent of theoretical. The results, shown in Table I-1, indicate that high densities cannot be obtained at $1260 \mathrm{C}$ just by varying the particle size. Metallographic study of these specimens, to include quantitative measurements of pore volume for more accurate densities, is in progress.

Raising hot-pressing temperature $30 \mathrm{C}$ has sometimes caused capsule leaks arising from reaction with insulating material, which results in los of pressure. This 
problem has been overcome by a different insulating technique. A compact of minus 80mesh powder was pressed at $1290 \mathrm{C}$ to 87 to 91 per cent of theoretical density indicating that raising temperature $30 \mathrm{C}$ aids densification. Results are shown in Table I- 1 .

TABLE I-1. RESULTS OF ISOSTATICALLY HOT-PRESSING COLD-COMPACTED DEGASSED(a) URANIUM NITRIDE POWDER COMPACTS 3 HR AT 1260 C AND 5 TSI IN TYPE 304 STAINLESS STEEL CAPSULES

\begin{tabular}{|c|c|c|c|c|c|}
\hline \multicolumn{3}{|c|}{ Powder Characteristics } & \multirow{3}{*}{$\begin{array}{c}\text { Green } \\
\text { Density, } \mathrm{g} \text { per } \mathrm{cm}^{3}\end{array}$} & \multirow{2}{*}{\multicolumn{2}{|c|}{$\begin{array}{l}\text { Density of Hot-Pressed } \\
\text { Compact, g per } \mathrm{cm}^{3}\end{array}$}} \\
\hline \multirow{2}{*}{$\begin{array}{c}\text { Oxygen Content, } \\
\text { w/o }\end{array}$} & \multirow{2}{*}{$\begin{array}{c}\text { Nitrogen Content, } \\
\text { w/o }\end{array}$} & \multirow[b]{2}{*}{ Mesh Size } & & & \\
\hline & & & & X-Ray & Buoyancy \\
\hline 0.0290 & 5.47 & -80 & 10.5 & 12 & 12.1 \\
\hline 0.0290 & 5.47 & -80 & 10.3 & 11 & 12.2 \\
\hline 0.0290 & 5.47 & -100 & 10.5 & 12 & 11.5 \\
\hline 0.0290 & 5.47 & -100 & 10.7 & 12 & 11.8 \\
\hline 0.0290 & 5.47 & $-200+400$ & 10.5 & 12 & 12.2 \\
\hline 0.0290 & 5.47 & -400 & 10.1 & 11 & 11.6 \\
\hline 0.0290 & 5.47 & -400 & 10.1 & 12 & 12.1 \\
\hline 0.0290 & 5.47 & $-80(b)$ & $10.1(b)$ & $13(b)$ & $12.5(\mathrm{~b})$ \\
\hline
\end{tabular}

(a) Carbowax 6000 used as binder.

(b) Hot pressed at $1290 \mathrm{C}$.

Molybdenum and Armco iron capsules are being prepared to hot press UN at higher temperatures, since these materials should be capable of higher temperatures than stainless steel, and they appear to be compatible with UN. Higher temperatures may yield core densities of 95 to 99 per cent of theoretical.

\section{Melting and Casting Studies}

R. W. Endebrock, E. L. Foster, and R. F. Dickerson

This portion of the program deals with the preparation of stoichiometric UN by melting and casting techniques.

Predictions of the equilibrium nitrogen pressures required to produce UN which were based upon extrapolations of existing thermodynamic data indicate that stoichiometry can be achieved at pressures of less than 3 atm (absolute). However, such calculations point to considerable sensitivity of the UN system to minor changes in temperature and nitrogen pressure. To a degree, recent experimentation in arc melting uranium in a nitrogen atmosphere has shown that stoichiometric UN can be produced in the $1 / 2$ to 3-atm pressure range provided that (1) the temperature of the melt is near the melting point, (2) the melt is heated uniformly, (3) the melt has been maintained at temperature long enough to complete the reaction, and (4) high-purity reactants have been used. Obviously, the reaction rate increases as the temperature of the melt increases above the melting point.

In an effort to better meet the above pressure, temperature, and material requirements, a two-stage procedure to prepare UN was attempted. A narrow bar of substoichiometric UN first was prepared by arc melting center-cut biscuit uranium under a $1 / 2 \mathrm{~atm}$ of purified nitrogen. The end of the bar was sectioned and, by metallographic inspection, found to contain roughly $3.5 \mathrm{w} / \mathrm{o}$ nitrogen and a well-developed structure of 
UN. The bar was then mounted upright by wedging one end into a hole drilled into a small supporting disk of tantalum (m.p. $\pm 2990 . \mathrm{C}$ ). This assembly was centered in a graphite susceptor (so that the UN could not touch the graphite) and placed in an induction furnace. The susceptor and its contentis were then heated under a nitrogen pressure of about $0.9 \mathrm{~atm}$ for $1 / 2 \mathrm{hr}$. The temperature of the unsupported portion of the bar was approximately $1760 \mathrm{C}$; that of the portion wedged in the tantalum support was about $2335 \mathrm{C}$. Throughout the soaking period no sagging of the bar was observed. After this treatment the bar was again inspected metallographically, and its structure was found to have remained unchanged with the exception of a very thin (less than 10 mils) surface casing of pure UN. These results indicate that at the soaking temperature the reaction rate, which is dependent upon a diffusion mechanism, is too low to be useful.

A second experiment was devised in which material prepared by arc melting uranium under $3 \mathrm{~atm}$ of nitrogen and containing $5.15 \mathrm{w} / 0$ nitrogen was soaked for $1 / 2$ $\mathrm{hr}$ by heating in a low-current arc under $1 / 2$ atm of nitrogen. The arc was maintained at the center of the button throughout the soaking period, and a central area of only about $1 / 4 \mathrm{in}$. in diameter appeared to be molten. During the soaking period, optical temperature readings were obtained which showed the edge of the button to be between 1870 and $1980 \mathrm{C}$ and the center of the button to be between 2425 and $2540 \mathrm{C}$.

A metallographic examination of the button revealed a portion located roughly midway between the center and the edge to be nearly pure UN, while the central and edge portions were substoichiometric. The Knoop hardness number of clear, massive grains of UN averaged 563. A sample of the button that was analyzed for nitrogen content varied from 3.5 to 4.25 w/o, reflecting the inhomogeneity of the material.

The results of this test emphasized the need for uniform heating and indicated that only at or near the melting point of UN can stoichiometry be attained for nitrogen pressures of about $1 \mathrm{~atm}$.

A final low-pressure ( $1 \mathrm{~atm}$ ) experiment is planned before experimentation begins in the 5 to 30-atm pressure range of nitrogen. A heavy-walled tantalum cup, pretreated in a nitrogen atmosphere at high temperature, is to be used as a susceptor and charge container in an induction furnace. After a nitride case has been formed on its surfaces, the tantalum cup is to be loaded with substoichiometric UN. In an attempt to heat the UN uniformly and at a higher temperature than in the other induction-furnace experiment, this assembly is to be insulated to reduce heat losses during heating.

Irradiation of UN Specimens

G. E. Raines and J. H. Stang

Plans are being formulated for the encapsulation and irradiation of UN specimens containing depleted (approximately $0.4 \mathrm{w} / \mathrm{o}$ ) and natural (approximately $0.7 \mathrm{w} / \mathrm{o}$ ) uranium and uranium enriched 5 per cent. The irradiations will be conducted for a period of approximately 6 months at effective fluxes in the neighborhood of $1 \times 10^{14} \mathrm{nv}$. This exposure will provide specimens having burnups of the total uranium atoms originally present which vary over a fairly wide range: however, the amount of hydrogen produced as a result of the $(n, p)$ reaction with nitrogen will be fairly constant. These specimen 
$I-\underline{6}$

conditions are of interest since one part of the assessment of irradiation damage to the materials will be directed toward obtaining a semiquantitative evaluation of effects stemming from the accumulation of hydrogen in the UN matrices.

It is desirable in these irradiations to minimize the specimen-surface temperatures in-pile to retain, insofar as possible, the hydrogen within the specimen matrices. Consequently, attention in capsule design has been focused on the use of single-wall capsules in which the specimens are immersed in a sodium heat-transfer bath. Aluminum will be the material of consitruction for the capsule bodies. Preliminary heattransfer calculations indicate that, in the maximum fission-heat-generation case, the surface temperature of specimens $0.3 \mathrm{in}$. in diameter will be approximately $500 \mathrm{~F}$.

According to present plans, a total of six capsules, each containing two UN specimens, will be irradiated. Negotiations for irradiation space at the Materials Testing Reactor or the Engineering Test Reactor have been initiated with a view toward starting the irradiations about April 1, 1961. 
BMI-1489, Section J

MATERIALS DEVELOPMENT AND EVALUATION (HAPO)

F. R. Sliober

The thermal conductivity of irradiated and unirradiated $\mathrm{UO}_{2}$ is being studied. Measurements have been made on a disk specimen over the range from room temperature to $1400 \mathrm{C}$. An investigation to study the creep properties of Zircaloy-2 at elevated temperatures is continuing with 20 specimens in test.

A corrosion study directed toward finding a suitable metallic material to be used as a container for the fused chloride-electrolytic fuel-recovery process continued with the preparation of 15 new alloys.

Thermal Conductivity and Electrical Conductivity of $\mathrm{UO}_{2}$

C. F. Lucks and H. W. Deem

The objective of this program is to measure the thermal and electrical conductivity of irradiated and unirradiated $\mathrm{UO}_{2}$. An apparatus based on a steady-state, absolute, thermal-conductivity method has been asserrbled for the thermal-conductivity measurements of the irradiated $\mathrm{UO}_{2}$. Existing Battelle equipment is being used for the thermaland electrical-conductivity measurements or unirradiated specimens.

The assembly and calibration of a thermal-conductivity apparatus were discussed and measurements of four control $\mathrm{UO}_{2}$ specimens were reported in BMI-1448 (Rev). Included in the report were data on an irradiated $\mathrm{UO}_{2}$ specimen with a burnup of 0.005 a/o. Tentative thermal-conductivity data we re reported for an irradiated $\mathrm{UO}_{2}$ specimen having a burnup of 0.016 a/o in $\mathrm{BMI}-1455$ and for a sintered $\mathrm{UO}_{2}$ disk specimen in BMI- 1480 .

Data reported in BMI- 1480 have been checked by repeating the measurements because of failure of a brazed joint in the guard cylinders of the the rmal-conductivity apparatus. The apparatus has been repairecl. There is no significant difference between the measurements before and after the repairs.

These measurements complete the work on the first disk specimen, identified as Fabrication Specimen A.

Specimen A was fabricated at HAPO by cold pressing micronized PWR-grade $\mathrm{UO}_{2}$, mixed with Carborwax binder, in a 300-ton press, and subsequently sintering in hydrogen at $1600 \mathrm{C}$. Battelle's measured density for this specimen is 95.3 per cent of theoretical.

Faint hairline cracks showed in the disk specimen as received and visual examination indicated that the cracks widened and propagated with thermal cycling. Table J-1 of BMI- 1480 gave the tentative interpolated thermal conductivity of the specimen as received. The experimental points, after the high-temperature cycle, fell about 10 per cent below the best curve. 
TABLE J 1. INTERPOLATED(a) THERMAL CONDUCTIVITY OF UO ${ }_{2}^{(b)}$

\begin{tabular}{ccc}
\hline & \multicolumn{2}{c}{$\begin{array}{c}\text { Thermal Conductivity of Specimen as } \\
\text { Received, } w /(\mathrm{cm})(\mathrm{C})\end{array}$} \\
\cline { 2 - 3 } Temperature, $C$ & $\rho=95.3(\mathrm{c})$ & $\rho=100(\mathrm{~d})$ \\
200 & 0.064 & 0.067 \\
400 & 0.049 & 0.051 \\
600 & 0.039 & 0.041 \\
800 & 0.032 & 0.034 \\
1000 & 0.029 & 0.030 \\
1200 & 0.026 & 0.027 \\
1400 & 0.024 & $0.025(\mathrm{e})$ \\
\hline
\end{tabular}

(a) Values read from a smooth curve drawn through experimental points.

(b) Sintered $\mathrm{UO}_{2}$. The specimen is 95.3 per cent of theoretical density.

(c) $\rho=$ density, per cent of theoretical.

(d) Values adjusted linearly with density to 100 per cent of theoretical density.

(e) Extrapolated using data from the second determination.

The measurements made after the repair of the apparatus agree with these lower values. Measurements were extended to $1400 \mathrm{C}$. The second set of data gives a curve parallel to the data for the specimen as received but 11.7 per cent lower.

Table J-1 gives the final interpolated thermal-conductivity values for the $\mathrm{UO}_{2}$ specimen as received and supersedes the data in BMI-1480.

Techniques have been worked out for making thermal-conductivity measurements on vibrationally compacted $\mathrm{UO}_{2}$ specimens.

During the next work period, measurements on the vibrationally compacted specimens will begin as soon as they are received. Apparatus repair will be completed at the hot cell and measurements will be started on 536-MWD/T specimens supplied by HAPO.

\section{Mechanical Properties of Zirconium Alloys}

\section{J. A. VanEcho}

This research program has as its objective the determination of the long-time creep properties of Zircaloy-2 sheet material at 290 to $400 \mathrm{C}$. All tests are made in vacuum of the order of $1 / 2 \mu$ or better in standard creep-testing equipment. Temperatures are controlled to within $\pm 1-1 / 2 \mathrm{~F}$, and optical strain measurements are obtained with a sensitivity of $50 \mu$ in.

The program consists of four distinct phases which are being carried out simultaneously. Tests being conducted under each phase of the work have been in progress for times ranging from 2,000 to $26,500 \mathrm{hr}$. Work accomplished during the past month 
consisted of continuing the 20 creep tests for an additional 31 days. A summary of test results obtained to date under each of the four phases of the program is shown in Table J-2.

\section{Materials of Construction for the Fused Chloride-

Electrolytic $\mathrm{UO}_{2}$ Process

E. L. White, P. D. Mi.tler, C. L. Peterson,

W. K. Boyd, C. H. Lund, and D. C. Drennen

The object of this research program is to develop a metallic container material for the HAPO fused chloride-electrolytic fuel-recovery process.

A number of metals and alloys have been studied in the laboratory experiments, which simulate the conditions of the recovery process using chlorine as the chlorinating agent.

The report last month (BMI-1480) summarized the results of the initial program, except for the nicke1-32 w/o aluminum alloy. It showed an average penetration rate of 55 mils per month.

To further investigate the effect of aluminum, copper, molybdenum, and silicon in the more promising alloy systems, a group of about 15 alloys will be melted and evaluated. 
TABLE J -2. CURRENT STATUS OF CREEP TESTS ON ZIRCALOY -2 SHEET

\begin{tabular}{|c|c|c|c|c|c|c|}
\hline \multirow[b]{2}{*}{ Specimen } & \multirow{2}{*}{$\begin{array}{c}\text { Temperature, } \\
\text { C }\end{array}$} & \multirow{2}{*}{$\begin{array}{c}\text { Stress, } \\
\text { psi }\end{array}$} & \multirow{2}{*}{$\begin{array}{c}\text { Time in } \\
\text { Progress(a), } \\
\text { hr }\end{array}$} & \multicolumn{2}{|c|}{ Deformation, per cent } & \multirow{2}{*}{$\begin{array}{c}\text { Tentative } \\
\text { Minimum } \\
\text { Creep Rate, } \\
\text { per cent per hr }\end{array}$} \\
\hline & & & & On Loading & At Present & \\
\hline \multicolumn{7}{|c|}{15 Per Cent Cold-Worked Material } \\
\hline $7-2-1$ & 345 & 25,000 & 26,500 & 0.230 & 1.518 & 0.00003 \\
\hline $7-4-3$ & 400 & 12,500 & 24,000 & 0.134 & 1.998 & 0.00006 \\
\hline \multicolumn{7}{|c|}{ Annealed Material } \\
\hline $\mathrm{Zr}-\mathrm{A}-10$ & 290 & 22,500 & 14,500 & 3.180 & 4.337 & 0.000005 \\
\hline-13 & 290 & 20,000 & 12,000 & 1.511 & 2.845 & 0.000003 \\
\hline-14 & 290 & 17,500 & 11,500 & 1.250 & 1.959 & 0.000002 \\
\hline-18 & 290 & 15,000 & 11,500 & 0.635 & 0.958 & $<0.000001$ \\
\hline-27 & 290 & 12,500 & 8,000 & 0.216 & 0.404 & $<0,000001$ \\
\hline$Z \tau-A-15$ & 345 & 20,000 & 11,500 & 2.240 & 9.80 & 0.00010 \\
\hline-17 & 345 & 17,500 & 11,500 & 1.778 & 2.495 & 0.000065 \\
\hline-25 & 345 & 15,000 & 10,000 & 0.971 & 1.250 & 0.000030 \\
\hline-28 & 345 & 12,500 & 7,500 & 0.321 & 0.457 & 0.000007 \\
\hline $\mathrm{Zr}-\mathrm{A}-16$ & 400 & 12,500 & 11,500 & 0.447 & 4.815 & 0.00035 \\
\hline-21 & 400 & 10,000 & 11.000 & 0.113 & 1.670 & 0.00010 \\
\hline-26 & 400 & 9,000 & 8,500 & 0.082 & 0.550 & 0.000035 \\
\hline \multicolumn{7}{|c|}{15 Per Cent Cold-Worked Material, Temperature Cycled } \\
\hline $\mathrm{Zr}-\mathrm{A}-33$ & 290 & 14,000 & 4,200 & 0.316 & 0.863 & 0.00002 \\
\hline \multicolumn{7}{|c|}{ Annealed Material, Temperature and Stress Cycled } \\
\hline $\mathrm{Zr}-\mathrm{A}-36$ & 290 & 15,000 & 2,000 & 0.765 & 1.120 & 0.000005 \\
\hline-31 & 290 & 12,500 & 5,500 & 0.170 & 0.500 & 0.000005 \\
\hline $\mathrm{Zr}-\mathrm{A}-34$ & 345 & 15,000 & 3,000 & 0.949 & 1. 135 & 0.000035 \\
\hline-32 & 345 & 12,500 & 5,500 & 0.265 & 0.550 & 0.000025 \\
\hline-35 & 345 & 9,000 & 2,500 & 0.063 & 0.100 & 0.000010 \\
\hline
\end{tabular}

(a) Less than actual test time but within $500 \mathrm{hr}$. 
COATED-PARTICLE FUEL، MATERIALS (AEC-DRD)

R. W. Dayton and J. H. Oxley

This program on coated-particle fuels is being carried out to provide performance data on various coated-particle fuel systems of general interest and to develop optimum materials for specific reactor applications. Various combinations of fissionable-core, protective-coating, and matrix-support materials are to be evaluated, primarily in terms of fission-product retention as a function of burnup and operating temperature. The immediate objective is to evaluate fully a fuel material containing approximately $125-\mu$ uranium dioxide particles coated with $40 \mu$ of alumina. Preliminary experimental studies during Fiscal Year 1961 are also being carried out on carbon- and berylliacoated fissile materials.

During December, considerable attention was given to further refinements in the coating processes, and the most significant sesult has been the improvement in the quality of the beryllia coatings. Ceramic-matrix studies and capsule design and construction are proceeding on schedule. Good results have been obtained with at least three techniques for separating unirradiated alumina-coated uranium dioxide particles from a graphite matrix. Procedures to evaluate irradiated specimens have been selected. Information on coolant-contamination limitations and compatibility of alumina and urania with pyrolytic carbon is being obtained. Studies of corrosion by gaseous coolants, radiation damage of ceramics, and thermal conductivity of ceramic dispersion elements were initiated this month.

\section{Evaluation of Comrnercial Products}

T. S. Elleman and D. N. Sunderman

Expressions of interest in the evaluation of commercially produced coated particles were received from 11 manufacturers during December. Information was given to these companies on the nature and extent of the preliminary phase of the evaluation program. 
M. F. Browning, H. Carlton, A. C. Secrest, V. S. Secrest, R. B. Landrigan, and J. M. Blocher, Jr.

$\mathrm{Al}_{2} \mathrm{O}_{3}$ Coating of Fuel Particles

Investigation of the coating $\mathrm{UO}_{2}$ with $\mathrm{Al}_{2} \mathrm{O}_{3}$ by hydrolysis of $\mathrm{Al}_{2} \mathrm{Cl}_{6}$ vapor in a fluidized bed of the powder has been continued. The initial objective of this work is to develop reproducible coating methods and to optimize process variables. It is intended that this program will permit the preparation of suitable specimens for an in-pile evaluation scheduled for February, 1961.

The evaluation of the reactor design discussed in the last monthly report (BMI-1480) was continued. Both designs continued to show promise, especially when used in conjunction with a fluidizing gas preheater and a center-tube bayonet heater. Two runs were made in which approximately $40-\mu \mathrm{Al}_{2} \mathrm{O}_{3}$ coatings were deposited without interruption at $1000 \mathrm{C}$. The coatings produced in the se runs were dense and free of voids. The coating thickness of one of the products was quite uniform from particle to particle, while the other product was less uniform in coating thickness because of the tendency for the bed particles to stick to the walls during processing. This problem is tentatively attributed to the use of lower gas-flow rates in the second run. Further investigation of process variables should minimize this difficulty.

Equipment has been constructed and procedures are being developed to evaluate the compressive strength of single coated particles. Other evaluations include determining the effect of thermal cycling between $400 \mathrm{C}$ and $1350 \mathrm{C}$ in helium and determining the oxidation resistance of coatings at $1100 \mathrm{C}$ in oxygen.

Future studies will continue to be concerned with the development of the coating process and coating-evaluation procedures so that suitable specimens can be prepared for an in-pile evaluation.

\section{BeO Coating of Fuel Particles}

Investigation of the conditions for depositing $\mathrm{BeO}$ on fuel particles by the hydrolysis of $\mathrm{BeCl}_{2}(\mathrm{~g})$ in a fluidized bed has been continued.

Uniform, void-free, dense-appearing BeO coatings were deposited on minus 100 plus $140-$ mesh $\mathrm{UO}_{2}$ particles in two runs. Coating thicknesses of 5 and $13 \mu$ were obtained. In both cases, the uniformity of coating thickness between particles was good. This was a considerable improvement over earlier experiments with the BeO-coating process. No major problems were encountered in the coating operation. However, there was a tendency for $\mathrm{BeO}$ to collect on the walls of the reactor above the fluidized bed. In the longer runs required to deposit greater thicknesses, this situation may lead to plugging difficulties. However, if this problem develops, it can probably be minimized by 
altering the reactor design in the direction of that adopted for the $\mathrm{Al}_{2} \mathrm{O}_{3}$ coatings. This modification has been deferred because of the added complexity.

Future studies will include the preparation of a product having approximately a $20-\mu$ coating and then the thorough evaluation of this coating along with the $5-$ and $13-\mu$ coatings on hand. The immediate goal is to develop the conditions for depositing a BeO coating suitable for in-pile evaluation in March.

\section{Pyrolytic Carbon Coating of Fuel Particles}

Investigation of the coating of fuel particles with pyrolytic carbon by the decomposition of a hydrocarbon in a fluidized bed of the particles was continued. The primary purpose of the program is to develop conditions for depositing a dense carbon coating for in-pile evaluation in March of 1961.

Most of the experimental studies performed on carbon coatings this month were carried out at coating temperatures greater than $1500 \mathrm{C}$. All previous carbon work was done at less than $1500 \mathrm{C}$ in a Glo-Bar heated Mullite reactor. Consideration of the design of a fluidized-bed reactor to operate at $2000 \mathrm{C}$ revealed problems which appeared to require more development time for their solution than was immediately available. These related to the necessity of injecting the hydrcicarbon vapor at a temperature of less than about $1200 \mathrm{C}$ to prevent its premature decomposition, and to contact it with particles at $2000 \mathrm{C}$ without having the particles undergo thermal cycling in contacting areas of intermediate temperature. The most straightforward initial approach appeared to be the use of a barrel-plating technique with a water-cooled vapor injector.

The current barrel-plating unit is an induction-heated rotating graphite-tube furnace. Sixteen-mesh graphite chips and $120-$ mesh $\mathrm{UC}_{2}$ particles previously coated with pyrolytic carbon at $1200 \mathrm{C}$ in the fluidized-bed unit have been coated with pyrolytic carbon at $2000 \mathrm{C}$ and $1800 \mathrm{C}$, respectively. Methane decomposition was used in both runs. The $2000 \mathrm{C}$ coating was 20 to $30 \mu$ thick, fairly uniform, and free of voids. The coating prepared at $1800 \mathrm{C}$ had a thickness of approximately $10 \mu$ and appeared to be free of voids. However, several uncoated particles were detected.

Experimental work on the development of equipment and conditions for depositing carbon coatings at temperatures greater than $1600 \mathrm{C}$ will be continued in an effort to prepare suitable specimens for an in-pile evaluation. Concurrently, the conditions and equipment for preparing carbon coatings at temperatures up to $1500 \mathrm{C}$ will be determined so that specimens of these materials may also be submitted for an in-pile evaluation.

Ceramic-Matrix Studies

M. C. Brockway, A. K. Smalley, D. J. Bowers, and W. H. Duckworth

Graphite-Matrix Fuel Elements

The objective of this phase of the program is to prepare and characterize graphitematrix bodies containing coated fuel particles. 
To meet the program schedule for initial irradiation tests, an alternate raw material for the filler in the graphite bodies has been chosen. Unfueled specimens are being made using AGOT graphite flour as filler. Highly graphitized needle coke flour was selected originally but cannot be obtained in time to meet the schedule. The change in properties resulting from this filler substitution is not expected to be of critical importance in the initial irradiation studies. Coal-tar pitch is being used for the binder in the se specimens.

Laboratory studies during the month involved selection of processing conditions for the preparation of specimens to be irradiated. Using unfueled bodies, two series of specimens were prepared; one was hot mixed and the other "solvent" mixed. The binder-filler ratio was varied in each series. The molding conditions were essentially constant, and selected on the basis of past experience. Both series are now being baked. Evaluation will be based on density and strength, and baking shrinkage will be measured.

Using information gained in the above work, the next step in the investigation will be to establish methods and techniques for obtaining a uniform and reproducible dispersion of coated fuel particles in the matrix.

\section{Oxide-Matrix Fuel Elements}

The aim of this study is to explore the feasibility of a fuel element comprising oxide-coated $\mathrm{UO}_{2}$ particles dispersed in an oxide matrix that is resistant to hightemperature oxidation.

$\mathrm{BeO}$ is of principal interest as the matrix and the fuel coating because of its moderating properties. However, early work is being based on $\mathrm{Al}_{2} \mathrm{O}_{3}$, pending a supply of sound $\mathrm{BeO}$-coated $\mathrm{UO}_{2}$ particles. These studies, using $\mathrm{Al}_{2} \mathrm{O}_{3}$, are being performed to evaluate the problems of dispersing unsinterable particles in a sinterable matrix.

An initial study this month demonstrated the difficulty of densifying a matrix of finely divided sinterable oxide powder containing coarse, dense particles. In this work, fused $\mathrm{Al}_{2} \mathrm{O}_{3}$ grains were used to simulate coated fuel particles. These grains were minus 80 plus 100 mesh ( 149 to $177 \mu$ ). Various fractions were mixed with a special grade of sinterable $\mathrm{Al}_{2} \mathrm{O}_{3}$ powder. The mixtures were treated with $3 \mathrm{w} / \mathrm{o}$ of beeswax and pressed into pellets at 40,000 psi in a steel die. The compacts then were sintered for $1 \mathrm{hr}$ at $3000 \mathrm{~F}$ in flowing hydrogen. Bulk-density and shrinkage measurements were. made on the sintered pellets, and are shown in Table L-1.

TABLE L-1. EFFECTS OF FUSED-GRAIN ADDITIONS ON SINTERED $\mathrm{Al}_{2} \mathrm{O}_{3}$ COMPACTS

\begin{tabular}{ccc}
\hline $\begin{array}{c}\text { Content of Fused } \mathrm{Al}_{2} \mathrm{O}_{3}, \\
\text { volume per cent }\end{array}$ & $\begin{array}{c}\text { Sintered Bulk Density }(\mathrm{a}), \\
\text { per cent of theoretical }\end{array}$ & $\begin{array}{c}\text { Sintering Shrinkage }(\mathrm{b}), \\
\text { per cent }\end{array}$ \\
\hline None & 99.0 & 18.7 \\
25 & 82.0 & 11.1 \\
50 & 71.9 & 3.3 \\
75 & 74.6 & 1.1 \\
\hline
\end{tabular}

(a) By xylene absorption and displacement; theoretical density of $\mathrm{Al}_{2} \mathrm{O}_{3}$ taken as $3.99 \mathrm{~g}$ per $\mathrm{cm}^{3}$.

(b) Average of length and diametral shrinkage. 
The data in Table L-l show that use of nonshrinking particles in a sinterable matrix seriously interferes with densification of the composite body. The density decrease was approximately linear with increasing inert additions, up to 50 volume per cent of fused grain.

A means of simulating shrinkage in the fuel particles seems essential. This might be done by coating the particles with a volatile organic material prior to incorporating them into the sinterable matrix. During the early stages of sintering, the organic layer would volatilize, leaving voids around the particles into which the matrix could shrink without restraint.

Means of coating individual particles with a layer of hard wax are now being explored. A coating thickness of 18 to 20 per cent of the particle radius will be sought. When suitable organic-coated particles have been prepared, they will then be incorporated into a sinterable matrix and sintered, as described before. Particular attention will be given to the microstructures of the sintered bodies, and attempts will be made to minimize internal cracks and voids in the matrix. Since a supply of BeO-coated fuel is now available as a result of the progress in the particle-coating studies, emphasis will be shifted to an investigation of the use of a EieO matrix for the $\mathrm{BeO}$-coated $\mathrm{UO}_{2}$ particles.

\title{
Fuel-Irradiation Studies
}

\author{
W. J. Zielenbach, N. E. Miller, G. E. Raines,
} and W. H. Goldthwaite

The objective of this program is to evaluate coated-fuel-particle materials in irradiation-capsule experiments where temperature and burnup levels will reach those anticipated in power-producing reactors. Both static and sweep-gas experiments are planned for core-position exposures at the Battelle Research Reactor. In the static system, several canned fuel specimens will be irradiated simultaneously in a single capsule, and radiation damage will be assessed as a function of temperature and burnup in postirradiation hot-cell examinations. In addition, qualitative fission-gas-release data will be obtained by sampling the gas within each specimen can. In the sweep-gas experiments, a single specimen will be encapsulated and, as the irradiation progresses, a stream of purified helium will be swept past it to carry the released fission gases to out-of-pile adsorption traps. Quantitative fission-gas-release data will be obtained from radioas says of the adsorption traps.

In the first series of static experimentis, specimens containing $\mathrm{Al}_{2} \mathrm{O}_{3}-$ coated $\mathrm{UO}_{2}$ (highly enriched) particles will be irradiated at two nominal temperatures levels, approximately $300 \mathrm{~F}$ and approximately $1800 \mathrm{~F}$, to burnups ranging from 20,000 to 50,000 MWD/Tonne. The lower temperature experiment will provide specimens in which annealing is minimized and, consequertly, irradiation damage may be maximized. This condition has been paired with the elevated-temperature condition for initial experiments to provide a range of data for appraisal of modes of coating failure and relative merit of the following coated-particle designs that will be exposed: (1) dense $\mathrm{UO}_{2}$ and dense $\mathrm{Al}_{2} \mathrm{O}_{3},(2)$ porous $\mathrm{UO}_{2}$ and dense $\mathrm{Al}_{2} \mathrm{O}_{3}$, and (3) porous $\mathrm{UO}_{2}$ and dense $\mathrm{Al}_{2} \mathrm{O}_{3}$ with a $10-\mu$ porous layer adjacent to the $\mathrm{UO}_{2}$ surface. 
Four static capsules are involved in the se initial experiments. Their design is nearly complete. The lower temperature systems will be quite simple in that no instrumentation will be used; NaK will surround the specimen and serve as the heat-dissipation medium. The higher temperature capsules will be provided with both thermocouples and auxiliary electrical heaters. In these systems, heat transfer will be primarily by conduction through argon which will fill the capsule chamber.

The irradiation of these systems will start in February. Soon thereafter, the irradiation of two sweep capsules ( 1800 to $2000 \mathrm{~F}$ specimen temperature) is scheduled to start. One system is to contain $\mathrm{BeO}$-coated $\mathrm{UO}_{2}$ particles while the other will contain carbon-coated UC or $\mathrm{UC}_{2}$ particles. The design of these sweep systems is nearly complete, and their construction will nearly parallel that of the static systems described above.

In addition to irradiation-experiment planning and design, evaluation of data from the SP-5 sweep capsule continued during December. This experiment was operated in conjunction with Battelle's fission-gas-release studies for the Pebble-Bed Reactor under the auspices of Sanderson \& Porter. The appraisal of the activity release data for the coated-particle specimen (FA-22, No. 470) in this experiment is continuing on the basis described in BMI-1480. This assessment of data should be completed during January. The radiochemical analysis of the final daughter-trap sample from the specimen with the failed external SiC coating has been completed, and the data are being evaluated.

\section{Postirradiation Studies}

R. J. Burian, M. S. Farkas, J. E. Gates, and R. F. Dickerson

Preparation of equipment for the postirradiation examination of two fueledgraphite spheres irradiated in Capsule SP-5 is in progress. These two spheres, nominally $1.5 \mathrm{in.}$ in diameter, are each fueled to about $8 \mathrm{w} / 0$ with fully enriched $125-\mu-$ diameter $\mathrm{UO}_{2}$ particles coated with about $40 \mu$ of $\mathrm{Al}_{2} \mathrm{O}_{3}$. These spheres were irradiated to an estimated burnup of $6 \mathrm{a} / 0$ of the uranium-235 at surface temperatures of about 950 to $1200 \mathrm{~F}$.

The postirradiation examination will include visual inspection augmented by photography, dry-weight and diameter measurements, compression testing ( 1 sphere only), metallographic examination, and X-ray diffraction studies. Metallographic examination of the particles will be performed in situ and after their separation from the graphite.

Both gaseous oxidation and mechanical techniques have been investigated as a means for removing the particles from the graphite. In tests of unirradiated fueledgraphite specimens the graphite has been successfully separated from the particles by controlled oxidation with pure oxygen in helium at about $1025 \mathrm{~F}$. The particles recovered in this manner appear clean and undamaged. The mechanical method investigated involved rotating the graphite specimen in a thick slurry of sand and water. Although this method also shows great promise, it has been conditionally discarded because it requires a second step of sieving to separate the sand and graphite from the fuel particles. 
Metallographic techniques for the in situ examination of the fuel particles are being developed. Studies have also been made of methods for sectioning the graphite balls and indicate that abrasive sawing offers the most promise.

Metallographic preparation of unirradiated graphite-containing particle samples can be performed by using normal grinding procedures with a solid stick wax lubricant. Rough polishing is accomplished by use of Blue Diamond abrasive on a silk-covered wheel, with a kerosene lubricant. The final polish is performed with Linde $B$ abrasive on a silk-velvet-covered wheel using water. Inasmuch as metallographic preparation of irradiated specimens must be performed on specialized remote equipment, techniques were modified to include use of vibratory polishers.

Presently, it appears that satisfactory preparation of irradiated specimens can be accomplished. Normal grinding, using stick wax, followed by polishing on a vibrator covered with Microcloth which in turn is covered with silk using a diamond abrasive with a kerosene lubricant is satisfactory. The firal polish is accomplished on a silk-velvetcovered vibrator using Linde $B$ with water.

\section{Physics and Engineering Guidance}

R. G. Wooton, H. M. Epstein, and J. W. Chastain

The objective of this work is to determine the importance of effects of coated particles on the physics and engineering characteristics of reactors which may utilize coated particles as fuel material. Work is currently being conducted in two areas: (1) coolant-contamination limitations and (2) the effects of fuel-particle coatings on the characteristics of present reactor designs.

\section{Coolant-Contamination Limitations}

The coolant-contamination study was initiated to examine and summarize the available information on the amount of fission-product release which can be tolerated without interfering with normal maintenance of the system. A literature survey has been completed, and a few preliminary conclusions are stated here.

For direct maintenance of reactor systems which have few facilities for fissionproduct removal, the approximate magnitude of the permissible release fraction for gross fission-product activity is about $10^{-6}$. Permissible release fractions for individual fission products have not been established. However, reactor designers have identified the significant isotopes and classified them according to their importance in terms of shielding requirements, maintenance, and health hazards. An experiment designed to monitor the most important isotope(s) in each of the se three categories would yield valuable information on fission-product release from coated particles. 
$\underline{\text { Reactor Physics }}$

In helping to guide the material investigations in this project, it is important to know the effects of such materials variables as coating thickness, coating material, and volume fraction of coating particles on reactor performance. Obviously, any attempt to determine the effect of such variables in a comprehensive manner is far beyond the scope of this project. However, it is possible to perform elementary analyses on reactors now designed, using perturbation techniques, with little effort. Such analyses will suffice to provide the kind of guidance required. This is the type of study planned for this project.

Plans for the immediate future include a study of the effects of $\mathrm{Al}_{2} \mathrm{O}_{3}$ fuel-particle coatings on the physics of a "typical" gas-cooled graphite-moderated reactor. A pebblebed type reactor has been selected for study, and contacts have been made to obtain the available nuclear cross sections. The fuel loading will be the principal parameter studied.

As this phase of the program progresses, the work will be extended to cover other reactor designs and parameters. Parameters that will be investigated are coating material $\left(\mathrm{Al}_{2} \mathrm{O}_{3}\right.$ and $\left.\mathrm{BeO}\right)$, coating thickness, particle size, fuel enrichment, fuel and moderator loading, and core size.

Fission-Gas-Release Studies

T. S. Elleman and D. N. Sunderman

Fission-Gas Analytical Techniques

The purpose of this study is to develop improved gamma-ray spectrometer techniques for the analysis of fission-gas mixtures. The program will involve the determination of spectrometer detection efficiencies for representative fission gases, the measurement of fission-gas breakthrough on charcoal collection traps, and the investigation of techniques for the analysis of gamma-ray-emitting fission-gas mixtures for individual radioisotopes.

As indicated in the previous report (BMI-1480), the initial experiment was to involve the standardization of xenon-133 and xenon-133m in the gamma-ray spectrometer. Delays in obtaining the iodine-133 precursor have delayed this experiment, and it has, therefore, been necessary to carry out the fission-gas-breakthrough experiments at this time.

The rate of elution of xenon-133 from charcoal traps containing several grams of charcoal was measured at liquid-nitrogen temperatures. Counting rates observed in the elution trap and the backup trap showed that the time required for xenon breakthrough was at least a factor of four longer than had been previously suspected. Longer trapping times will result in increased sensitivity for the detection of low-level fission-gas mixtures.

Arrangements have been made to obtain iodine-133, and the originally scheduled xenon-133 and xenon-133m standardizations will be carried out during the coming month. 
Fission-Gas-Diffusion Studies

Fission-gas release from coated fuel particles and from fission-productimpregnated alumina will be studied. The initial experiment in this program will be the measurement of fission-gas release from solid alumina spheres containing recoiled fission fragments in the particle surfaces. Measurements will be made on pure alpha alumina spheres and on spheres coated with alumina by the fluidized-bed deposition technique. Irradiation conditions and suitable experimental techniques have been developed, and the experiment will be initiated upon completion of the particle-coating operation. Results will be discussed in future progress reports.

Matrix-Separation Techniques

Techniques for the separation of coated particles from a graphite matrix are being developed for use in hot-cell postirradiation studies and burnup analyses. Two promising techniques for coated-particle separation which are being investigated experimentally are disintegration with fuming nitric acid and electrolytic disintegration. Each method involves only simple physical manipulations and neither requires elaborate equipment. Although either technique would be suitable for in-cell use on irradiated specimens, electrolytic disintegration is preferred as being more rapid and easier to handle.

Botl techniques have been tested on sections of Sphere 437 ( $\mathrm{UO}_{2}$ particles coated with approximately $20 \mu$ of $\left.\mathrm{Al}_{2} \mathrm{O}_{3}\right)$. Extremely clean separated coated particles resulted by either technique. Losses of uranium to the solvent were about 0.5 per cent when disintegration was accomplished by fuming nitric: acid or by electrolysis with a 30 per cent chromic acid electrolyte. Efforts are now being made to select an electrolyte in which $\mathrm{UO}_{2}$ is less soluble. Losses have been reduced to the 0.1 to 0.2 per cent level by the use of 50 per cent $\mathrm{H}_{2} \mathrm{SO}_{4}$ or 7.5 per cent chromic acid electrolytes. Studies on this aspect of the matrix-separation program are continuing.

Separation of pyrolytic carbon-coated particles from graphite matrices is to be investigated after optimum conditions for electrolytic disintegration are better established.

\section{Fission-Gas-Retention Requirements}

A study is being made to determine the effect of fission-product release into the primary circulating coolant of gas-cooled reactors. This program is being carried out in conjunction with the study on coolant-contarnination limitations which are imposed by the problems of shielding, radiological hazarc.s due to leakage, and equipment maintenance. Emphasis is on ceramic-coated nuclear fuels and it is assumed that the fissionproduct rare gases and solid daughter products are the principal sources of radiation hazard. It is expected that the results will be useful in determining the fission-gasretention requirements for ceramic-coated fuels. 


\title{
Fuel-Compatibility Studies
}

\author{
S. J. Paprocki, G. W. Cunningham, D. C. Carmichael, \\ and J. J. Ward
}

Reactions which may affect the maximum operating time or temperature of coated fuel particles are being investigated. Initial studies are concerned with the stability of $\mathrm{Al}_{2} \mathrm{O}_{3}$-coated $\mathrm{UO}_{2}$ in an oxidizing atmosphere, $\mathrm{Al}_{2} \mathrm{O}_{3}$-coated $\mathrm{UO}_{2}$ in a graphite matrix, and diffusion of uranium from $\mathrm{UC}, \mathrm{UC}_{2}$, or $\mathrm{UO}_{2}$ through a pyrolytic carbon coating. Preliminary tests are being run to obtain qualitative data necessary for planning experiments to determine diffusion coefficients and reaction rates.

The stability of $\mathrm{Al}_{2} \mathrm{O}_{3}$-coated $\mathrm{UO}_{2}$ particles in air is expected to be dependent upon the diffusion of oxygen through the $\mathrm{Al}_{2} \mathrm{O}_{3}$ and the subsequent reaction to form a higher uranium oxide. The reaction should thus be very slow unless the coating is cracked or porous. Particles of $\mathrm{UO}_{2}$-coated with $\mathrm{Al}_{2} \mathrm{O}_{3}$ of three thicknesses ( 5 to 10,22 to 29, and $53 \mu$ ) have been prepared and are being evaluated. Equipment is being modified for the oxidation studies and it is anticipated that the first run ( $48 \mathrm{hr}$ at $1600 \mathrm{C}$ in 1 atm of oxygen) can be completed during the next report period.

Alumina-coated $\mathrm{UO}_{2}$ fuel particles in a graphite matrix may be susceptible to reaction between the $\mathrm{Al}_{2} \mathrm{O}_{3}$ and graphite, as reported last month in BMI-1480. The reaction is being investigated using massive $\mathrm{Al}_{2} \mathrm{O}_{3}-\mathrm{graphite}$ couples and $\mathrm{UO}_{2}$ particles coated with $\mathrm{Al}_{2} \mathrm{O}_{3}$ and overcoated with pyrolytic carbon. Fuel particles of this type have been heated in vacuum at $1800 \mathrm{C}$ for $2 \mathrm{hr}$. Evaluation of the sample is in progress but no visible change in the coated particles was noted and no significant weight change occurred. Equipment has been modified, and samples of massive graphite of various types and $\mathrm{Al}_{2} \mathrm{O}_{3}$ are being prepared for the diffusion-couple study.

The diffusion of uranium through pyrolytic carbon coatings will be studied by techniques involving the use of uranium-235. For the study, uranium diffusion from particles of enriched UC which have been coated with pyrolytic carbon will be utilized. Fully enriched UC has been melted which has a composition of about $5.0 \mathrm{w} / \mathrm{o}$ carbon and a structure of UC containing $\mathrm{UC}_{2}$. This material is being crushed, and the particles will be coated with pyrolytic carbon by vapor deposition.

The reaction of $\mathrm{UO}_{2}$ and carbon to form $\mathrm{UC}$ or $\mathrm{UC}_{2}$ is known to occur at elevated temperatures in a vacuum. However, the reactions are dependent upon the partial pressure of $\mathrm{CO}$, and a strong impervious coating of pyrolytic carbon may permit the reaction to be suppressed by maintaining an equilibrium $\mathrm{CO}$ pressure at the $\mathrm{UO}_{2}$-carbon reaction zone. For the first experiment to test this hypothesis, $\mathrm{UO}_{2}$ coated with a 7 - $\mu$-thick layer of pyrolytic carbon was heated for $2 \mathrm{hr}$ at $1800 \mathrm{C}$ in vacuo. The sample showed considerable reaction and loss of weight. A detailed evaluation has not been made, but, since coatings were applied at considerably lower temperatures, it is possible that cracking occurred upon heating. During the reaction itself, pressures on the order of $0.3 \mathrm{~atm}$ would be developed which should not be sufficient to rupture the coating. Specimens will be prepared to determine whether cracking due to thermal stresses occurs. 
A study of the technical literature has been started to evaluate the chemical stability of ceramic fuels, coatings, or matrices in contact with various gases that may be used as coolants. The major objectives of this study are to compare various combinations of gas coolants and ceramic solids in terms of their tendency to react with each other, to estimate temperature limits below which the gas-solid reactions are negligible, and to define experimental studies that may be necessary to establish the most stable combinations as potentially useful.

The materials to be considered as coolants are the gases helium, hydrogen, nitrogen, oxygen, $\mathrm{CO}, \mathrm{CO}_{2}$, and $\mathrm{H}_{2} \mathrm{O}$, as ceramic: fuels the oxides, carbides, and possibly nitrides of plutonium, thorium, and uranium, as ceramic coatings the oxides of aluminum, beryllium, magnesium, and zirconium, the carbides of silicon, zirconium, and pyrolytic carbon, and as matrix materials for the ceramic-coated fuel particles BeO and carbon.

Although the survey has covered some properties of many of the materials listed, the collection of data from additional sources is continuing, and evaluation in detail has not yet started. It is planned that both thermodynamic and kinetic interpretations will be undertaken.

\section{$\underline{\text { Radiation-Damage Studies }}$}

T. G. Knorr and C. M. Schwartz

A study of the physical changes and probable damage mechanisms occurring during the irradiation of nonfissionable ceramics is being started. It is planned to incorporate the present knowledge in this field with a set of well-chosen experiments in an attempt to describe the nature and extent of the damage. Some manner of decorating fission tracks will probably be the major method of observation. Theoretical support is also to be included in the interpretive stages of this program.

\section{Thermal-Conductivity Studies}

H. W. Deem and C. F. Lucks

The objective of this study is to experimentally determine the the rmal conductivity (thermal diffusivity) of unirradiated and irradiated specimens containing coated fuel particles. The program to date has been directed toward the selection of a method suitable for measuring the thermal diffusivity of specimens of a size dictated by coatedparticle size, encapsulation requirements, and irradiation conditions. Particular consideration was given to methods of producing high-thermal-flux cyclic heating for the specimens, and measuring heat-wave attenuation with varying frequency in the specimen. 


\title{
PROBLEMS ASSOCIATED WITH THE RECOVERY OF SPENT REACTOR FUEI ELEMENTS (ORNL)
}

\author{
R. A. Ewing and G. L. Peterson
}

The evaluation of materials of construction for the hydrofluorinator of the Fluoride-Volatility process is being resumed. In the present work the hydrofluorination of oxide-type fuels of uranium, beryllium, and zirconium will be simulated.

Average burnups of the first two ORR-irradiated high-burnup prototype Consolidated Edison fuel pins dissolved were in the 20,000 to 22,000-MWD/T range on the basis of cesium burnup analyses. A significant fraction of the total cesium formed was found in decladding solution from the Darex process; losses of cesium to Sulfex decladding solution were slight, just over 1 per cent.

On the basis of experimentally determined terminal uranium contents, uranium losses to the decladding solutions were higher than those previously estimated. Loss during Sulfex decladding approached 0.1 per cent, and exceeded 3 per cent for Darex decladding.

\section{Corrosion Studies of the Fluoride-Volatility Process}

\author{
P. D. Miller, E. L. White, and C. L. Peterson
}

Equipment has been assembled for an evaluation of materials of construction for the hydrofluorinator of the Fluoride-Volatility process. Conditions simulating the hydrofluorination of oxide-type fuels containing $\mathrm{UO}_{2}, \mathrm{BeO}, \mathrm{ZrO}_{2}$, or combinations thereof, in either a NaF-ZrF 4 or $\mathrm{NaF}-\mathrm{LiF}$ melt will be studied. The construction material of primary interest will be INOR-8 (Hastelloy N), although plans call for screening tungsten and perhaps some other metals, also. The assembly has been completed with the exception of a flowmeter for the HF sparge, which has not arrived. A shakedown run, made without metering the H.F, showed that the equipment will perform satisfactorily.

Study of the Effects of Irradiation on Claddingand Core-Dissolution Processes

R. A. Ewing, H. B. Brugger, and D. N. Sunderman

Analytical results are now complete on the first two ORR-irradiated high-burnup $(15,000$ to 25,000 MWD/T) prototype Consolidated Edison fuel pins. Cesium analyses indicate that Pins 12 and 22 had burnups in the range of 20,000 to $22,000 \mathrm{MWD} / \mathrm{metric}$ ton of core. Calculation of uranium-235 a/o burnup is complicated by the growth and subsequent fission of uranium-233. Burnup of all uranium (added and formed) was about 40 a $/ 0$; this indicates that uranium-235 burnup was in the 50 to 60 a/o range. A negligible fraction ( 1.5 per cent) of the total cesium was found in the Sulfex decladding solution, but about 8.5 per cent of the total was found in the decladding solution from the 
$\mathrm{M}-\underline{2}$

Darex decladding experiment, in line with the greater losses of fuel and associated fission products to Darex solutions.

Previous estimates of uranium losses to these decladding solutions (BMI-1473) were based on the original uranium content of the specimen, in the absence of analytical data. These losses are revised upward on the basis of the uranium contents subsequently determined. Loss to Sulfex decladding solution increased to 0.09 per cent; loss to Darex decladding solution increased to over 3 per cent.

Dissolution of two additional ORR-irradiated high-burnup Consolidated Edison pins, both by the Darex-Thorex process, has just been completed. During this same hot-cell campaign, sections of two high-burnup B\&W CETR pins, remaining from postirradiation examination, were also dissolved by the Sulfex-Thorex process. Severe fragmentation of the fuel pellets was observed in all specimens.

January will be devoted to analyses of the solutions from the se four experiments. The next hot-cell campaign is scheduled for February. 
PEBBLE-BED REACTCIR MATERIALS (S\&P)

B. W. Dunnington

Battelle is investigating graphite spherical fuel elements in support of the PebbleBed Reactor project. A major requirement is good fission-product retention. Promising results have been achieved by coating individual fuel particles with alumina. Current efforts involve the use of carbon-coated particles.

Preliminary neutron-activation tests on experimental bodies recently indicated the probable presence of cracked coatings. A cornbination of leaching tests and alphaemission measurements this month indicates the presence of persistent uranium contamination in the coatings.

\section{Laboratory Evaluation of Fueled-Graphite Spheres}

A. J. Roese, A. K. Smalley, and H. S. Rosenberg

One of the spheres containing carbon-coated $U_{2}(F A-25$, No. 6) was selected for acid leaching and alpha assay. The results are shown in Table $\mathrm{P}-1$. The increased counting rate after leaching indicates that uranium was leached through defective coatings and spread through the pores of the sphere.

TABLE P-1. SURFACE URANIUM CONT AMINATION OF FUELED-GRAPHITE SPHERE FA-25, NO. 6

\begin{tabular}{lccr}
\hline $\begin{array}{c}\text { Sphere } \\
\text { Condition }\end{array}$ & $\begin{array}{c}\text { Sphere } \\
\text { Position Counted (a) }\end{array}$ & $\begin{array}{c}\text { Counting Rate Normalized } \\
\text { to Total Ball Surface, cpm }\end{array}$ & $\begin{array}{c}\text { Surface Uranium } \\
\text { Contamination, } \\
\text { mg of uranium }\end{array}$ \\
\hline \multirow{2}{*}{ As received } & Area 1 (P) & $15.4 \pm 4.9$ & $0.020-0.040$ \\
& Area 2 (P) & $12.6 \pm 4.2$ & $0.017-0.034$ \\
& Area 3 (E) & $4.2 \pm 2.8$ & $0.0056-0.011$ \\
& Area 4 (E) & $16.8 \pm 4.9$ & $0.022-0.044$ \\
& Area 1 (P) & $147 \pm 15$ & $0.194-0.388$ \\
Acid leached & Area 2 (P) & $371 \pm 23$ & $0.490-0.980$ \\
& Area 3 (E) & $155 \pm 15$ & $0.205-0.410$ \\
& Area 4 (E) & $464 \pm 26$ & $0.612-1.22$ \\
\hline \hline
\end{tabular}

(a) P and E signify "polar" and "equator". 


\title{
DEVELOPMENT OF FABRICATION PROCESSES FOR COLD BONDING OF ZIRCALOY-2 TO TYPE 4:L STAINLESS STEEL (SRO)
}

\author{
S. W. Porembka
}

In assistance to the Canadian CANDU reactor program, an investigation of fabrication processes for joining Zircaloy- 2 to Type 410 stainless steel was established. The objective of this research is to develop cold-bonding techniques for joining pressure tubes of these materials with the potential of such operations being performed in-pile. Presently, efforts in this program include experiments with friction bonding, a study of the effects of surface preparation in roll forming, and an investigation of explosive joining. In past work, joining of Zircaloy to stainless steel and self-bonding of the individual materials were achieved with the friction techniques. More recently apparent bonding of Zircaloy to stainless steel has been attained, and a study of explosive joining initiated.

\section{Friction Bonding}

S. J. Paprocki, E. S. Hodge, and H. D. Hanes

The purpose of this study is to investigate the joining of Type 410 stainless steel to Zircaloy- 2 by friction bonding. Since a potential method for joining these materials may be through a transition member, self-bonding of the two materials is also being considered. Friction bonding is attractive because of the high surface deformation and localized heating effects characteristic of the process. Rod samples of the three materials combinations have been bonded by this technique to determine process variables. More recently, preliminary tubing studies have been initiated.

On the basis of previous results with rod-type samples, a systematic study of variables for stainless steel-to-Zircaloy-2 and Zircaloy-to-Zircaloy joints was conducted. The objective of this series of tests was to define the minimum conditions required for friction bonding these materials. Apparent bonding with limited deformation was achieved in these tests; however, metallographic examination will be required for a more complete evaluation.

A preliminary investigation of joining 0.5-in. -OD stainless steel tubing to $0.375-$ in. -OD Zircaloy- 2 was initiated. In all tests a taper fit of the two components was employed. Early specimens appeared good superficially and are presently being examined metallographically.

Two rod-type self-bonded Zircaloy- 2 specimens were corrosion tested for 14 days in $750 \mathrm{~F}$ steam. Prior to corrosion testing the deformed metal at the joint areas of the bonded samples was removed by machining. A shiny black corrosion film was observed over the entire specimen surface, indicating no adverse corrosion effects of the frictionbonding operation.

Preliminary design of a friction-bonding apparatus was completed. This equipment will permit a greater flexibility than the present use of a lathe and pressure cylinder. 
Major emphasis on this portion of the program will be shifted to the joining of small-diameter tubing during the next month. This study will include an investigation of process variables, correlation of these variables with rod-type samples, and a study of joint design.

Effects of Surface Preparation in Roll Forming

S. J. Paprocki, R. J. Carlson, C. C. Simons, and E. G. Smith

In order to establish the feasibility of achieving cold bonding in the roll-forming process, the effects of prior surface preparation on cold bonding is being investigated. The joining of Zircaloy- 2 to Type 410 stainless steel and the self-bonding of these individual materials by this technique are being considered in this portion of the program. Present efforts concern cold rolling flat-plate assemblies representing different surfacepreparation methods.

A second series of cold-bonding assemblies consisting of 17 tack-welded flat-plate packs was cold rolled at single reductions of from 45 to 75 per cent. A portion of these included grooves machined into the bonding faces of the Type 410 stainless steel components. It was noted that reductions of approximately 50 per cent and higher were required to achieve joining, as evidenced by visual and metallographic observation. Of the surface preparations utilized in this series of tests those consisting of a 300- $\mu$ in. rms surface subsequently treated with a slurry of $\mathrm{MgO}$ and $\mathrm{NaCO}_{3}$ yielded the most promising results. In general, the surfaces which were pickled or abraded resulted in either a complete lack of bonding or spotty bonds, as noted in metallographic observations. Currently, bonded specimens are being heat treated in order to define the extent of bonding.

\section{Explosive Joining}

S. J. Paprocki, R. J. Carlson, and C. C. Simons

As a further method for joining Zircaloy- 2 to Type 410 stainless steel, a brief study of the use of explosives has been initiated. The objective of this effort is to determine the feasibility of achieving mechanical and metallurgical bonding between the two materials under consideration. Use of groove-joint designs similar to that presently used in the roll-forming operation coupled with the deformation afforded through the detonation of explosives serves as the basic technique in this study. To date only a limited number of tests have been completed.

An initial series of $1-1 / 2$ by $1-1 / 2-i n$. explosive-joining assemblies consisting of Zircaloy- 2 plates placed over grooved Type 410 stainless steel plates has been detonated in air. Sheet explosive ( 2 g PETN per in. 2) was used in all cases, being placed atop the Zircaloy components. The surface-preparation techniques represented in these tests included 300- $\mu \mathrm{in}$. rms finishes which were either treated with a $\mathrm{MgO}-\mathrm{NaCO}_{3}$ slurry, washed, or pickled. Of these methods, the slurry treatment produced the greatest degree of apparent bonding. Specimens for further tests utilizing a water medium are currently being prepared. 
BMI-1489, Section S

S- 1 and $S-\underline{2}$

DEVELOPMENT OF MATERIALS FOR THE MGCR

AND HTGR (GA)

W. H. Goldthwaite

Radiation-effects studies of potential MGCR fuel materials are in progress.

DEVELOPMENT AND EVALUATION OF FUEL ELEMENTS FOR THE MGCR

Radiation-Effects Study of Potential Fuels

W. E. Murr, N. E. Miller, J. E. Gates, and

R. F. Dickerson

Ceramic-matrix fuel specimens of uranium dioxide in beryllium oxide, uranium monocarbide in graphite, and uranium dicarbide in graphite are being irradiated at $1500 \mathrm{~F}$ to 1 to 12 uranium a/o burnup. The specimens, made up of four cylindrical pellets $0.222 \mathrm{in.}$ in diameter and $0.250 \mathrm{in}$. long, clad in stainless steel, contain the uranium equivalent of 20 volume per cent of: 30 per cent enriched uranium dioxide.

Two specimens of each composition were examined after an estimated burnup of 1.0 to 1.7 uranium a/o and two more of each composition after an estimated burnup of 6 to 8 uranium a/o. Two more specimens of each composition are still being irradiated at the MTR and will be discharged in Narch, 1961, after an estimated burnup of 12 to 16 uranium a/o.

Experimental Capsule Studies

P. M. Steinback and J. H. Stang

Fuel pellets of $\mathrm{UO}_{2}$ ( 30 volume per cent, 12 per cent enriched) in $\mathrm{BeO}$ are to be irradiated, in Hastelloy $X$ cans, at $1700 \mathrm{~F}$ for 18 months in the $M T R$. The fuel specimens, to be supplied by General Atomic, will be encapsulated as soon as they arrive. 


\section{DEVELOPMENTAL STUDIES FOR THE SM-2 (ALCO)}

\section{S. J. Papprocki}

Reference and prototype SM-2 fuel specimens contained in six instrumented capsules are being irradiated in the ETR.

\section{Radiation-Stability Studies of Reference and Alternate SM-2 Fuels}

J. F. Lagedrost, J. H. Stang, and W. H. Goldthwaite

Studies of radiation effects on clad $\mathrm{UO}_{2}$-stainless steel dispersions are in progress. Specimens (nominally $26 \mathrm{w} / \mathrm{o} \mathrm{UO}_{2}$, highly enriched) are being irradiated in instrumented capsules in the ETR beryllium reflector.

Cycle 33 of the ETR, which started on November 11, will end about December 15, 1960 , after approximately 30 days of full-power operation. The performance of all BMI32 series capsules has been satisfactory during the cycle. During the shutdown following Cycle 33, all temperature-recording and-controlling instruments will be recalibrated, and efforts will be made to restore several thermocouples to operation. Of the total of 24 thermocouples, 3 have been inoperative, and 3 have been erratic.

Table T-1 gives estimates of specimen-surface temperatures (for Cycle 33) and total-burnup data for the peak-flux specimen in each capsule as of December 15, 1960. As pointed out previously, axial neutron-flux profiles along the capsules, based on temperature data, appear to be fairly irregular. Therefore, peak-flux specimens were chosen for convenience.

TABLE T-1. TEMPERATURE AND BURNUP DAT A FOR PEAK-FLUX SPECIMENS IN BMI-32 SERIES CAPSULES AS OF DECEMBER 15, 1960

\begin{tabular}{lcccc}
\hline & $\begin{array}{c}\text { Estimated } \\
\text { Specimen-Surface } \\
\text { Capsule }\end{array}$ & $\begin{array}{c}\text { Estimated } \\
\text { Total } \\
\text { Temperature in Cycle 33, F }\end{array}$ & $\begin{array}{c}\text { Estimated In-Pile } \\
\text { Time to Reach 70 a/o } \\
\text { Total Burnup, days }\end{array}$ & $\begin{array}{c}\text { Total In-Pile Time as of } \\
\text { December 15, 1960, days }\end{array}$ \\
\hline BMI -32-5 & 700 & 35 & 150 & 60 \\
BMI -32-6 & 530 & 50 & 190 & 123 \\
BMI -32-7 & $600($ a) & 45 & 160 & 87 \\
BMI-32-8 & 550 & 52 & 180 & 123 \\
BMI -32-9 & $1000^{(b)}$ & 75 & 90 & 100 \\
BMI -32-10 & 700 & 33 & 155 & 60 \\
\hline \hline
\end{tabular}

(a) The reference thermocouple for the top specimen in this capsule indicates a surface temperature of $1150 \mathrm{~F}$. However, this thermocouple is believed to be unreliable.

(b) The highest reading thermocouple in this capsule failed during Cycle 32. The listed temperature is based on previous data. 
$T-2$

In general, peak-flux specimens in most of the capsules have remained at fairly constant temperature levels throughout the irradiations thus far. However, that in BMI32-9 has dropped gradually during its five-reactor-cycle irradiation, a total of approximately $300 \mathrm{~F}$, while that in BMI-32-10 dropped $50 \mathrm{~F}$ from its first to its second cycle.

The burnups listed in Table $\mathrm{T}-1$ are based on comparisons of the temperature performance of the in-pile capsules with that of BMI-32-4 (irradiated previously); the burnup of the peak-flux specimen in BMI-32-4 was determined by isotopic analyses. These burnup levels are in substantial agreement with those predicted on the basis of temperature (thermocouple) computed fission-heat-generation rates based on analog and IBM704 analyses of heat transfer within the capsule. 
GAS-COOLED REACTOR PROGRAM (AGN)

D. L. Keller

Studies for Aerojet-General Nucleonics (AGN) and the Army Reactors Branch (ARM) in support of the ML-1 reactor development program are reported in this section. This program consists primarily of in-pile-capsule studies of $\mathrm{UO}_{2}$ and $\mathrm{UO}_{2}-$ $\mathrm{BeO}$ specimens clad in Hastelloy $\mathrm{X}$, which represent the fuel materials for the $\mathrm{ML}-1$, fatigue studies on Hastelloy $\mathrm{X}$, critical-assembly studies on a mock-up of the ML-1 core, and advanced fuel studies with $\mathrm{UO}_{2}$ bodies vapor coated with $\mathrm{Al}_{2} \mathrm{O}_{3}$.

Advanced ML-1 Fuel Pellets

J. W. Lennon and A. K. Smalley

Laboratory work continued on developing oxidation-resistant fuel pellets containing at least 60 volume per cent $\mathrm{UO}_{2}$.

Samples of $\mathrm{UO}_{2}$ shot averaging 50 and $127 \mu$ in diameter and coated with 4 to $8 \mu$ of $\mathrm{Al}_{2} \mathrm{O}_{3}$ by vapor deposition were found previously to be oxidation resistant. Mixtures of the coated shot with $\mathrm{Al}_{2} \mathrm{O}_{3}$ powder (about 60 volume per cent $\mathrm{UO}_{2}$ equivalent) were compacted into 1/4-in. -diameter by 1/4-in. -long pellets and sintered at $3000 \mathrm{~F}$ for $1 \mathrm{hr}$ in hydrogen. The $\mathrm{Al}_{2} \mathrm{O}_{3}$ powder used sintered to about 97 per cent of theoretical density, under similar conditions, when formed into pellets containing no $\mathrm{UO}_{2}$ shot. The compositions of the mixtures are shown below. These compositions and size ranges were selected with a view to obtaining maximum packing density in unsintered compacts.

\begin{tabular}{|c|c|c|c|c|}
\hline \multirow[b]{3}{*}{ Batch } & \multicolumn{3}{|c|}{ Composition, $\mathrm{w} / \mathrm{o}$} & \multirow{3}{*}{$\begin{array}{c}\text { Calculated } \mathrm{UO}_{2} \text {, volume } \\
\text { per cent }\end{array}$} \\
\hline & \multicolumn{2}{|c|}{ Coated $\mathrm{UO}_{2}$ Shot } & \multirow[b]{2}{*}{$\mathrm{A}_{2} \underline{\mathrm{O}}_{3}$} & \\
\hline & $127 \mu$ & $50 \mu$ & & \\
\hline 1 & 60 & 30 & 10 & 63.9 \\
\hline 2 & 80 & 5 & 15 & 64.2 \\
\hline 3 & 60 & 10 & 30 & 51.9 \\
\hline
\end{tabular}

Batches 1 and 2 were pressed in a steel die at a pressure of 40,000 psi. Experience indicated that this is about the minimum forming pressure required for maximum densification of the matrix $\mathrm{Al}_{2} \mathrm{O}_{3}$. The coatings on the $\mathrm{UO}_{2}$ shot apparently were damaged. The UO 2 shot in unsintered pellets oxidized almost completely when heated at $1200 \mathrm{~F}$ for $5 \mathrm{hr}$ in air. The $\mathrm{UO}_{2}$ in sintered pellets also oxidized in a similar test. It was of interest that shrinkage of the pellets during sintering was 1 to 2 per cent. Pellets have not yet been compacted from Batch 3. Whether the $\mathrm{Al}_{2} \mathrm{O}_{3}$ coatings are damaged when lower forming pressures are used will be investigated.

The damage to the $\mathrm{Al}_{2} \mathrm{O}_{3}$ coating is attributed to the fact that only 10 to $15 \mathrm{w} / \mathrm{o}$ $\mathrm{Al}_{2} \mathrm{O}_{3}$ powder could be used in the matrix in order to maintain the $\mathrm{UO}_{2}$ content at 60 volume per cent or higher. This low $\mathrm{Al}_{2} \mathrm{O}_{3}$-powder content was insufficient to provide a cushioning effect to prevent crushing of the $\mathrm{Al}_{2} \mathrm{O}_{3}$ coatings during pressing. This points to the need for coated $\mathrm{UO}_{2}$ shot of larger size, which would permit the use of more matrix $\mathrm{Al}_{2} \mathrm{O}_{3}$. 
Batches 1 and 3 were pressed hydrostatically to $100,000 \mathrm{psi}$. It was thought that this method would produce less strain on the vapor-deposited coating and leave it intact. The dearth of $\mathrm{Al}_{2} \mathrm{O}_{3}$ powder in $\mathrm{Batch} 1$ compact $(10 \mathrm{w} / 0)$ caused the pressed piece to crumble on handling. The Batch 3 compact was stronger, but the piece was still mechanically weak. Tests of these compacts are not yet complete.

Samples of $\mathrm{UO}_{2}$ shot averaging $415 \mu$ in diameter were coated with about $12 \mu$ of $\mathrm{Al}_{2} \mathrm{O}_{3}$, and their oxidation resistance was determined. After $5 \mathrm{hr}$ at $1200 \mathrm{~F}, 8$ per cent of the $\mathrm{UO}_{2}$ was oxidized to $\mathrm{U}_{3} \mathrm{O}_{8}$. The batch then was leached with nitric acid to remove the exposed $\mathrm{U}_{3} \mathrm{O}_{8}$, and the unfueled $\mathrm{Al}_{2} \mathrm{O}_{3}$ shells were removed by heavy-liquid separation. This proof-tested shot will be used in future work.

A problem exists in that the fuel particles shrink very little or not at all during sintering, whereas the matrix $\mathrm{Al}_{2} \mathrm{O} 3$ does undergo shrinkage. An approach to this problem will be made by coating the $\mathrm{UO}_{2}$ shot with a material which will burn out during sintering, thus providing space into which the $\mathrm{Al}_{2} \mathrm{O}_{3}$ powder can shrink without cracking. The burnout material, probably a wax, would also be expected to provide some cushioning for the coated shot and minimize coating fracture during pressing.

\section{An Alternate Method of Fabricating Advanced ML-1 Fuels}

$$
\text { S. J. Paprocki, D. L. Keller, and J. B. Fox }
$$

The objective of this program is to evaluate the simultaneous densification and cladding of $\mathrm{UO}_{2}$ bodies diluted with no more than 40 volume per cent $\mathrm{Al}_{2} \mathrm{O}_{3}$ as a method of obtaining an oxidation-resistant fuel material. By hot pressing in a stainless steel tube spherical $\mathrm{UO}_{2}$ which has been coated with a thin layer of $\mathrm{Al}_{2} \mathrm{O}_{3}$, a dense body possessing a continuous $\mathrm{Al}_{2} \mathrm{O}_{3}$ matrix may be obtained.

During December, four compacts were pressed at 50 tsi from spherical $\mathrm{UO}_{2}$ powder coated with $\mathrm{A}_{2} \mathrm{O}_{3}$. The $\mathrm{UO}_{2}$ was $150 \mu$ in diameter and the $\mathrm{Al}_{2} \mathrm{O}_{3}$ coating was 6 to $8 \mu$ thick. These conditions represent 88.9 volume per cent $\mathrm{UO}_{2}$ and a theoretical density of $10.18 \mathrm{~g}$ per $\mathrm{cm}^{3}$. The compacts were loaded into a steel tube and isostatically pressed in a 10,000-psi helium atmosphere for $3 \mathrm{hr}$ at $2300 \mathrm{~F}$. The resulting density was $9.63 \mathrm{~g}$ per $\mathrm{cm}^{3}$, or approximately 95 per cent of theoretical.

Preliminary metallographic examination showed that a large majority of the particles were sound and that their $\mathrm{Al}_{2} \mathrm{O}_{3}$ coatings were intact. However, the spaces between sound particles were filled with shattered particles. It is felt that this has resulted primarily from the use of a narrow particle-size range but it is not known whether the particles were crushed during cold compacting or hot pressing. This effect can certainly be improved by the use of (1) a wider distribution of particle sizes, (2) additional $\mathrm{Al}_{2} \mathrm{O}_{3}$ diluent as fine powder to fill the voids between particles, and (3) by both slip casting and vibratory compacting. Several of these methods will be investigated in future studies. 


\section{Encapsulation Studies}

J. H. Stang, J. Lagedrost, E. O. Fromm, and W. J. Zielenbach

Two irradiation-capsule experiments are currently being conducted in this program, one at the Materials Testing Reactor and one at the Battelle Research Reactor. The former capsule, designated $\mathrm{BMI}-38-1$, contains six Hastelloy X-clad compacts containing 70 and $80 \mathrm{w} / 0$ highly enriched $\mathrm{UO}_{2}$ dispersed in $\mathrm{BeO}$. During the recent operation of this capsule, it has been necessary to supply a considerable amount of auxiliary electrical heat to maintain temperatures near the desired level of $1725 \mathrm{~F}$ at the surface of the peak-flux specimens. Only two of the original seven thermocouples in this capsule are still operative; these operative thermocouples are adjacent to relatively low-flux specimens. Consequently, the temperatures of the high-flux specimens of major interest must be inferred from lower temperature readings, the inference made on the basis of temperature data obtained during the early stages of the exposure before the thermocouple failures occurred. As of December 30 (after five MTR Cycles) the maximum accrued burnup of the specimens is estimated to be 4 per cent of the original uranium-235 atoms; a total of about 9 a/o is desired.

The other capsule, designated AGN-BRR-III, contains six Hastelloy X-clad compacts of highly enriched $\mathrm{UO}_{2}$. During the past month, the desired peak-flux specimen-surface temperature of $1725 \mathrm{~F}$ has been maintained although, again, supplementary electrical heat has been required. After seven reactor cycles, heat-transfer computations indicate a maximum specimen burnup of about 1.5 a $/ 0$ uranium-235; the desired level, 2.0 a/o will probably be reached by March 1, 1961.

High-Temperature Fratigue Evaluation of Hastelloy X Tubing

G. M. McClure, H. J. Grover, and A. R. Duffy

The objective of this study is to evaluate the high-temperature fatigue characteristics of Hastelloy $\mathrm{X}$ tubing. The 1/4-in. $-O D$ tubing will be tested in Krouse axial-load fatigue machines to develop $S-N$ curves out to $10^{6}$ cycles. Five temperature levels will be used with a stress ratio of $A=1$ to determine the effect of temperature on the $\mathrm{S}-\mathrm{N}$ curves. The temperature levels are $1400,1600,1725,1800$, and $2000 \mathrm{~F}$. In addition, Goodman diagrams based on failure at $10^{6}$ cycles will be developed at stress ratios of $A=0, A=0.25, A=1.0$, and $A=\infty$ (approximately) for each of the temperature parameters. About 120 specimens will be requiled for the evaluation. A cyclic speed of 1725 cycles per min will be used for all of the tests.

End clamps which do not introduce detrimentally high stress intensification have been satisfactorily developed, and all specirnens have failed near the center in the heat zone of controlled temperature. The S-N curves for $1600,1725,1800$, and $2000 \mathrm{~F}$ have been completed and preliminary reduction of data indicated that stresses of 18,500 , $8,700,5,300$, and $3,200 \mathrm{psi}$, respectively, are necessary to instigate failure of $10^{6}$ cycles. Also, it has been noted and previously reported that the new supply of tubing is slightly different dimensionally than the original supply of tubing. 
During the month of December, 25 specimens were failed. Nine of these were at the $1400 \mathrm{~F}$ temperature level, and preliminary reduction of data indicates that a stress level of 35,000 to $38,000 \mathrm{psi}$ is necessary to instigate failure at $10^{6}$ cycles. The remaining specimens were run at 1800 and $1600 \mathrm{~F}$ and indicated a consistent deviation from the results previously reported for these two temperatures. The difference is tentatively attributed to the change in tube supply and in attempt to verify this, hardness tests were conducted on one sample of the original supply and one sample of the new supply. This metallographic study revealed a distinct difference in hardness and structure between the new and original tubes.

Plans for January are to extend the metallographic studies to attempt to determine the reason for the difference in fatigue strength between the original and the new tubes. Also, an attempt will be made to determine the quantitative difference so that all of the new tube-test results can be corrected to the reference strength of the original supply. By using this approach, Goodman diagrams can be developed on the basis of fatigue strengths determined experimentally from either the new or original supply.

\section{ML-1 Critical-Assembly Experiments}

J. W. Ray, R. G. Matthews, W. S. Hogan, D. A. Dingee, and J. W. Chastain

During December experiments were performed to evaluate methods of using reactivity differences between modified and standard fuel elements in a single core position to extrapolate to the reactivity associated with this same element exchange throughout an entire core. In addition, final data analysis and report preparation were continued.

Two types of fuel elements were used for calibration purposes. One was a standard critical-assembly element and the other, designated the Modification 3 element, differed from it by the absence of the center fuel pin. The Modification 3 elements were exchanged with the standard core elements stepwise until the core contained all Modification 3 elements. The reactivity change for each step was measured. Knowing the reactivity effect of an exchange of standard elements for modified elements over a full core and in a single position, it was possible to determine ratios between the single-element exchange and the full-core exchange. These ratios define "weighting functions" which should be independent of the type of elements exchanged, for small differences in elements, and should depend only on the core position in which the exchange is made.

These weighting functions were applied to reactivity data from exchanges between standard core elements and production fuel elements. Table U-l shows the reactivity effects of full core changeovers predicted from measured reactivity worths of exchanges in Positions 1 and 13 in the core.

The consistent prediction of the full-core reactivity effect from single-element measurements in these two coxe positions appears to confirm the use of the weighting functions. 
TABLE U-1. PREDICTED REACTIVITY ElFFECTS DUE TO A FULL CORE EXCHANGE FROM STANDARD ELEMEN?'S TO MODIFIED ELEMENTS

\begin{tabular}{lcc}
\hline & $\begin{array}{c}\Delta \rho \text { over Standard Core from Reactivity } \\
\text { Type of Element }\end{array}$ & $\begin{array}{c}\text { Worth at Location Shown, per cent } \\
\text { Position 1 }\end{array}$ \\
\hline Modification $1^{*}$ & 1.94 & 1.96 \\
ML-1 production & 3.32 & 3.56 \\
1B-2L production & 0.83 & 0.80 \\
\hline
\end{tabular}

The experimental portion of the present project has been completed. Final data analysis and report writing will be continued during January. 


\title{
CORROSION OF THORIUM: AND URANIUM UNDER STORAGE CONDITIONS (LIVERMORE)
}

\author{
P. D. Miller
}

Blistering of electroplated coatings on thorium is attributed to hydrogen gas formed from the decomposition of surface thorium hydrides. Three processes for plating chromium over nickel-plated thoriun were studied. The hydrogen content of thorium subjected to several surface treatments was measured.

The corrosion-evaluation program is being continued.

Electrodeposited Coatings for Thorium (SC)

J. G. Beach and C. L. Faust

Electrodeposited coatings on thorium are being studied to prevent corrosion and to aid joining by adhesives or by soldering.

Chromium plate over nickel-plated therium (Item 5, BMI-1480) to prevent tarnishing and/or corrosion of the nickel was studied. Three chromium-plating processes were compared over as-plated and buffed nickel on thorium. Although corrosion of the thorium was not evident during exposure of the samples to water-saturated air at $200 \mathrm{~F}$ for the test period of more than $600 \mathrm{hr}$, small random blisters of the plated coatings were evident after 50 to $100 \mathrm{hr}$ of exposure. Chromium-plated samples using the Duramir 100 or Duramir 300 processes (proprietary process, General Development Corporation) showed fewer blisters than chromium-plated samples using the HTHR (high temperature-high $\mathrm{CrO}_{3} / \mathrm{SO}_{4}$ ratio bath). All three processes deposit crack-free chromium.

Blistering of electroplated coatings on thorium during exposure at $200 \mathrm{~F}$ in watersaturated air is attributed to hydrogen gas (formed from the decomposition of surface thorium hydrides) which is trapped under the nickel plate. Presumably, the Duramir processes introduce less hydrogen into the thorium. Rapid heating $(<1 / 2 \mathrm{hr})$ of plated samples to $500 \mathrm{~F}$ (in vacuum) also results in blistering of the 2 -mil nickel plate.

The hydrogen content of the thorium (Item 3, BMI-1480) resulting from the preparation and plating steps is related to the extent of blistering of plated thorium. Electropolishing of thorium to remove about 2 mils of the surface metal (vapor-blasted, cold-rolled sheet) reduced the hydrogen content from 47 to $<2 \mathrm{ppm}$. Activating the thorium for plating introduced about $20 \mathrm{ppm}$ of hydrogen, and nickel plating introduced $5 \mathrm{ppm}$. Outgassing of nickel-plated thorium reduced the hydrogen content to $7 \mathrm{ppm}$. Electropolishing of thorium resulted in a lower hydrogen content - <2 versus 8 ppm than did chemical pickling. The LRL modification of the procedure for activating thorium for plating resulted in a lower hydrogen content - 18 versus $22 \mathrm{ppm}$ - than did the original BMI procedure. These data support the benefits that have been observed for electropolishing as a prefinishing step and for the modified activation procedure toward producing protective electroplated coatings for thorium. Means of outgassing plated thorium to avoid blistering of the plated coating are being explored further. 
$\mathrm{V}-\underline{2}$

Further improvements in the conditions for electropolishing and activation of thorium for adherent plating (Items 1 and 2, BMI-1480) will be investigated in efforts toward minimizing the roughness of the thorium surface. A smoother activated surface should permit protection of thorium with thinner plated coatings.

Anodic coatings on thorium for corrosion protection and as a basis for adhesive bonding or organic coatings also will be studied further.

Further work toward joining of thorium to thorium or to other metals by soldering to the plated coatings (Item 3, BMI-1480) will be recessed until the blistering problem is resolved.

\section{Corrosion Evaluation (UCRL)}

E. F. Stephan, P. D. Miller, and F. W. Fink

Specimens of thorium, uranium, and uranium-10 w/o molybdenum - singly, and joined in several ways to other metals - have been exposed for almost $2000 \mathrm{hr}$ in 100 per cent relative humidity at $120 \mathrm{~F}$. The corrosion on the specimen will be measured during the next month, and the results will be summarized.

No significant corrosion has occurred on the specimens exposed under warehouse conditions in the Phase III program. 


\title{
GAS-PRESSURE BONDING OF BERYLLIUM-CLAD ELEMENTS (ORNL)
}

\author{
S. J. Paprocki, E. S. Flodge, and J. S. Perrin
}

Oak Ridge National Laboratory is considering beryllium-clad uranium dioxide fuel elements for use in gas-cooled reactors. The fabrication of this fuel system by gaspressure bonding is being studied.

The self-bonding of beryllium as a function of surface preparation and bonding parameters is being studied. A specimen boncled with as-pickled surfaces at $1650 \mathrm{~F}$ at 10,000 psi for $4 \mathrm{hr}$ exhibited grain growth across the original bond interface. The specimen, consisting of two beryllium sheets $0.055 \mathrm{in}$. in thickness, appeared to be bonded along the entire interface.

Four beryllium specimens containing $\mathrm{UO}_{2}$ cores in the form of a sandwich composite were bonded at various parameters and examined for evidence of core-to-cladding reaction. The bonding conditions employed were $1550 \mathrm{~F}$ at $10,000 \mathrm{psi}$ for $\mathrm{l}$ and $4 \mathrm{hr}$, and $1650 \mathrm{~F}$ at $10,000 \mathrm{psi}$ for $\mathrm{l}$ and $4 \mathrm{hr}$. No reaction was observed between the beryllium and the uranium dioxide with any of the parameters employed.

In an attempt to determine if bonds could be achieved between all members of a piece-component compartmented fuel plate, a beryllium structural specimen in the form of an I-beam was prepared by pressure bonding. The three components, used to simulate cladding-to-rib joints in a fuel plate, were each 0.065 by 0.450 by 2 in. The surfaces at the interfaces were abraded prior to bonding. Surface conditioning by abrading was accomplished under water with silicon carbide grit. Bonding conditions of $1600 \mathrm{~F}$ for $2 \mathrm{hr}$ at 10,000 psi produced an I-beam specimen that appeared visually to be vell bonded. The specimen has been prepared for metallographic study.

Specimen bonded at temperatures below $1600 \mathrm{~F}$ at 10,000 psi have not yielded bonds as satisfactory as those bonded at 1600 and $1650 \mathrm{~F}$. It is not known, however, if the bond improvement is entirely a matter of temperature. Additional specimens are being processed to determine with different surface preparations the minimum satisfactory bonding temperature.

RWD/CRT:all 